Portland State University

PDXScholar

\title{
Calibrating the HSM Predictive Methods for Oregon Highways
}

\author{
Karen Dixon \\ Oregon State University \\ Christopher M. Monsere \\ Portland State University, monsere@pdx.edu \\ Fei Xie \\ Oregon State University \\ Kristie Gladhill \\ Portland State University
}

Follow this and additional works at: https://pdxscholar.library.pdx.edu/trec_reports

Part of the Transportation Commons, Urban Studies Commons, and the Urban Studies and Planning Commons

Let us know how access to this document benefits you.

\section{Recommended Citation}

Dixon, Karen, and Chris Monsere, Fei Xie and Kristie Gladhill. Calibrating the HSM Predictive Methods for Oregon Highways. OTREC-RR-12-02. Portland, OR: Transportation Research and Education Center (TREC), 2012. https://doi.org/10.15760/trec.24

This Report is brought to you for free and open access. It has been accepted for inclusion in TREC Final Reports by an authorized administrator of PDXScholar. Please contact us if we can make this document more accessible: pdxscholar@pdx.edu. 


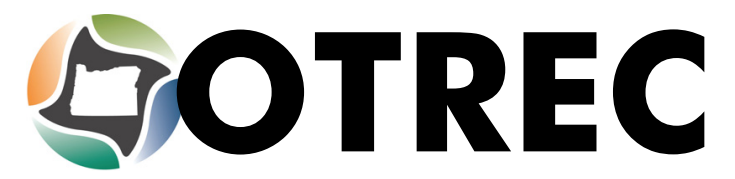

FINAL REPORT

\section{Calibrating the Future Highway Safety Manual Predictive Methods for Oregon State Highways}

OTREC-RR-12-02

February 2012 


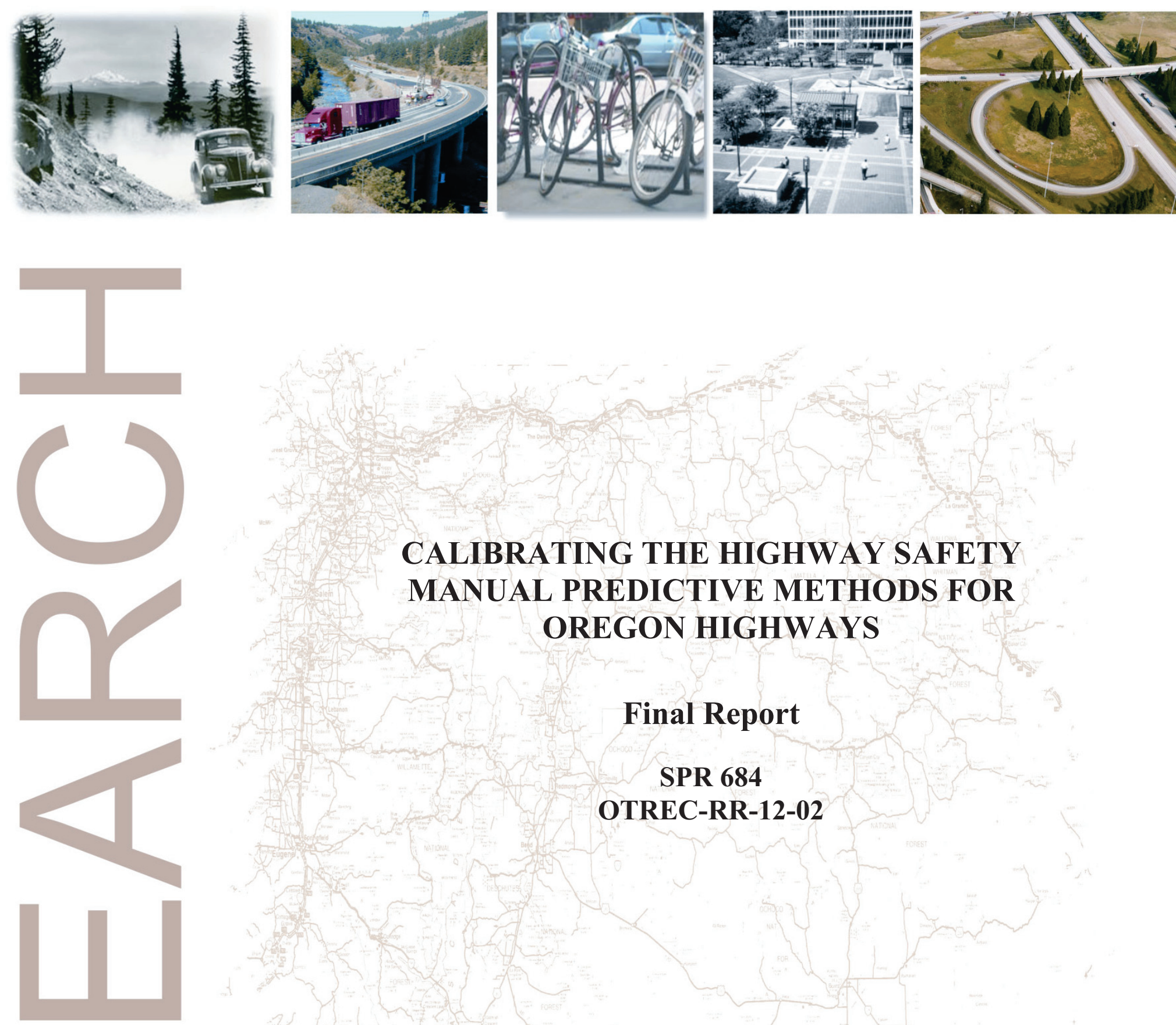

\title{
CALIBRATING THE HIGHWAY SAFETY MANUAL PREDICTIVE METHODS FOR OREGON HIGHWAYS
}
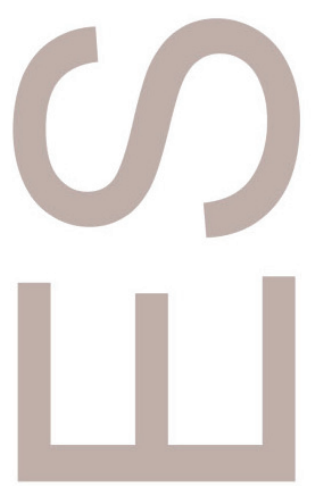

\author{
Final Report
}

SPR 684

OTREC-RR-12-02
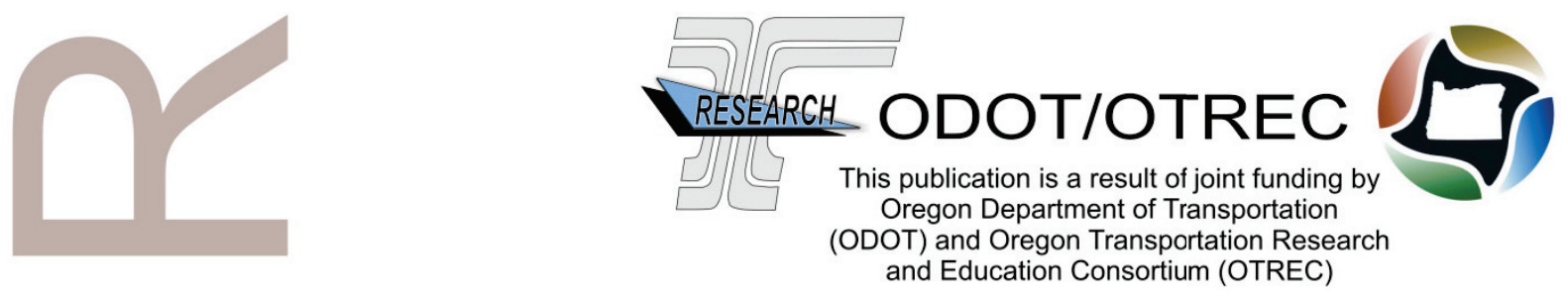



\title{
CALIBRATING THE FUTURE HIGHWAY SAFETY MANUAL PREDICTIVE METHODS FOR OREGON STATE HIGHWAYS
}

Final Report

SPR 684

OTREC-RR-12-02

by

\author{
Karen Dixon \\ Oregon State University \\ Chris Monsere \\ Portland State University \\ Fei Xie \\ Oregon State University \\ Kristie Gladhill \\ Portland State University \\ for \\ Oregon Department of Transportation \\ Research Section \\ 200 Hawthorne Avenue SE, Suite B-240 \\ Salem OR 97301-5192 \\ and \\ Oregon Transportation Research \\ and Education Consortium (OTREC) \\ P.O. Box 751 \\ Portland, OR 97207
}

February 2012 

Technical Report Documentation Page
1. Report No.
FHWA-OR-RD-12-07
2. Government Accession No.
4. Title and Subtitle
Calibrating The Future Highway Safety Manual Predictive Methods For Oregon State Highways
7. Author(s)
Karen Dixon, Oregon State University; Chris Monsere, Portland State University; Fei Xie, Oregon State University; Kristie Gladhill, Portland State University

3. Recipient's Catalog No.

5. Report Date

February 2012

6. Performing Organization Code

9. Performing Organization Name and Address

Oregon Department of Transportation

Research Section and

200 Hawthorne Ave. SE, Suite B-240

Salem, Oregon 97301-5192

12. Sponsoring Agency Name and Address

Oregon Department of Transportation

Research Section

and Federal Highway Administration

200 Hawthorne Ave. SE, Suite B-240 400 Seventh Street, SW

Salem, OR 97301-5192

Washington, DC 20590-0003
Oregon Transportation Research and Education Consortium (OTREC) P.O. Box 751

Portland, Oregon 97207
8. Performing Organization Report No

\section{Supplementary Notes}

\section{Abstract}

The Highway Safety Manual (HSM) was published by the American Association of State Highway and Transportation Officials (AASHTO) in the spring of 2010. Volume 2 (Part C) of the HSM includes safety predictive methods which can be used to quantitatively estimate the safety of a transportation facility. The resulting information can then be used to provide guidelines to identify opportunities to improve transportation safety. The safety performance functions (SPFs) included with this content, however, were developed for several states other than Oregon. Because there are differences in crash reporting procedures, driver population, animal populations, and weather conditions (to name a few), the State of Oregon needs to use calibrated SPFs when applying the HSM procedures to local Oregon facilities. Currently, the predictive methods have been developed for three facility types: rural two-lane two-way roads, rural multilane roads, and urban and suburban arterial roads. In this project, the research team calibrated SPFs for all three facility types based on their historic safety performance in Oregon. The report illustrates methods of site selection, the collection of crash and site-specific data, and analysis methods for calibration. Also, the report includes an evaluation of the crash severity distribution methods. With this information, Oregon agencies can use the calibrated HSM predictive methods to assess expected facility safety performance for Oregon conditions and facility alternatives.

17. Key Words

SAFETY, MANUAL, HSM, SPF, OREGON, CRASH, MULTILANE, CALIBRATION, SEVERITY

\section{Distribution Statement}

Copies available from NTIS, and online at http:/www.oregon.gov/ODOT/TD/TP RES/

\section{Security Classification (of this report) Unclassified}

\section{Security Classification (of this page) Unclassified}

\section{No. of Pages 98}




\begin{tabular}{|c|c|c|c|c|c|c|c|c|c|}
\hline \multicolumn{10}{|c|}{ SI* (MODERN METRIC) CONVERSION FACTORS } \\
\hline \multicolumn{5}{|c|}{ APPROXIMATE CONVERSIONS TO SI UNITS } & \multicolumn{5}{|c|}{ APPROXIMATE CONVERSIONS FROM SI UNITS } \\
\hline Symbol & When You Know & Multiply By & To Find & Symbol & Symbol & When You Know & Multiply B & To Find & Symbol \\
\hline \multicolumn{5}{|c|}{ LENGTH } & \multicolumn{5}{|c|}{ LENGTH } \\
\hline in & inches & 25.4 & millimeters & $\mathrm{mm}$ & $\mathrm{mm}$ & millimeters & 0.039 & inches & in \\
\hline $\mathrm{ft}$ & feet & 0.305 & meters & $\mathrm{m}$ & $\mathrm{m}$ & meters & 3.28 & feet & $\mathrm{ft}$ \\
\hline yd & yards & 0.914 & meters & $\mathrm{m}$ & $\mathrm{m}$ & meters & 1.09 & yards & yd \\
\hline mi & miles & 1.61 & kilometers & $\mathrm{km}$ & $\mathrm{km}$ & kilometers & 0.621 & miles & $\mathrm{mi}$ \\
\hline \multicolumn{5}{|c|}{$\underline{\text { AREA }}$} & \multicolumn{5}{|c|}{$\underline{\text { AREA }}$} \\
\hline in $^{2}$ & square inches & 645.2 & millimeters squared & $\mathrm{mm}^{2}$ & $\mathrm{~mm}^{2}$ & millimeters squared & 0.0016 & square inches & in $^{2}$ \\
\hline $\mathrm{ft}^{2}$ & square feet & 0.093 & meters squared & $\mathrm{m}^{2}$ & $\mathrm{~m}^{2}$ & meters squared & 10.764 & square feet & $\mathrm{ft}^{2}$ \\
\hline $\mathrm{yd}^{2}$ & square yards & 0.836 & meters squared & $\mathrm{m}^{2}$ & $\mathrm{~m}^{2}$ & meters squared & 1.196 & square yards & $\mathrm{yd}^{2}$ \\
\hline ac & acres & 0.405 & hectares & ha & ha & hectares & 2.47 & acres & ac \\
\hline $\mathrm{mi}^{2}$ & square miles & 2.59 & kilometers squared & $\mathrm{km}^{2}$ & $\mathrm{~km}^{2}$ & kilometers squared & 0.386 & square miles & $\mathrm{mi}^{2}$ \\
\hline \multicolumn{5}{|c|}{ VOLUME } & \multicolumn{5}{|c|}{ VOLUME } \\
\hline $\mathrm{fl} \mathrm{oz}$ & fluid ounces & 29.57 & milliliters & $\mathrm{ml}$ & $\mathrm{ml}$ & milliliters & 0.034 & fluid ounces & $\mathrm{fl} \mathrm{oz}$ \\
\hline gal & gallons & 3.785 & liters & $\mathrm{L}$ & $\mathrm{L}$ & liters & 0.264 & gallons & gal \\
\hline $\mathrm{ft}^{3}$ & cubic feet & 0.028 & meters cubed & $\mathrm{m}^{3}$ & $\mathrm{~m}^{3}$ & meters cubed & 35.315 & cubic feet & $\mathrm{ft}^{3}$ \\
\hline $\mathrm{yd}^{3}$ & cubic yards & 0.765 & meters cubed & $\mathrm{m}^{3}$ & $\mathrm{~m}^{3}$ & meters cubed & 1.308 & cubic yards & $\mathrm{yd}^{3}$ \\
\hline \multicolumn{10}{|c|}{ NOTE: Volumes greater than $1000 \mathrm{~L}$ shall be shown in $\mathrm{m}^{3}$. } \\
\hline \multicolumn{5}{|c|}{$\underline{\text { MASS }}$} & \multicolumn{5}{|c|}{ MASS } \\
\hline $\mathrm{oz}$ & ounces & 28.35 & grams & $\mathrm{g}$ & $\mathrm{g}$ & grams & 0.035 & ounces & $\mathrm{oz}$ \\
\hline $\mathrm{lb}$ & pounds & 0.454 & kilograms & $\mathrm{kg}$ & $\mathrm{kg}$ & kilograms & 2.205 & pounds & $\mathrm{lb}$ \\
\hline $\mathrm{T}$ & short tons $(2000 \mathrm{lb})$ & 0.907 & megagrams & $\mathrm{Mg}$ & $\mathrm{Mg}$ & megagrams & 1.102 & short tons $(2000 \mathrm{lb})$ & $\mathrm{T}$ \\
\hline \multicolumn{5}{|c|}{ TEMPERATURE (exact) } & \multicolumn{5}{|c|}{ TEMPERATURE (exact) } \\
\hline${ }^{\circ} \mathrm{F}$ & Fahrenheit & $(\mathrm{F}-32) / 1.8$ & Celsius & ${ }^{\circ} \mathrm{C}$ & ${ }^{\circ} \mathrm{C}$ & Celsius & $1.8 \mathrm{C}+32$ & Fahrenheit & ${ }^{\circ} \mathrm{F}$ \\
\hline
\end{tabular}




\section{ACKNOWLEDGEMENTS}

The authors thank the members of the Oregon Department of Transportation (ODOT) Project Technical Advisory Committee for their advice and assistance in the preparation of this report. The authors would also like to thank the Oregon Transportation Research and Education Consortium (OTREC) for funding the project and the ODOT Research group for managing the project.

\section{DISCLAIMER}

The contents of this report reflect the views of the authors, who are solely responsible for the facts and the accuracy of the material and information presented herein. This document is disseminated under the sponsorship of the U.S. Department of Transportation University Transportation Centers Program and Oregon Department of Transportation in the interest of information exchange. The U.S. Government and the Oregon Department of Transportation assume no liability for the contents or use thereof. The contents do not necessarily reflect the official views of the U.S. Government or Oregon Department of Transportation. This report does not constitute a standard, specification, or regulation.

This document is disseminated under the sponsorship of the Oregon Department of Transportation and the United States Department of Transportation in the interest of information exchange. The State of Oregon and the United States Government assume no liability of its contents or use thereof. 


\section{TABLE OF CONTENTS}

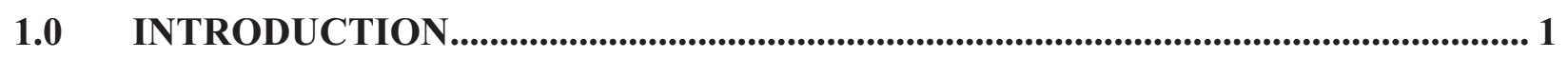

2.0 LITERATURE REVIEW .......................................................................................... 3

2.1 Predictive Methods in the Highway Safety ManUAL ………………………........... 3

2.2 CRASH REPORTING IN OREGON......................................................................... 4

2.3 AADT MODELS FOR RURAL LOCATIONS................................................................ 5

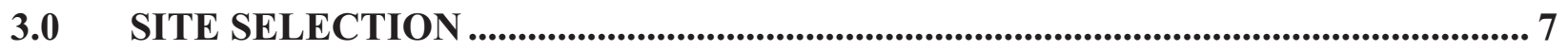

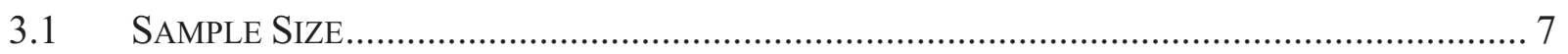

3.2 ROADWAY SEGMENT SELECTION ……………………………………………..... 8

3.2.1 Rural Two-Lane, Two-Way Undivided Road Site Selection ........................................................... 9

3.2.2 Rural Multilane Undivided Highways Site Selection.........................................................................10

3.2.3 Rural Multilane Divided Highways Segment Selection ....................................................................10

3.2.4 Urban and Suburban Arterial Segment Selection........................................................................ 10

3.3 INTERSECTION SITE SELECTION ......................................................................... 10

3.3.1 Rural Intersection Site Selection -- General Method ........................................................................11

3.3.2 Rural Two-lane Two-Way Four-leg Signalized Intersections Site Selection .....................................12

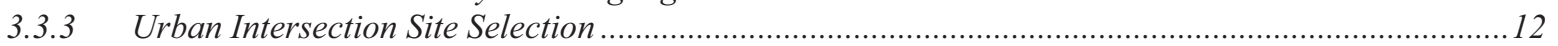

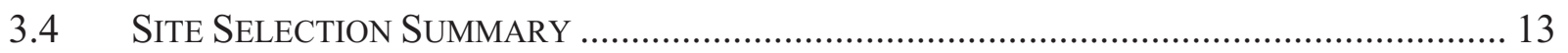

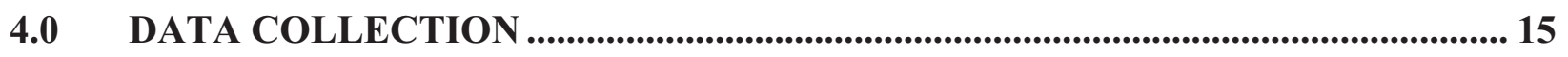

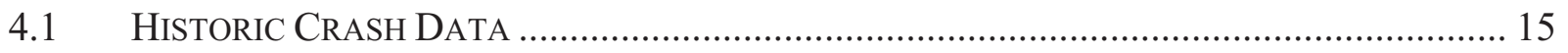

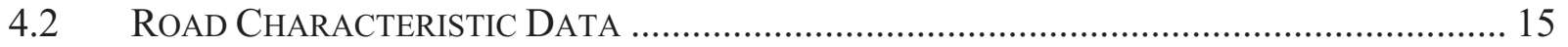

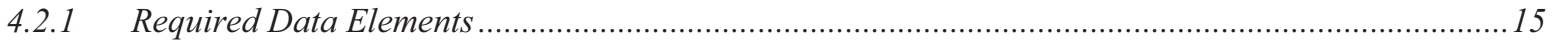

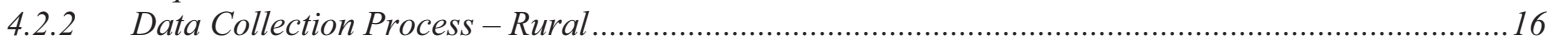

4.2.3 Data Collection Process - Urbann...………………………………………………………..2

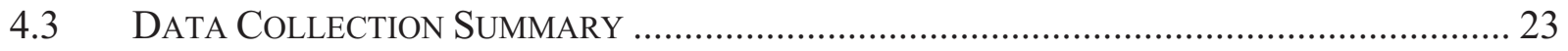

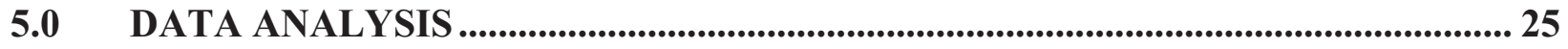

5.1 Dividing RoAdway Sites InTO Homogeneous SegmentS........................................ 25

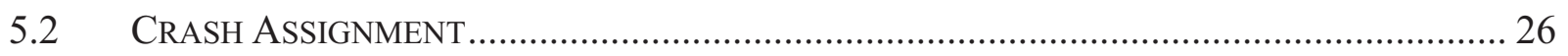

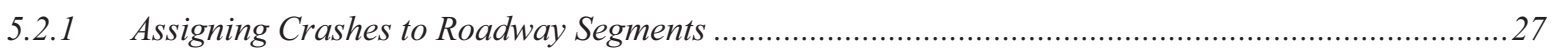

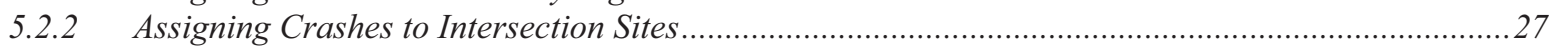

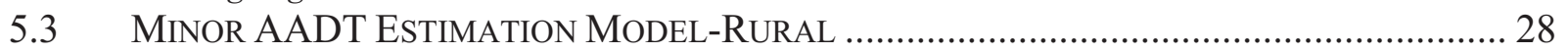

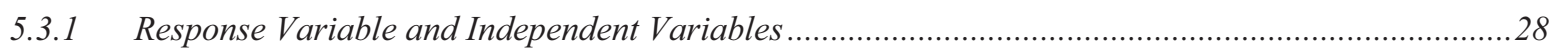

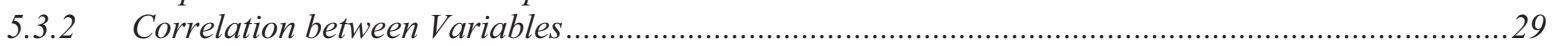

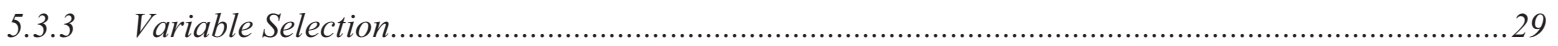

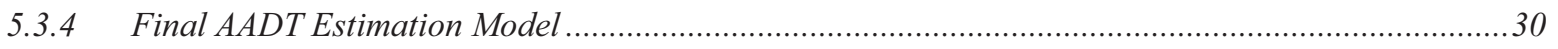

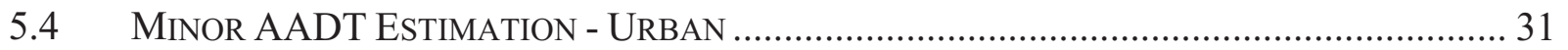

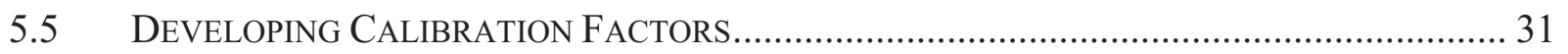

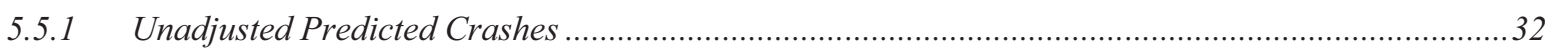

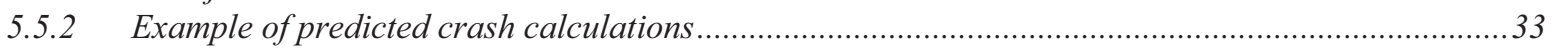

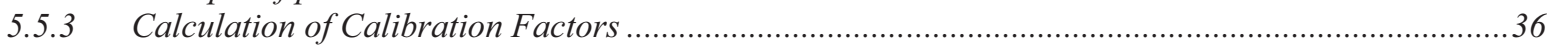

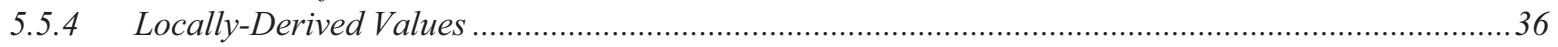

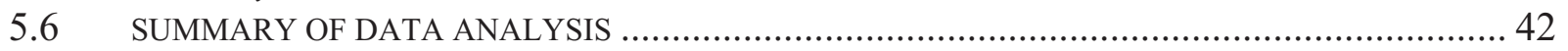


6.0 CALIBRATION RESULTS............................................................................................ 43

6.1 Calibration Factors Based on Default Proportions ............................................. 43

6.2 Default Proportions Versus LoCALly-Derived Proportions .............................. 46

6.3 Calibration Factors for Total Crashes Versus Fatal Plus Injury Crashes. 48

6.4 CALIBRATION FACTORS For TOTAL CRASHES BY GEOGRAPHIC REGION ....................... 51

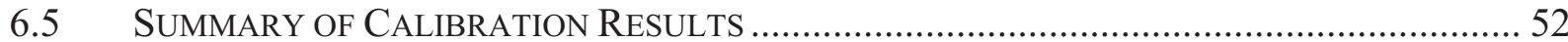

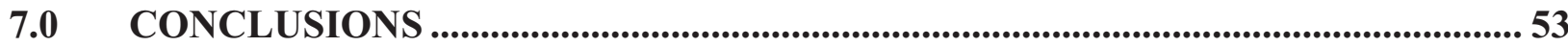

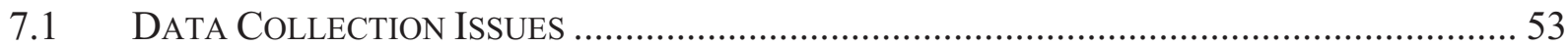

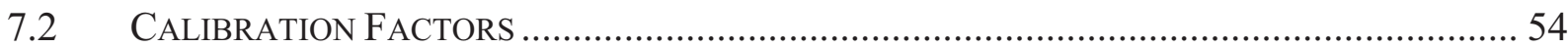

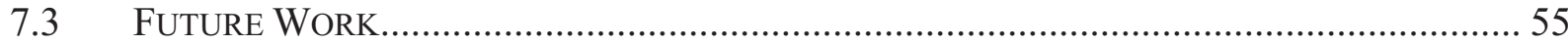

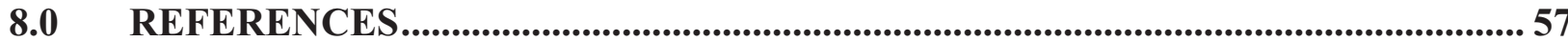

APPENDIX A - ABBREVIATION TABLE

APPENDIX B - LOCALLY-DERIVED VALUES

\section{LIST OF FIGURES}

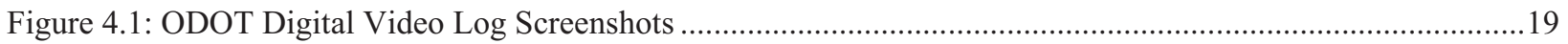

Figure 4.2 Google Earth View of Sample Rural Intersection................................................................................19

Figure 4.3: Google Data File Markup of Driveways on Urban Corridor ..............................................................20

Figure 4.4: Google Earth Sample Urban Intersection with Buffers of 250 and 1000 feet .....................................22

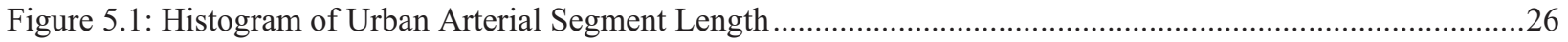

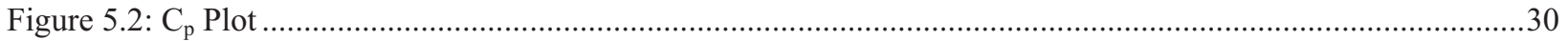

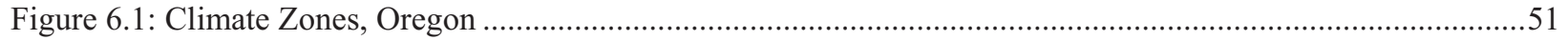




\section{LIST OF TABLES}

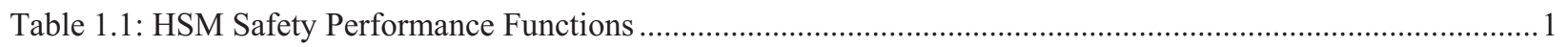

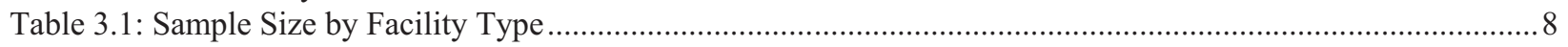

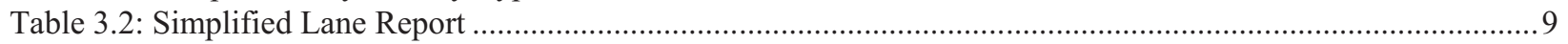

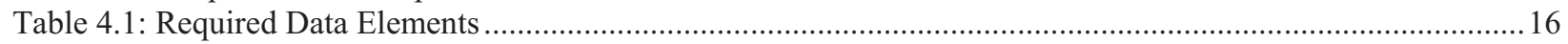

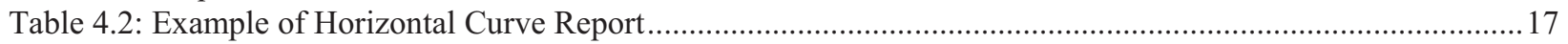

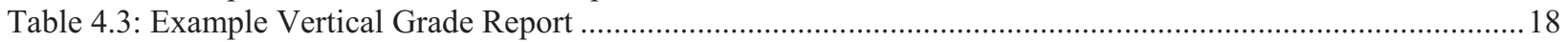

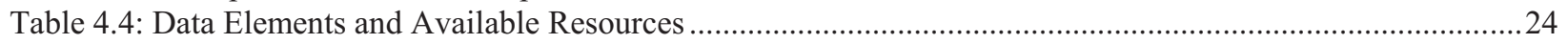

Table 5.1: Independent Variables for Minor AADT Estimation Models ....................................................................28

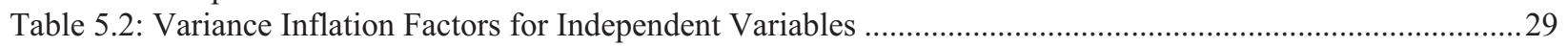

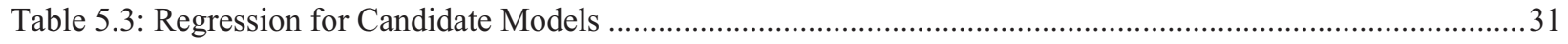

Table 5.4: Example Road Characteristic Data for Segments..................................................................................

Table 5.5: Example of Calculation Spreadsheet for Estimating Predicted Crashes ...................................................35

Table 5.6: HSM Tables or Equations for Which Local Calibration is Possible ........................................................38

Table 5.7: HSM-Default Crash Severity Levels versus Oregon Levels (2004-2006) for Rural Two-Lane, Two-

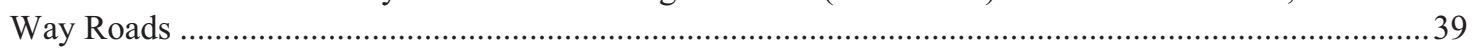

Table 5.8: HSM-Default Collision Distributions versus Oregon Distributions (2004 -2006) for Rural Two-

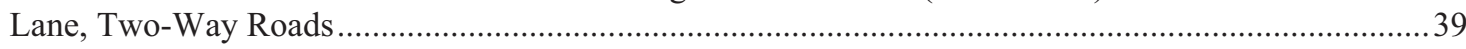

Table 5.9: HSM-Default Nighttime Proportions versus Oregon Proportions (2004 - 2006) for Rural Two-

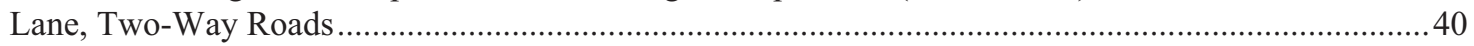

Table 5.10: Nighttime Crash Proportions for Unlighted Urban Roadway Segments (2004 -2006).........................40

Table 5.11: Distribution of Multiple-Vehicle Nondriveway Collisions for Roadway Segments by Manner of

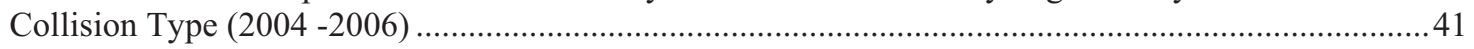

Table 5.12: Proportion of Pedestrian Accidents by Roadway Segment Type (2004-2006) .....................................41

Table 5.13: Local Proportions of Crashes by Intersection Type (2004-2006) ......................................................... 42

Table 6.1: Estimated Calibration Factors for Oregon (based on HSM default crash proportions).............................45

Table 6.2: Initial Comparison: HSM Default Proportions versus Locally-Derived Proportions (for each year) -

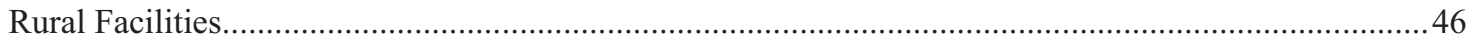

Table 6.3: Second Comparison: HSM Default Proportions versus Locally-Derived Proportions (average of

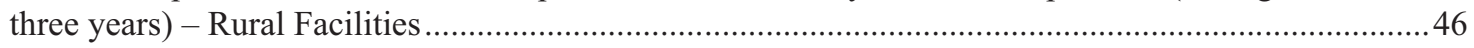

Table 6.4: Third Comparison: HSM Default Proportions versus Locally-Derived Proportions (three years then

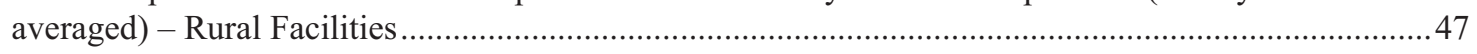

Table 6.5: Fourth Comparison: HSM Default Proportions versus Locally-Derived Proportions (three years) Urban and Suburban Facilities

0

0




\section{EXECUTIVE SUMMARY}

The Highway Safety Manual (HSM) was published by the American Association of State Highway and Transportation Officials (AASHTO) in the spring of 2010. Volume 2 (Part C) of the HSM includes safety predictive methods which can be used to quantitatively estimate the safety of a transportation facility. The resulting information can then be used to provide guidelines to identify opportunities to improve transportation safety. The safety performance functions (SPFs) included with this content, however, were developed for several states other than Oregon. Because there are differences in crash reporting procedures, driver population, animal populations, and weather conditions (to name a few), the State of Oregon needs to use calibrated SPFs when applying the HSM procedures to local Oregon facilities. Currently, the predictive methods have been developed for three facility types: rural two-lane two-way roads, rural multilane roads, and urban and suburban arterial roads. In this project, the research team calibrated SPFs for all three facility types based on their historic safety performance in Oregon. The report illustrates methods of site selection, the collection of crash and site-specific data, and analysis methods for calibration. Also, the report includes an evaluation of the crash severity distribution methods. With this information, Oregon agencies can use the calibrated HSM predictive methods to assess expected facility safety performance for Oregon conditions and facility alternatives. 


\subsection{INTRODUCTION}

Volume 2 of the recently published Highway Safety Manual (HSM) includes safety predictive methods which can be used to quantitatively estimate the safety of a transportation facility. The resulting information can then be used to provide guidelines to identify opportunities to improve transportation safety. The safety performance functions (SPFs) included with this content, however, were developed for several states other than Oregon. Because there are differences in crash reporting procedures, driver population, animal populations, and weather conditions (to name a few), the State of Oregon needs to use calibrated SPFs when applying the HSM procedures for local Oregon facilities. Therefore, the goal of this research project was to calibrate the HSM predictive method SPFs for conditions in the State of Oregon.

In the HSM predictive methods, the total expected crash frequencies for a facility are estimated by combining SPFs and crash modification factors. The SPFs are first used to calculate estimated crash frequency for a base condition. Next, the estimates are modified by applying crash modification factors (CMFs) to address non-base condition characteristics for specific segment and intersection locations. The predictive method can be used to estimate safety separately for intersections and segments. Currently, the HSM includes predictive methods for rural two-lane two-way roads; rural multilane highways, and urban and suburban arterials. All associated SPFs for these facility types should be calibrated. This project includes development of the associated segment and intersection type SPFs shown in Table 1.1. This table shows the specific SPFs included in the HSM and calibrated for Oregon conditions as a result of this research effort. In addition, there are a number of default crash distributions and parameters that can be calculated for the local conditions (these are shown later in Table 5.6)

Table 1.1: HSM Safety Performance Functions

\begin{tabular}{l|l|l}
\hline \multicolumn{1}{c|}{ Facility Type } & \multicolumn{1}{c}{ Segment Types } & \multicolumn{1}{c}{ Intersection Types } \\
$\begin{array}{l}\text { Rural Two-Lane, Two- } \\
\text { Way Roads }\end{array}$ & Undivided (R2) & $\begin{array}{l}\text { Three-Leg Stop (R3ST) } \\
\text { Four-Leg Stop (R4ST) } \\
\text { Four-Leg Signalized (R4SG) }\end{array}$ \\
\hline $\begin{array}{l}\text { Rural Multilane } \\
\text { Highways }\end{array}$ & $\begin{array}{l}\text { Undivided (MRU) } \\
\text { Divided (MRD) }\end{array}$ & $\begin{array}{l}\text { Three-Leg Stop (MR3ST) } \\
\text { Four-Leg Stop (MR4ST) } \\
\text { Four-Leg Signalized (MR4SG) }\end{array}$ \\
\hline \multirow{2}{*}{$\begin{array}{l}\text { Urban and Suburban } \\
\text { Arterials }\end{array}$} & $\begin{array}{l}\text { Two-lane undivided (2U) } \\
\text { Three-lane includes two-way left-turn lane } \\
\text { [TWLTL] (3T) } \\
\text { Four-lane undivided (4U) } \\
\text { Four-lane divided (4D) } \\
\text { Five-lane includes a TWLTL (5T) }\end{array}$ & $\begin{array}{l}\text { Three-Leg Stop (U3ST) } \\
\text { Four-Leg Stop (U4ST) } \\
\text { Three-Leg Signalized (U3SG) } \\
\text { Four-Leg Signalized (U4SG) }\end{array}$ \\
\hline
\end{tabular}

In this report, the authors provide a brief review of the applicable literature (see Chapter 2.0). Since the primary focus of the effort described in this report is the calibration of the HSM SPFs for Oregon conditions, the applicable literature is minimal and simply introduces the HSM procedure, provides a quick overview of Oregon crash reporting information, and presents 
information about an Indiana study where the researchers developed a model to estimate rural intersection annual average daily traffic (AADT). This background content is necessary because there is very little AADT data for Oregon rural intersection cross street locations, so one task performed by the research team and later included in Chapter 5.0 is the estimation of an Oregon AADT model that builds on the Indiana research.

Chapter 3.0 reviews the project approach for site selection for the rural and urban facilities. Included in Chapter 4.0 is a summary of data collection methods for crash data and road characteristic data for the State of Oregon.

Chapter 5.0 reviews the data analysis performed by the project team that ultimately resulted in the calibration factors included in Chapter 6.0. In addition to a summary of conclusions (Chapter 7.0) and a list of references (Chapter 8.0), the report also includes an abbreviation table (see Appendix A) and numerous tables depicting the locally-derived crash values used by the HSM procedures (see Appendix B). 


\subsection{LITERATURE REVIEW}

A brief review of the HSM predictive method is necessary to establish a context for the remaining content in this report. As a result, this section reviews the basic approach presented in the HSM (AASHTO 2010) and demonstrates the role calibration plays in this analysis procedure. In addition, the literature briefly reviews potential influencing issues about the Oregon crash reporting procedures. This section of the report concludes with a review of an AADT estimation model developed in Indiana. This content serves as a foundation for an additional AADT estimation applied to Oregon conditions.

\subsection{PREDICTIVE METHODS IN THE HIGHWAY SAFETY MANUAL}

In 2010, AASHTO published the first edition of HSM. The HSM contains four basic sections (referred to as Parts A, B, C, and D). Part A includes an introduction to the manual, a review of human factor issues critical to highway safety, and a safety fundamentals chapter. Part B introduces the various components that collectively make up the roadway safety management process. Part C, the focus of this research effort, provides key content that comprises the new HSM safety predictive methods. An appendix to Part $\mathrm{C}$ reviews how these predictive methods and their associated SPFs can and should be calibrated to reflect local or regional conditions. Part D of the HSM provides a catalog of high quality crash modification factors (CMFs).

The predictive models in Part $\mathrm{C}$ were developed based on historic site and crash data from select states. The research effort summarized in this report describes the calibration of these safety functions for conditions unique to state highways in Oregon. As an introduction to this calibration process, it is necessary to review the general HSM predictive estimation method and identify the calibration requirements for the various types of highway facilities. The predictive model initially estimates the predicted total crash frequency for a particular facility type, $N_{s p f}$, for a target year based on traffic volume and a set of base site conditions. Equation 2-1 demonstrates how this generic crash frequency value can then be modified for unique site characteristics using CMFs and a calibration factor, $C$.

\section{Equation 2-1: HSM Crash Prediction Method}

$$
N_{\text {predicted (adjusted })}=N_{s p f} \times\left(C M F_{1} \times C M F_{2} \times \ldots \times C M F_{n}\right) \times C
$$

Where:

$N_{\text {predicted (adjusted) }}=$ adjusted total predicted crash frequency,

$N_{s p f}=$ total predicted crash frequency under base condition,

$C M F_{1} \ldots C M F_{n}=$ Crash Modification Factors, and

$C=$ Calibration Factor. 
In Equation 2-1, $N_{s p f}$ is calculated using SPFs for the various facility types. The HSM SPFs are separated into segment and intersection models. For roadway segments, the SPF input variables include roadway length and AADT of the road segment. For intersections, the SPF input variables are the AADT values for the major and minor road.

The CMFs used in Equation 2-1 are included in the predictive method chapters of the HSM. These multiplicative CMFs are used to adjust for site characteristics that are different from the base conditions for the selected SPF. The CMFs are provided relative to the base condition. Thus, if a CMF has a value of 1.0, the associated road feature or countermeasure present at the site is equal to the base condition and will not influence the expected number of crashes (i.e. multiplying by 1.0 does not change the crash frequency estimate). If the CMF has a value less than 1.0, the associated road feature or countermeasure represented by this CMF is expected to result in fewer crashes than represented by base conditions. Finally, if the CMF value is greater than 1.0, the associated road feature or countermeasure can be expected to increase the number of crashes.

The predictive methods in the first edition of HSM can estimate a range of crash frequency conditions. The predictive methods for rural two-lane, two-way roads estimate total crash frequency and do not have SPFs based on injury level. To overcome this limitation, the analyst can apply expected crash proportions for injury levels by using those included in the HSM (based on California and Washington injury distributions) or by using locally derived crash injury proportions. The predictive methods for rural multilane highways include SPFs based on total crash frequency and injury level. CMFs for rural multilane four-leg signalized intersections (MR4SG), however, are not currently available. Predictive methods for urban and suburban arterials include crash frequency and severity. These models also help estimate expected crash conditions for pedestrian and bicycle collisions. As previously shown, Table 1.1 depicts the various SPFs included in the HSM and that have been calibrated as part of this research effort.

\subsection{CRASH REPORTING IN OREGON}

Several Oregon-specific characteristics indicate that the reported crash history for Oregon may differ from other states. One of these specific differences is the fact that Oregon crashes are selfreported. This means that when a person is involved in a crash and there are no injuries as a result of the crash, the individual drivers must prepare the crash reports (law enforcement officers do not generally respond to the crash location and, if they do, are only required to submit a crash report if they prepare a formal police report.

In addition to the self-reporting difference, Oregon also has different crash reporting thresholds than their neighboring states to the north and south (the states for which injury proportions are included in the HSM). For example, if a driver is involved in a crash which causes injury, death, more than $\$ 1,500$ damage to vehicles, or more than $\$ 1,500$ damage to vehicles and towing of another vehicle, the driver must file an Oregon Traffic Accident and Insurance Report within 72 hours. As a result, many property-damage-only (PDO) crashes are not reported in Oregon if their value is below the $\$ 1,500$ threshold. By comparison, the reporting thresholds for Washington and California are $\$ 700$ and $\$ 750$ respectively for PDO crashes (California Department of Motor Vehicles 2011, Washington State Highway Patrol 2006). 


\subsection{AADT MODELS FOR RURAL LOCATIONS}

Ideally, calibration for a jurisdiction should be based on field data for the entire sample size; however, some of the variables included in the predictive method are not readily available in many state databases and must either be simplified (using a default value) or estimated using known data for a sub-set of the locations. For this research effort, the project team determined that the minor AADT values for rural intersections are rarely available. Many of these locations are remote with low traffic volume, while some of these rural intersections are in close proximity to developed regions or freeways. Though this AADT information may not always be available, the authors identified one effort that estimated intersection AADT values for the State of Indiana.

Mohamad et al. (1998) developed an AADT prediction model for county roads in Indiana. They collected field data from 40 difference Indiana counties. The Indiana researchers generated an AADT model with multiple linear regression techniques. They also evaluated a variety of candidate explanatory variables and, based on the scatter of their field data, transformed the response variable (AADT) to a $\log 10$ configuration. The Indiana researchers determined that the AADT values for county highways were dependent on the road location (rural versus urban). They also discovered that critical variables included easy access to a major highway, total state highway mileage for a county, and the total arterial mileage of a county. The procedures used for evaluation and estimation of AADT for Indiana provided a basis for an estimation for rural Oregon AADT values that is presented later in this report. 


\subsection{SITE SELECTION}

The research team developed a method for selecting candidate sites as an initial step in performing the Oregon calibration procedure. The calibration guidance in the HSM provides a target number of sites and crashes; however, in some cases a facility may have a low crash frequency and applying the generic sample sizes recommended in the HSM may not be practical due to the low crash frequency for the location or facility type. As a result, the project team based site selection and sample size on the facility type, historic crashes for similar facilities, and random sampling procedures. This chapter presents the sample size, sampling procedures, segment site selection, and intersection site selection for the various SPFs included in the HSM. In an effort to demonstrate sample selection of a facility that may be under-represented for historic crash conditions, the authors demonstrate the sample selection procedure applied to the four-leg rural signalized intersection (R4SG) locations.

\subsection{SAMPLE SIZE}

The HSM recommends that sample size for calibration procedures should include 30 to 50 locations. The manual also emphasizes that these sites should be randomly selected and, upon initial selection, the analyst should determine the number of crashes per year. In general, the HSM recommends each facility type should have approximately100 crashes per year and the study period should be multiple years (AASHTO 2010). If one facility type has fewer than 30 sites, all sites should be included for calibration purposes. As previously indicated, select facility types may have very few actual recorded crashes and increasing the sample size until it includes 100 crashes per year could require a disproportionately large sample size that may not be necessary for proper calibration. Where possible, the Oregon team increased the number of sites to a sample size of 100 locations (the three-leg stop controlled rural multilane intersection is such an example). Since the rural two-lane two-way road is a common Oregon highway facility type, the project team increased the sample sizes for the three-leg and four-leg stop control intersections (R3ST and R4ST respective) to 200 locations. In urban areas, the HSM procedures require creating segment breaks at every intersection. Since most urban crashes occur at intersections, the short segments and low crash frequency required sampling a large number of "sites". Table 3.1 shows sample sizes for the Oregon facility types included in this analysis.

For the Oregon calibration effort, the project team used random site selection for facilities located on the state highway systems. Though there may be some differences in state highway facilities and those maintained by local jurisdictions, the analysis focused on the state facilities because these state-maintained highways have a more comprehensive data set available for road characteristics. For a select number of facilities that did not have a large state-maintained sample size, the project team extended the analysis on a limited basis to other non-state-maintained locations. The selection for roadway segments differed from that for intersections. This is further discussed in the following section. For locations with very limited crash history, the project team modified the sample size (using sampling statistical procedures based on typical crash 
frequency). One example location is the rural four-leg signalized intersection. Locations where the sample size requirements were modified are further reviewed in the following section.

Table 3.1: Sample Size by Facility Type

\begin{tabular}{|c|c|c|}
\hline & Facility Type & Sample Size (Sites) \\
\hline \multicolumn{3}{|c|}{ Rural Two-Lane, Two-Way Roads } \\
\hline \multicolumn{3}{|l|}{ Segments } \\
\hline $\mathrm{R} 2$ & 2-lane undivided & 75 \\
\hline \multicolumn{3}{|l|}{ Intersections } \\
\hline R3ST & 3-leg, minor STOP & 200 \\
\hline R4ST & 4-leg, minor STOP & 200 \\
\hline R4SG & 4-leg, signalized & 25 \\
\hline \multicolumn{3}{|c|}{ Rural Multilane Highways } \\
\hline \multicolumn{3}{|l|}{ Segments } \\
\hline MRU & 4-lane undivided & 50 \\
\hline MRD & 4-lane divided & 19 \\
\hline \multicolumn{3}{|l|}{ Intersections } \\
\hline MR3ST & 3-leg, minor STOP & 100 \\
\hline MR4ST & 4-leg, minor STOP & 107 \\
\hline MR4SG & 4-leg, signalized & 34 \\
\hline \multicolumn{3}{|c|}{ Urban and Suburban Arterials } \\
\hline \multicolumn{3}{|l|}{ Segments } \\
\hline $2 \mathrm{U}$ & 2-lane undivided & 491 \\
\hline $3 \mathrm{~T}$ & 3-lane with TWLTL & 205 \\
\hline $4 \mathrm{U}$ & 4-lane undivided & 375 \\
\hline $4 \mathrm{D}$ & 4-lane divided & 86 \\
\hline $5 \mathrm{~T}$ & 5-lane with TWLTL & 323 \\
\hline \multicolumn{3}{|l|}{ Intersections } \\
\hline U3ST & 3-leg, minor STOP & 73 \\
\hline U4ST & 4-leg, minor STOP & 48 \\
\hline U3SG & 3-leg, signalized & 49 \\
\hline U4SG & 4-leg, signalized & 57 \\
\hline
\end{tabular}

\subsection{ROADWAY SEGMENT SELECTION}

The HSM (2010) predictive methods address three specific road configurations. First, the rural two-way two-lane road category (designated as R2) includes an undivided segment safety performance function as well as intersection SPFs. The rural multilane highway includes undivided and divided segments (designated as MRU and MRD respectively) as well as associated intersection SPFs. The urban and suburban arterial also includes undivided two-lane and four-lane segments (designated as $2 \mathrm{U}$ and $4 \mathrm{U}$ respectively) as well as a four-lane divided segment (4D) and a three-lane and five-lane section with a center TWLTL (3T and 5T respectively). There are also four associated urban intersections SPFs. The site selection process 
varied for the different road types. This section describes the site selection procedure for the rural two-lane, rural multilane, and urban and suburban arterials sites.

\subsubsection{Rural Two-Lane, Two-Way Undivided Road Site Selection}

The research team used randomly selected sites for the R2 category that were previously identified for a recent Oregon research project that focused on rural two-lane roads (Dixon and Rohani 2008). To develop the database, that research team used the Functional Classification and National Highway System Status on Oregon State Highways (ORStateHwysFCandNHS) (http://www.oregon.gov/ ODOT/TD/TDATA/rics/FunctionalClassification.shtml ) to select rural state highways. Next, they used the Lane Report (http://www.oregon.gov/ODOT/TD/ TDATA/otms/OTMS_Highway_Reports.shtml ) to select rural two-lane two-way roadways. Table 3.2: depicts a simplified example of data included in the ODOT lane report for HWY092 [Milepoint (MP) from 41.65 to 39.65]. For the data shown in this table, only locations with intersections or where physical geometric dimensions changed are depicted.

Table 3.2: Simplified Lane Report

\begin{tabular}{|c|c|c|c|c|c|c|c|c|c|c|c|c|}
\hline \multirow{2}{*}{$\begin{array}{l}\text { Mile } \\
\text { Point }\end{array}$} & \multirow{2}{*}{$\begin{array}{c}\text { Intersection or } \\
\text { Landmark }\end{array}$} & \multicolumn{6}{|c|}{ Lane Width (ft) } & \multirow{2}{*}{$\begin{array}{l}\text { Shoulder } \\
\text { Type }\end{array}$} & \multicolumn{2}{|c|}{$\begin{array}{l}\text { Shoulder } \\
\text { Width (ft) }\end{array}$} & \multicolumn{2}{|c|}{ Median } \\
\hline & & 6 & 5 & 4 & 3 & 2 & 1 & & $\mathbf{L t}$ & Rt & Type & $\begin{array}{c}\text { Width } \\
\text { (ft) }\end{array}$ \\
\hline \multicolumn{13}{|c|}{ Highway \#: 092 Lower Columbia River Highway } \\
\hline 41.65 & Begin Segment & 0 & 0 & 0 & 0 & 12 & 12 & Paved & 6 & 7 & 0 & 0 \\
\hline 40.80 & Neer City Rd & 0 & 0 & 0 & 0 & 12 & 12 & Paved & 6 & 6 & 0 & 0 \\
\hline 40.76 & -- & 0 & 0 & 0 & 0 & 12 & 12 & Paved & 6 & 6 & 0 & 0 \\
\hline 40.47 & Nicolai/Moorage Rd. & 0 & 0 & 0 & 0 & 12 & 12 & Paved & 6 & 6 & 0 & 0 \\
\hline 40.16 & -- & 0 & 0 & 0 & 0 & 12 & 12 & Paved & 6 & 6 & 0 & 0 \\
\hline 40.13 & -- & 0 & 0 & 0 & 0 & 12 & 12 & Paved & 7 & 7 & 0 & 0 \\
\hline 39.91 & Jaquish/Wilbur Rd. & 0 & 0 & 0 & 0 & 12 & 12 & Paved & 7 & 7 & 0 & 0 \\
\hline 39.87 & -- & 0 & 0 & 0 & 0 & 12 & 12 & Paved & 6 & 8 & 0 & 0 \\
\hline 39.65 & End Segment & 0 & 0 & 0 & 0 & 12 & 12 & Paved & 6 & 8 & 0 & 0 \\
\hline
\end{tabular}

In the lane report, the lane width category includes six possible lanes and their associated widths. As can be expected, rural two-lane two-way roads should typically have only two lanes. A value of zero in a lane width column indicates that lane does not exist. Median type indicates the presence and type of median. Since the HSM SPFs for R2 segments do not include roadways with medians, the median type and width should have values of zero as shown.

For inclusion in the study, the project team listed all rural two-way two-lane roadway segments and subdivided them into segment lengths of approximately two miles. Each segment length was represented by a number and then the numbers were randomly selected (resulting in randomly selected two-mile road corridors). Finally, the project team selected 75 of the approximately two-mile long segments to include in the calibration analysis data set and determined the crash history of the selected locations. The total selected sites experienced, on 
average, 131 crashes per year. The HSM calibration procedure recommends verifying that the data is represented by at least 100 crashes per year, so the randomly selected data set of 75 twomile long segments fulfilled this criterion.

\subsubsection{Rural Multilane Undivided Highways Site Selection}

The selection of multilane rural undivided (MRU) segments was similar to the method used for the R2 segments. Instead of two lane segments, the project team used the lane reports and functional classification to identify four-lane candidate segments without medians. For the multilane rural highway segments identified in the state database, many of these locations were in the proximity of rural towns and their associated segment length was considerably shorter. In an effort to prevent the introduction of bias by including extremely short segments, only multilane segments 0.5 miles or longer were included in the dataset. Any of the segments that were longer than 2.5 miles were subdivided with a target of two-mile segment lengths where feasible. Finally, the project team randomly selected 50 roadway segments from the total population. These segment locations had, on average, 121 crashes per year.

\subsubsection{Rural Multilane Divided Highways Segment Selection}

In the State of Oregon, only a limited number of rural multilane highways have been constructed with a median. As a result, the selection method the project team used for the rural multilane divided highways (MRD) included identification of segments using the Oregon Department of Transportation (ODOT) resources previously indicated and then a selection of all qualifying segments for the data set. The resulting MRD database consisted of 19 roadway segments of varying length with a total combined length of 8.27 miles.

\subsubsection{Urban and Suburban Arterial Segment Selection}

The selections for urban and suburban arterials were similar to the process for identifying candidate segments, though a GIS-based method was used to identify the sample pool to accurately represent urban boundaries. The state highway network was spatially joined with urban area boundaries to identify candidate sections of highway. This resulted in 289.71 miles of highway available for using for selection. The highway segments were joined with the roadway inventory database and preliminarily classified as type $2 \mathrm{U}, 3 \mathrm{~T}, 4 \mathrm{U}, 4 \mathrm{D}, 5 \mathrm{~T}$ based on number of lanes and median type. The candidate highways were then segmented (in an automated fashion) based on changes in other variables as specified in the HSM. Next, the research team randomly sampled these segments with the objective of obtaining 100 reported crashes per year for each facility type. Once a facility type reached this threshold, the analysts stopped sampling.

\subsection{INTERSECTION SITE SELECTION}

The selection of candidate Oregon intersections for this calibration effort required that the research team identify a large number of intersection types for each road type. For the rural twolane road environment, the SPFs had to be calibrated for the rural three-leg and four-leg STOP controlled intersections (R3ST and R4ST respectively) as well as for the four-leg signalized intersection (R4SG). Similarly, for the rural multilane highway environment, the associated 
HSM SPFs included the multilane rural three-leg STOP, four-leg STOP, and four-leg signalized intersections (MR3ST, MR4ST, and MR4SG respectively). Finally for the urban and suburban arterial SPFs, the associated intersections include the three-leg STOP (U3ST), four-leg STOP (U4ST), three-leg signalized (U3SG), and four-leg signalized (U4SG) intersections.

The site selection method for this wide variety of intersections varied based on the data format, site conditions, and total available number of candidate intersections. In the following sections, these various methods for intersection site selection are reviewed.

\subsubsection{Rural Intersection Site Selection -- General Method}

For initial intersection identification at rural locations, the ODOT lane report includes general intersection information that identifies the milepoint as well as the basic intersection orientation (T-intersection versus cross-intersection, signalized versus other traffic control device configuration); however, prior to incorporating an intersection into the analysis the project team confirmed the traffic control device as well as intersection orientation using the ODOT video log supplemented by on-line aerial photographs.

The project team then randomly selected each study intersection from the resulting database of candidate intersection types. Following the initial selection of 30 sites, the team members then verified whether the selected sites represented the HSM crash history target of 100 crashes per year. If the historic crash target resulted in values less than 100 crashes per year, additional sites were then selected. During this process, it became apparent that certain intersection types do not have a substantial number of crashes and that the 100 crash target merits additional consideration to more directly represent the expected number of crashes for each facility type.

The STOP-controlled intersections (R3ST, R4ST, MR3ST and MR4ST) experienced a small number of reported crashes in Oregon; therefore, alternative sample sizes are appropriate for these facilities. For example, the crash frequency for the MR3ST intersection is consistently small, so the project team used a sample size of 100 sites (more than twice the HSM recommendation) so as to capture additional crashes. The rural two-lane intersection locations experienced very few crashes. Since R3ST and R4ST are typical intersection types for a rural highway system and additional intersections could be easily identified, the research team increased the sample size for these two STOP-controlled intersection types to 200 locations. In the Oregon database there are only 107 MR4ST intersections, all 107 intersections were included in the MR4ST sample. Similarly, for intersection types that exist in a limited number, when the target number of intersections or crashes could not be achieved the study included the entire population for that type of intersection. As a result, since there are only $25 \mathrm{R} 4 \mathrm{SG}$ and 34 MR4SG intersections in Oregon, all these intersections were included in the data base. The 25 R4SG intersections are further reviewed in Section 3.3.2. 


\subsubsection{Rural Two-lane Two-Way Four-leg Signalized Intersections Site Selection}

As indicated in the overview for intersection site selection (see Section 3.3.1), the project team included 25 R4SG intersections in the study sample. According to the ODOT database, there are actually only 19 R4SG intersections located along rural state highways in Oregon. Since the HSM recommends that calibration should be performed on all available intersections for a specific intersection type if the target sample size cannot be achieved, the project team explored two-lane rural road locations that are not on the state highway system for Oregon to see if comparable county road locations could be identified. Currently, there is not a comprehensive road characteristic database for Oregon highways not on the state system, so members of the project team used geographic information system (GIS) programs to search for this intersection type.

All of the known 19 R4SG state-system intersections share the characteristic that they are located in the vicinity of towns or cities. Therefore, the project team extended the intersection search to county roads in the proximity of cities and identified 6 additional R4SG intersections located along county highways. These additional intersections increased the 19 state-system-only R4SG intersection set to a total of 25 state and county target intersections. The project team further evaluated select county aerial photographs to confirm that the GIS selection method identified all available county R4SG intersections. The authors systematically selected 14 counties and visually searched all areas in these counties. They then compared their findings to those from the GIS search for the same counties and were not able to identify any additional candidate intersections. This supplemental search confirmed, therefore, that the GIS search procedure provided representative results and that the calibration database could now be reasonably considered to include all available candidate R4SG intersections.

\subsubsection{Urban Intersection Site Selection}

The research team determined that the most comprehensive data for urban AADT values was available in a statewide layer of functionally classified roads. Using GIS, they created a layer of the functionally classified intersections (11,131 intersections). This layer was spatially intersected with the urban state highway layer to identify intersections on urban state highways. This list was then filtered for locations with recent volume estimates on the minor approaches. This resulted in a candidate pool of 2,671 intersections (171 of which were state highway-tostate highway intersections). The team then randomly selected intersections from this list. As each intersection was selected, the researchers confirmed the volume on all minor and major legs. If the volume data did not meet criteria, an attempt was made to gather more recent data. If more recent data could not be identified, the intersection was not selected. The research team then used the Digital Video Log and aerial photography to confirm that all legs are two-way streets (one-way legs are not included in the HSM) and to classify the intersection as either three-leg STOP (U3ST), four-leg STOP (U4ST), three-leg signalized (U3SG), or four-leg signalized (U4SG) intersections. The research team assessed the crash count of the intersection group to confirm the 100 reported crashes per year threshold. 


\subsection{SITE SELECTION SUMMARY}

The selection of representative segment and intersection locations for calibration efforts is critical to effective SPF calibration. During the data collection stages of this project, the research team identified a few elements that merit further consideration during future calibration efforts as well as for future enhancements to the HSM overall procedures.

First, random selection of sites is critical so that an agency can confidently state that the calibration factors are representative of the larger road population. Developing a calibration database could be expedited if the site selection focuses on high-crash locations since this would result in a smaller sample size; however, such a selection procedure would bias the results. Similarly, segments and intersections that are randomly selected and do not have any recent crash history are also critical to precise SPF calibration. To adequately represent diverse rural regions, the random selection of rural sites should also extend to good geographic representation of the target region, so a secondary site selection step for these rural locations confirmed this diverse geographic representation of the study sample.

A second and more significant item identified during the site selection process is that the HSM sample size and minimum crash thresholds appear to be somewhat arbitrary and merit additional enhancements. For example, the number of segment crashes for rural two-lane roads can be easily identified and achieved if a jurisdiction has a large rural area; however, the 100 crashes per year should be facility-specific. The criteria for identifying 100 crashes per year for a rural multilane signalized intersection, for example, may not be indicative of the number of crashes that can be expected per year for such facilities. In other words, if you select 50 sites and they must have a total of approximately 100 crashes per year this equates to at least two crashes per site per year on average. Some locations such as the rural three-leg STOP controlled intersections do not typically experience this number of crashes while other locations such as urban signalized intersections would be expected to have a number of annual crashes much greater than two. Future enhancements to the calibration procedure should target sample sizes representative of the expected number of crashes for a particular type of facility.

For this research effort, the project team has attempted to adhere to the HSM recommended thresholds where possible. The procedure for site selection, however, could have been potentially streamlined if site-specific thresholds are developed and then expanded into appropriate sample size estimates. 


\subsection{DATA COLLECTION}

As a fundamental component of site selection data collection, the calibration procedure requires the collection of historic crash data for at least a three year period. For the calibration effort reviewed in this report, the project team used crash information for the years from 2004 to 2006. In addition to the historic crash information, successful calibration requires comprehensive road characteristic data. The data collection effort for these two types of data is reviewed in this section of the report.

\subsection{HISTORIC CRASH DATA}

The research team obtained historic crash data for the year 2004 to 2006 from the Oregon Department of Transportation's Statewide Crash Data System (CDS). When the project started, the 2007 and later crash data was not yet available so the selected time period represented the most recent crash data at that time. For non-intersection roadway segments, all crashes that occurred within the site limits classify as segment crashes. For intersections, the HSM indicates that crashes that occurred within the physical limits of the intersections as well as associated crashes located on the intersection approach legs (within 250 feet $(15.3 \mathrm{~m})$ ) should be included in the analysis. The project team then further evaluated the crashes that were located on the intersection approach legs to determine if they qualified as intersection-related crashes.

The data for each crash included a unique crash identity number, the crash type and collision type, character of roads, intersection-related as designated by reporting officers, direction from intersection, and direction of travel. The data also included the severity level for each crash. This information was critical so that the team could obtain calibration factors for SPFs for fatal and injury crashes.

\subsection{ROAD CHARACTERISTIC DATA}

Each SPF and associated road or intersection type requires specific site information for successful application to the calibration procedure. In this section, the report summarizes this required road characteristic data. In addition, this section of the report summarizes the data collection procedures used to acquire the necessary road characteristic data.

\subsubsection{Required Data Elements}

For each road segment and intersection SPF, specific data elements are required; however, these key data elements vary for the different facility types. All road characteristic data needed for calibration for the various facility types are listed in Table 4.1. The HSM includes recommendations about ways to simplify the calibration effort by using default values for some of the less critical variables; however, to minimize the loss of precision, the research team elected to collect all possible variables for this Oregon calibration project. 
Table 4.1: Required Data Elements

\begin{tabular}{|c|c|c|c|c|c|c|c|c|c|c|c|c|c|c|c|c|c|c|}
\hline \multirow{3}{*}{ Data Elements } & \multicolumn{18}{|c|}{ Data Requirements per Facility Type } \\
\hline & \multicolumn{4}{|c|}{$\begin{array}{l}\text { Rural Two- } \\
\text { Lane, Two- } \\
\text { Way Roads }\end{array}$} & \multicolumn{5}{|c|}{$\begin{array}{l}\text { Rural Multilane } \\
\text { Highways }\end{array}$} & \multicolumn{9}{|c|}{ Urban and Suburban Arterials } \\
\hline & $\approx$ & 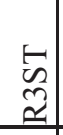 & 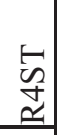 & 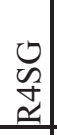 & $\underset{z}{\gtrless}$ & $\underline{\Omega}$ & $\begin{array}{l}\qquad \\
\sim \\
2 \\
\tilde{z} \\
\Sigma\end{array}$ & $\begin{array}{l}-\oplus \\
\infty \\
\searrow \\
\Sigma \\
\Sigma\end{array}$ & 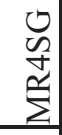 & 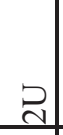 & $\stackrel{m}{m}$ & 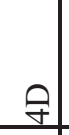 & $\vartheta$ & in & 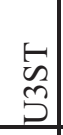 & 旨 & 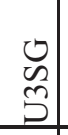 & Ð \\
\hline AADT of Major Road & - & $\bullet$ & $\bullet$ & $\bullet$ & $\bullet$ & $\bullet$ & $\bullet$ & $\bullet$ & $\bullet$ & $\bullet$ & $\bullet$ & $\bullet$ & $\bullet$ & $\bullet$ & $\bullet$ & $\bullet$ & $\bullet$ & $\bullet$ \\
\hline AADT of Minor Road & & - & $\bullet$ & - & & & $\bullet$ & $\bullet$ & $\bullet$ & & & & & & $\bullet$ & - & $\bullet$ & $\bullet$ \\
\hline Segment Length & $\bullet$ & & & & $\bullet$ & $\bullet$ & & & & $\bullet$ & $\bullet$ & $\bullet$ & $\bullet$ & - & & & & \\
\hline Lane Width & $\bullet$ & & & & $\bullet$ & $\bullet$ & & & & & & & & & & & & \\
\hline Shoulder Width & $\bullet$ & & & & $\bullet$ & $\bullet$ & & & & & & & & & & & & \\
\hline Shoulder Type & $\bullet$ & & & & $\bullet$ & & & & & & & & & & & & & \\
\hline Horizontal Curve Data & $\bullet$ & & & & & & & & & & & & & & & & & \\
\hline Vertical Grades & $\bullet$ & & & & & & & & & & & & & & & & & \\
\hline Driveway Density & • & & & & & & & & & $\bullet$ & $\bullet$ & $\bullet$ & $\bullet$ & $\bullet$ & & & & \\
\hline Centerline Rumble Strips & 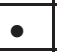 & & & & & & & & & & & & & & & & & \\
\hline Passing Lanes & $\bullet$ & & & & & & & & & & & & & & & & & \\
\hline TWLTLs & $\bullet$ & & & & & & & & & & & & & & & & & \\
\hline Roadside Hazard Rating & $\bullet$ & & & & & & & & & & & & & & & & & \\
\hline Side Slope & & & & & $\bullet$ & & & & & & & & & & & & & \\
\hline Roadside Fixed Object Density & & & & & & & & & & $\bullet$ & $\bullet$ & $\bullet$ & $\bullet$ & $\bullet$ & & & & \\
\hline $\begin{array}{l}\text { Average Offset to Fixed } \\
\text { Objects }\end{array}$ & & & & & & & & & & $\bullet$ & $\bullet$ & $\bullet$ & $\bullet$ & • & & & & \\
\hline Median Type and Width & & & & & & $\bullet$ & & & & & $\bullet$ & - & & $\bullet$ & & & & \\
\hline Lighting & $\bullet$ & $\bullet$ & $\bullet$ & $\bullet$ & $\bullet$ & $\bullet$ & $\bullet$ & $\bullet$ & & $\bullet$ & $\bullet$ & $\bullet$ & $\bullet$ & - & $\bullet$ & $\bullet$ & $\bullet$ & - \\
\hline Speed Category & & & & & & & & & & $\bullet$ & $\bullet$ & $\bullet$ & $\bullet$ & $\bullet$ & & & & \\
\hline Automated Speed Enforcement & $\bullet$ & & & & $\bullet$ & $\bullet$ & & & & $\bullet$ & $\bullet$ & $\bullet$ & $\bullet$ & $\bullet$ & & & - & $\bullet$ \\
\hline Intersection Skew Angle & & - & - & & & & - & - & & & & & & & & & & \\
\hline Left-Turn Signal Phasing & & & & & & & & & & & & & & & & & $\bullet$ & $\bullet$ \\
\hline Right-Turn Signal Phasing & & & & & & & & & & & & & & & & & $\bullet$ & $\bullet$ \\
\hline Intersection Left-Turn Lane & & $\bullet$ & $\bullet$ & $\bullet$ & & & $\bullet$ & $\bullet$ & & & & & & & $\bullet$ & $\bullet$ & $\bullet$ & $\bullet$ \\
\hline Intersection Right-Turn Lane & & $\bullet$ & $\bullet$ & $\bullet$ & & & $\bullet$ & $\bullet$ & & & & & & & $\bullet$ & $\bullet$ & $\bullet$ & $\bullet$ \\
\hline Right-turn-on-red Prohibited & & & & & & & & & & & & & & & & & $\bullet$ & $\bullet$ \\
\hline On-Street Parking Type & & & & & & & & & & $\bullet$ & $\bullet$ & $\bullet$ & $\bullet$ & $\bullet$ & & & & \\
\hline $\begin{array}{l}\text { Maximum lanes for pedestrian } \\
\text { crossing }\end{array}$ & & & & & & & & & & & & & & & & & $\bullet$ & • \\
\hline Pedestrian Volumes & & & & & & & & & & & & & & & & & • & $\bullet$ \\
\hline Bus stops within $1000 \mathrm{ft}$ & & & & & & & & & & & & & & & $\bullet$ & $\bullet$ & $\bullet$ & $\bullet$ \\
\hline Schools within $1000 \mathrm{ft}$ & & & & & & & & & & & & & & & $\bullet$ & $\bullet$ & $\bullet$ & $\bullet$ \\
\hline $\begin{array}{l}\text { Alcohol sales establishments } \\
\text { within } 1000 \mathrm{ft}\end{array}$ & & & & & & & & & & & & & & & • & & - & $\bullet$ \\
\hline
\end{tabular}

\subsubsection{Data Collection Process - Rural}

As shown in Table 4.1, many of the data elements are readily available in current ODOT databases. Lane width, shoulder width, shoulder type, passing lane information, and median 
width are located in the ODOT State Highway Lane Report (shown as Table 3.2 in Section 3.2). Horizontal curve data including curve length, curve radius, the presence of spiral transition curve, and superelevation are included in the ODOT State Highway Horizontal Curve Report (an example of which is shown in Table 4.2). For the rural two-lane road segments, a previous research effort included confirmation of the horizontal curve information by using a combination of aerial photography and field visits, so this information confirmed or corrected that acquired from the ODOT database.

Table 4.2: Example of Horizontal Curve Report

\begin{tabular}{|c|c|c|c|c|c|c|c|c|c|c|}
\hline Roadway & $\begin{array}{l}\text { Overlap } \\
\text { Mileage }\end{array}$ & $\begin{array}{l}\text { Beginning } \\
\text { Mile Point }\end{array}$ & $\begin{array}{c}\text { Contract } \\
\text { ID }\end{array}$ & $\begin{array}{c}\text { Location } \\
\text { Seq \# }\end{array}$ & $\begin{array}{c}\text { Super- } \\
\text { Elevation }\end{array}$ & & \multicolumn{4}{|c|}{ Spirals } \\
\hline $\begin{array}{c}\text { Degree } \\
\text { Curve } \\
\text { Angle } \\
\text { (degrees) }\end{array}$ & Dir & $\begin{array}{c}\text { Central } \\
\text { Angle } \\
\text { (degrees) }\end{array}$ & $\begin{array}{l}\text { Curve } \\
\text { Length } \\
\text { (ft) }\end{array}$ & $\begin{array}{l}\text { Tangent } \\
\text { Length } \\
\text { (ft) }\end{array}$ & & & $\begin{array}{c}\text { Length } \\
(\mathrm{ft})\end{array}$ & $\begin{array}{c}\text { Angle } \\
\text { (degrees) }\end{array}$ & $\begin{array}{c}\text { Tangent } \\
\text { (ft) }\end{array}$ & $\begin{array}{c}\text { Increase } \\
\text { Rate }\end{array}$ \\
\hline \multicolumn{11}{|c|}{ Highway \#: 026 MT. HOOD Hwy } \\
\hline 1 & & 80.48 & 26 & 180 & 0 & Spiral In & 0 & 0 & 0 & 0 \\
\hline 0 & & 0 & 0 & 0 & & Spiral Out & 0 & 0 & 0 & 0 \\
\hline 1 & & 80.32 & 26 & 180 & 0 & Spiral In & 300 & 9 & 0 & 2 \\
\hline 6 & $\mathrm{~L}$ & 17.7958 & 296.6 & 148.84 & & Spiral Out & 300 & 9 & 0 & 2 \\
\hline 1 & & 80.23 & 26 & 180 & 0 & Spiral In & 0 & 0 & 0 & 0 \\
\hline 0 & & 0 & 0 & 0 & & Spiral Out & 0 & 0 & 0 & 0 \\
\hline
\end{tabular}

As shown in Table 4.2, there is a horizontal curve present for the segment of ODOT Highway 26 (US-26) that extends from MP 80.32 to MP 80.48. The curve length is 0.16 miles which is equivalent to the distance between MP 80.32 and MP 80.48. The degree curvature is 6 degrees. Using the Equation 4-1, the associated curve radius can be calculated to be $955 \mathrm{ft}$.

Radius $=\frac{5729.58}{\text { Degree of Curvature }}$

The curve does not include any superelevation and each end of the horizontal curve transitions to the tangent via a $300 \mathrm{ft}$ long spiral curve.

One key variable that is required for all segments and intersections is the AADT. For most state highways, this information is available in either a measured or estimated format. The AADT information for state highways is located in the ODOT Traffic Volumes and Vehicle Classification Report. For intersections, the $\mathrm{AADT}_{\text {major }}$ as well as the $\mathrm{AADT}_{\text {minor }}$ values are needed for the SPFs. Generally, the major roads for most intersection locations were the associated state highways; however, in some instances the traffic volume for local roads 
exceeded that observed for state highways. For these locations, the major road was then

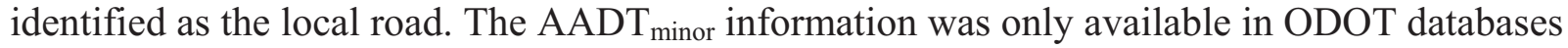
at locations where both the major and minor roads were state highways. For the rural intersection, the project team acquired much of the $\mathrm{AADT}_{\text {minor }}$ information from the local county public works departments.

At some rural locations, the local jurisdiction did not have available traffic volume information. At these locations, the project team developed an estimation procedure for the AADT values. This procedure is described in Section 5.3.

Vertical grades are required input variables for the rural two-lane road SPFs. This information can be obtained from the ODOT State Highway Vertical Grade Report. Table 4.3 depicts an example of the vertical grade information for ODOT Highway 26 from MP 80.40 to MP 90.21. As an example, the vertical grade from MP 80.4 to MP 82.91 is approximately 1.03 percent.

Table 4.3: Example Vertical Grade Report

\begin{tabular}{|c|c|c|c|c|c|c|}
\hline $\begin{array}{l}\text { Beginning } \\
\text { Milepoint }\end{array}$ & $\begin{array}{c}\text { Location } \\
\text { Seq \# } \\
\end{array}$ & $\begin{array}{c}\text { Percent } \\
\text { Grade }\end{array}$ & $\begin{array}{l}\text { Sag/ } \\
\text { Crest }\end{array}$ & $\begin{array}{c}\text { Curve } \\
\text { Length (ft) }\end{array}$ & $\begin{array}{c}\text { Contract } \\
\text { ID } \\
\end{array}$ & $\begin{array}{c}\text { Estimated } \\
\text { Data } \\
\end{array}$ \\
\hline \multicolumn{7}{|c|}{ Highway \#: 026 MT. HOOD Hwy } \\
\hline 90.21 & 100 & 2.57 & $\mathrm{~S}$ & 500 & 11,400 & $\mathrm{~N}$ \\
\hline 89.90 & 100 & 1.51 & $\mathrm{C}$ & 500 & 11,400 & $\mathrm{~N}$ \\
\hline 89.68 & 100 & 2.13 & $\mathrm{~S}$ & 200 & 11,400 & $\mathrm{~N}$ \\
\hline 89.45 & 100 & 2.39 & $\mathrm{~S}$ & 1200 & 11,400 & $\mathrm{~N}$ \\
\hline 89.22 & 100 & -2.28 & $\mathrm{C}$ & 200 & 11,400 & $\mathrm{~N}$ \\
\hline 88.92 & 100 & -2 & $\mathrm{C}$ & 500 & 11,400 & $\mathrm{~N}$ \\
\hline 88.67 & 100 & -1.1 & $\mathrm{~S}$ & 500 & 11,400 & $\mathrm{~N}$ \\
\hline 88.35 & 100 & -3.12 & $\mathrm{C}$ & 600 & 11,400 & $\mathrm{~N}$ \\
\hline 84.97 & 180 & -1.86 & $\mathrm{C}$ & 800 & 26 & $\mathrm{~N}$ \\
\hline 84.69 & 180 & -0.27 & $\mathrm{~S}$ & 400 & 26 & $\mathrm{~N}$ \\
\hline 84.42 & 180 & -1.85 & $\mathrm{~S}$ & 200 & 26 & $\mathrm{~N}$ \\
\hline 84.04 & 180 & -2.77 & $\mathrm{~S}$ & 200 & 26 & $\mathrm{~N}$ \\
\hline 83.94 & 180 & -4.43 & $\mathrm{C}$ & 400 & 26 & $\mathrm{~N}$ \\
\hline 83.81 & 180 & -1.51 & $\mathrm{~S}$ & 400 & 26 & $\mathrm{~N}$ \\
\hline 83.27 & 180 & -3.58 & $\mathrm{C}$ & 500 & 26 & $\mathrm{~N}$ \\
\hline 82.91 & 180 & -2.45 & $\mathrm{C}$ & 800 & 26 & $\mathrm{~N}$ \\
\hline 80.40 & 180 & 1.03 & $\mathrm{~S}$ & 1000 & 26 & $\mathrm{~N}$ \\
\hline
\end{tabular}

The project team was not able to identify a reliable database that includes information regarding driveway density, the presence of centerline rumble strips, the presence of two-way left-turn lanes (though the known presence of a lane is available from the ODOT lane report), the roadside hazard rating, the side slope, and the lighting of roadways. Therefore, the project team used the ODOT Digital Video Log to identify this missing data and, in the case of the roadside hazard rating and the side slope, make a subjective judgment about the value of the missing data element. Figure 4.1 shows example images from the video log. 

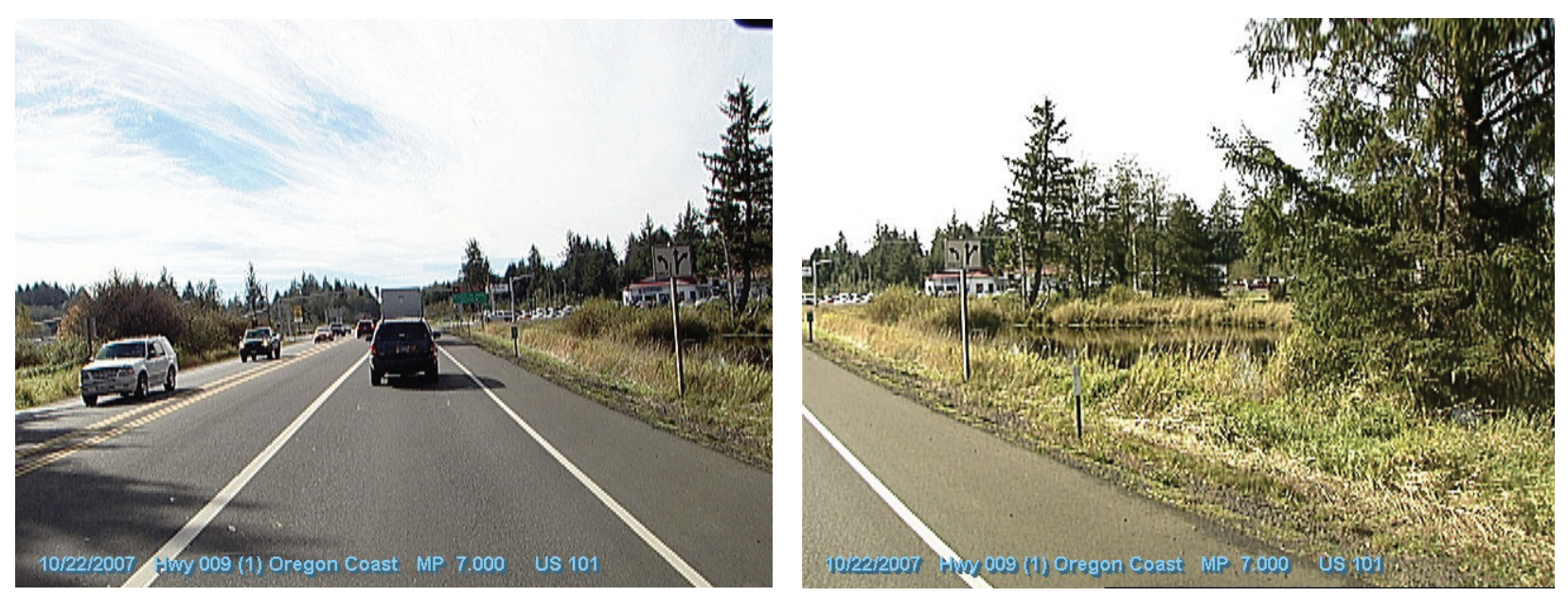

Figure 4.1: ODOT Digital Video Log Screenshots

The project team used aerial photos to acquire data such as intersection lighting, intersection skew angle, intersection left-turn lane, and intersection right turn-lane. When the calculated skew angle measured less than 10 degrees, the research team assumed a skew angle value of zero. Figure 4.2 depicts an example of an aerial intersection view as obtained from Google Earth. At the intersection shown, it is clear that there are four left-turn lanes (one for each approach) as well as two right-turn lanes (major approaches only). The skew angle is smaller than 10 degrees (about 8 degrees) and so was assumed to have an approximate value of zero degrees.

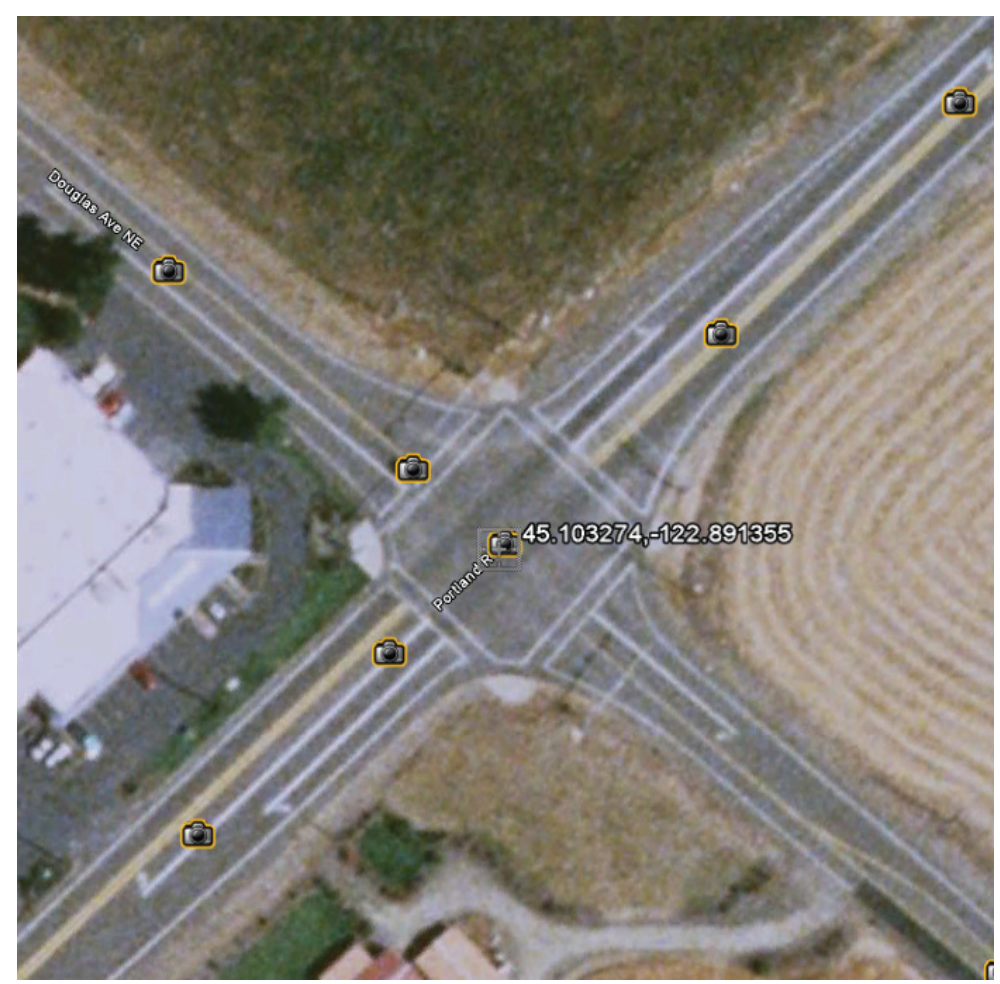

Figure 4.2 Google Earth View of Sample Rural Intersection 


\subsubsection{Data Collection Process - Urban}

Table 4.1 identifies the required elements for the urban and suburban arterial segments and intersections. Many of the data elements are readily available in current ODOT databases.

For urban segments, the number and type of driveway is needed for CMF calcualtions. The research team developed a data collection process where each driveway would be annotated in Google Earth in a data file. As the researcher placed the "pin", each driveway was classified as either minor commercial, major commercial ( $>50$ spaces), minor residential, major residential, minor industrial or institutional, major industrial or institutional, or other typically an empty or undeveloped lot. The distinction between driveway types was often difficult so the team used a combination of the digital video $\log$ (DVL) and Google Earth resources. The analysts used clues such as business signs, mailboxes, and curb-side trash cans to distinguish between residential and commercial driveways. As recommended in the HSM, the number of parking spaces available helps designate the primary distinction between minor and major uses. Some land uses could not be classified by parking spaces such as car dealership driveways, which even though total parking spaces may be greater than 50, were classified as minor commercial based on their expected activity.

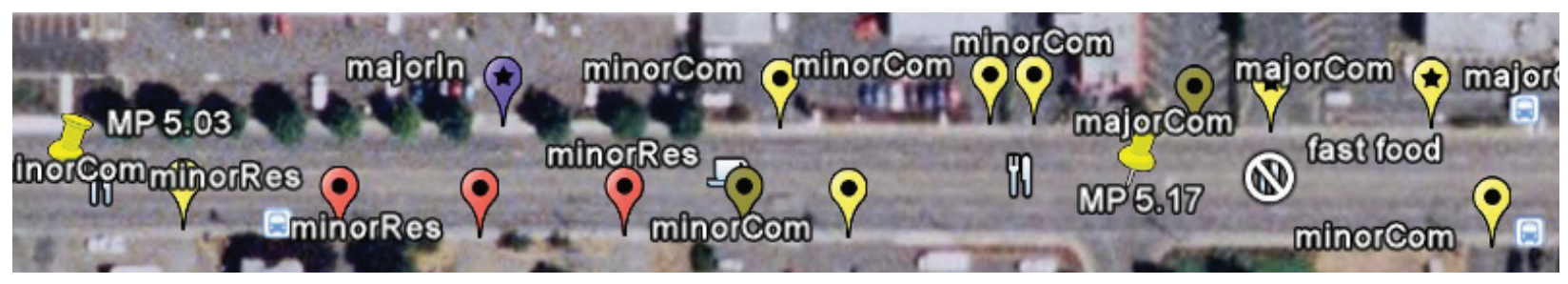

Figure 4.3: Google Data File Markup of Driveways on Urban Corridor

The research team counted roadside objects using the DVL to identify them, and Google Earth to estimate distance from the side of the rightmost lane. The research team counted roadside objects within 30 feet of the roadway; objects within 70 feet of each other only count once. If a roadside feature was identified as continuous, the team then divided the segment length by 70 feet. No minimum object height is specified in the HSM, so objects over one foot tall were included. Steep roadside backslopes were assumed to be continuous roadside objects.

The team acquired the posted speed information from the ODOT Integrated Transportation Information System (ITIS) - speed category (above or below $30 \mathrm{mph}$ ).

Urban intersections required a significant amount of data elements that are not available in any database. Intersection geometry (number of approaches with left-turn lanes, number of approaches with right-turn lanes, maximum number of lanes for pedestrian crossings, intersection median type and width) can be easily obtained from aerial photography. The team also determined the presence of parking and lighting using the DVL and Google Earth. Members of the research team measured length of parking using the Google distance measurement tool. 
Oregon does not maintain a comprehensive statewide database of signal timing so identification of the type of left-turn phasing is not a straightforward process. The HSM requires identifying permissive, protected/permissive or permissive/protected, or protected phasing on all approaches. For the major approaches, the research team used the DVL photo log to determine the configuration of the signal heads and accompanying signs or markings to determine the most likely signal phasing. If there is a left-turn section head, 4 or more section heads were assumed to be protected/permissive signal phasing (including a "doghouse" arrangement). For 3-section heads, if there was no "left-turn yield on green" sign, protected phasing was assumed. If the "left-turn yield on green" was visible, protected/permissive phasing was assumed. These assumptions do not cover all possible arrangements (e.g. flashing yellow arrow configurations).

Signal phasing information on the minor approaches for Oregon highways is also not readily available. Since the DVL does not allow the minor approach signal configuration to be viewed and Google Streetview was not available for all locations, the research team made an assumption that if the major street had protected or permissive phasing and the minor street had dedicated left-turn lanes, the same signal phasing existed on the minor approach. The CMF for left turn phasing is applied by intersection approach and the CMFs are multiplicative. Thus, at a 4-leg signalized intersection where it was determined the major approaches have protected phasing and the minor approaches have left-turn lanes, these assumptions would result in a calculated CMF value of $0.78\left(0.94^{4}\right)$. If the minor approach phasing was actually protected/permissive instead of the assumed protected phasing the CMF should be 0.86 . If there were left-turn lanes but no dedicated phasing, the CMF should be 0.88 . Most intersections with left-turn lanes in an urban area are likely to have some type of phasing, so the error introduced by this assumption ranges from 0 to 0.08 for the CMF.

The HSM also requires the number of residential driveways with within 250 feet of the intersection, number of bus stops within 1000 feet, number of schools within 1000 feet, and number of alcohol sales establishments within $1000 \mathrm{ft}$. These variables were collected from Google Earth by drawing a 250 and 1000 diameter circle around the intersection center.

Driveways were classified and counted as before within the buffer. For the major transit cities in Oregon, Google Earth provided an easy way to count the number of bus stops within 1000 feet by turning on the transit layer. Schools were also tallied using data provided in Google Earth. The number of alcohol sales establishments within 1000 feet of the intersection was more subjective. Using layers in Google Earth for bars and clubs, dining, grocery stores (which can sell alcohol in Oregon), and gas stations (which often sell beer in quick shops), the team determined the number of establishments selling alcohol. Another data collection approach considered by the research team was the use of Oregon Liquor Control Commission alcohol license data. In previous work (Monsere and Chi 2008), these data were geocoded for Multnomah County but required significant manual processing. The Google data is potential biased in that it may not report all establishments (since placement on the map is influenced by advertising. A sample intersection with these buffers is shown in Figure 4.4.

There is no available database that contains right-turn-on-red restrictions. The project team acquired this information from the ODOT DVL or Google Streetview where a "Right turn on red not permitted" or "No right turn on red" sign was posted. These signs are not always visible. Like the left-turn phasing this element was only collected for the major approach. Until recently, 
Oregon statutes permitted automated red-light cameras at a fixed number of locations in specific cities, though this has changed to be more permissive. However, there are still few intersections with this technology statewide. The research team obtained the most recent list of intersections with automated enforcement to cross reference during the data collection. No intersection used in the calibration data set had automated enforcement present.

One key variable that is required for all segments and intersections is the AADT. For most state highways, this information is available in either a measured or estimated format. The AADT information for state highways is located in the ODOT Traffic Volumes and Vehicle Classification Report. For intersections, the $\mathrm{AADT}_{\text {major }}$ as well as the $\mathrm{AADT}_{\text {minor }}$ values are needed for the SPFs. Generally, the major roads for most intersection locations were the

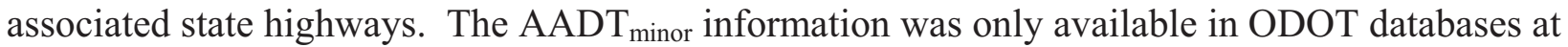
locations where both the major and minor roads were state highways. A supplemental GIS data base was obtained that collected AADT estimates on many functionally classified roads in the

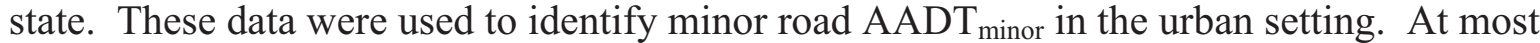
locations, $\mathrm{AADT}_{\text {minor }}$ volumes were not available for all years. In these cases, the team estimated the unknown years by the multiplying the $\mathrm{AADT}_{\text {major }}$ (which is known for each year) by the ratio of $\left(\mathrm{AADT}_{\text {major }} / \mathrm{AADT}_{\text {minor }}\right)$ for the year where the minor AADT is known.

No database could be identified that included pedestrian volumes counts at urban intersections. This data element is unlikely to be present for many jurisdictions. One option would be to estimate models based on surrounding land-use characteristics or other explanatory variables (similar rural minor AADTs) or to use methodologies developed for pedestrian volume estimation. The research team explored the sensitivity of the various HSM defaults in the pedestrian predictive and assumed a "medium" level of pedestrian activity for all intersections.

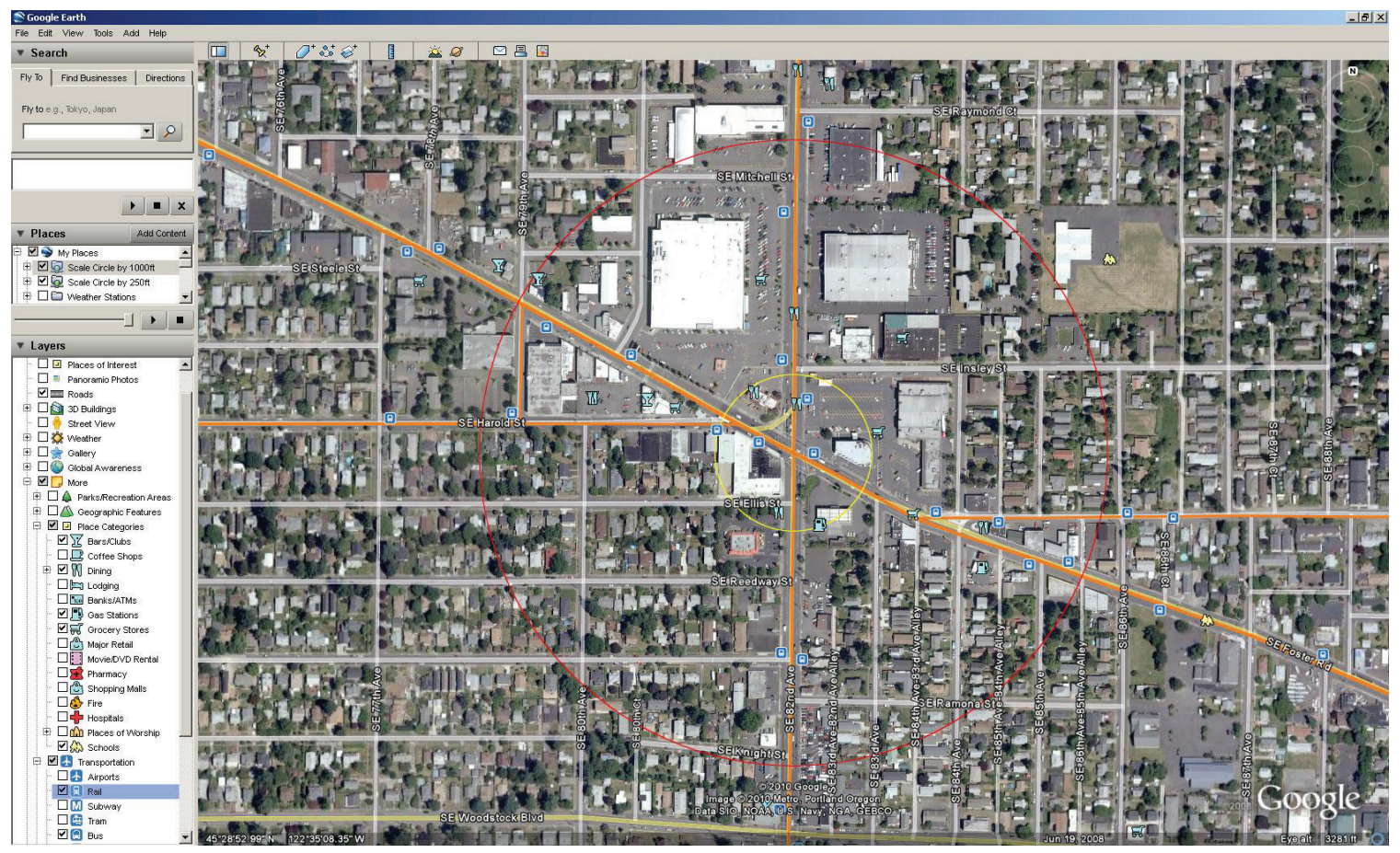

Figure 4.4: Google Earth Sample Urban Intersection with Buffers of 250 and 1000 feet 


\subsection{DATA COLLECTION SUMMARY}

Table 4.4: Dprovides a summary of the various data resources used to identify the elements required for Oregon calibration of the HSM SPFs. As summarized in this section of the report, the project team used a wide variety of resources to identify critical site elements needed for successful and comprehensive calibration of the HSM SPFs to Oregon conditions. In general, the data collection effort included the collection and analysis of historic crash data (years 2004 to 2006) as well as a wide variety of road characteristic information. Many of the required elements were readily available in regional databases; however, some elements required additional data collection. Since the HSM procedures ultimately will be used for a wide variety of locations it would be useful to consider identifying the key elements needed for comprehensive analysis and ultimately include these data elements in an Oregon database. In particular, the $\mathrm{AADT}_{\text {minor }}$ variable is a key input into the intersection SPFs and so this variable should be widely collected or efforts made to develop accurate estimation procedures for locations where this information is not available. Data on pedestrian volumes was also not available. The procedures estimated a default "medium" level of activity. 
Table 4.4: Data Elements and Available Resources

Data Elements

AADT of Major Road

AADT of Minor Road

Segment Length

Lane Width

Shoulder Width

Shoulder Type

Horizontal Curve Data

Vertical Grades

Driveway Density

Centerline Rumble Strips

Passing Lanes

TWLTLs

Roadside Hazard Rating

Side Slope

Roadside Fixed Object Density

Average Offset to Fixed Objects

Median Type and Width

Lighting

Speed Category

Automated Speed Enforcement

Intersection Skew Angle

Left-Turn Signal Phasing

Right-Turn Signal Phasing

Intersection Left-Turn Lane

Intersection Right-Turn Lane

Right-turn-on-red Prohibited

On-Street Parking Type

Maximum lanes for pedest

Pedestrian Volumes

Bus stops within $1000 \mathrm{ft}$

Schools within $1000 \mathrm{ft}$

Alcohol sales establishments within $1000 \mathrm{ft}$
Resources

ODOT Traffic Volumes and Vehicle Classification Report and County Public Works Departments

ODOT Traffic Volumes and Vehicle Classification Report, Local County

Public Works Departments, and AADT Estimate Model

Defined as part of the site selection process

ODOT State Highway Lane Report

ODOT State Highway Lane Report

ODOT State Highway Lane Report

ODOT State Highway Horizontal Curve Report and Field Verification

ODOT State Highway Vertical Grade Report

ODOT Digital Video Log

ODOT Digital Video Log

ODOT State Highway Lane Report and Aerial Photography

ODOT Digital Video Log and Aerial Photography

ODOT Digital Video Log

ODOT Digital Video Log

ODOT Digital Video Log

ODOT Digital Video Log and Aerial Photography

ODOT State Highway Lane Report

ODOT Digital Video Log (Roadways), Aerial Photography (Intersections)

ODOT State Highway Lane Report

ODOT TransGIS

Aerial Photography

ODOT Digital Video Log, Google Streetview (major legs)

ODOT Digital Video Log, Google Streetview (major legs)

Aerial Photography

Aerial Photography

ODOT Digital Video Log, Google Streetview (major legs)

Aerial Photography

Aerial Photography

*Default assumed -"Medium"

Aerial Photography

Aerial Photography

Aerial Photography 


\subsection{DATA ANALYSIS}

Upon successful completion of site selection and data collection, the research team initiated the analysis effort to develop the Oregon calibration values that adapt the HSM SPFs to local conditions. Prior to directly applying the calibration process outlined in the HSM (Volume 2, Part B Appendix), the non-intersection sites must be further divided into homogeneous segments, crashes must be assigned to the associated study segments and intersections, and missing data variables must be identified and estimated. Following these three key analysis steps, the calibration procedure can then be applied to the various facility types. This chapter reviews this process as it applied to the Oregon effort.

\subsection{DIVIDING ROADWAY SITES INTO HOMOGENEOUS SEGMENTS}

Before calculating the predicted crash frequency of roadway segment sites, each roadway segment site should be divided into similar (homogenous) roadway segments (AASHTO 2010). These homogeneous segments should contain consistent features as represented by the physical geometry requirements for the specific facility type. The HSM also recommends that, for practical application purposes, the minimum segment length should be approximately 0.1 miles. The HSM further includes recommendations for rounding the physical site characteristics. For example, lane widths of $11.8 \mathrm{ft}$ and $12.1 \mathrm{ft}$ would both be rounded to $12.0 \mathrm{ft}$ prior to segmentation so that the physical differences used for segmentation clearly indicate a definitive change in the road environment.

For rural segments, the research team determined that one alternative method for compiling homogeneous segments was to take the wide range of segments already available in the ODOT databases (often much smaller than 0.1 miles in length with many as small as 0.01 miles) and then combine them into homogeneous segments at least 0.1 miles long. When characteristics dramatically varied within a combined segment, the project team used a weighted CMF for the particular feature; however, the project team tried to avoid this approach unless the associated roadway elements differed dramatically.

In the urban areas, segmentation is required at each intersection (in addition to changes in lane widths, number of lanes, median type or width, posted speed limit, or speed category). In many of the urban environments, this resulted in sections that were less than 0.1 mile in length. A histogram of average segment length is shown in Figure 5.1. The average segment length is $395.9 \mathrm{ft}$ (0.07 miles). 


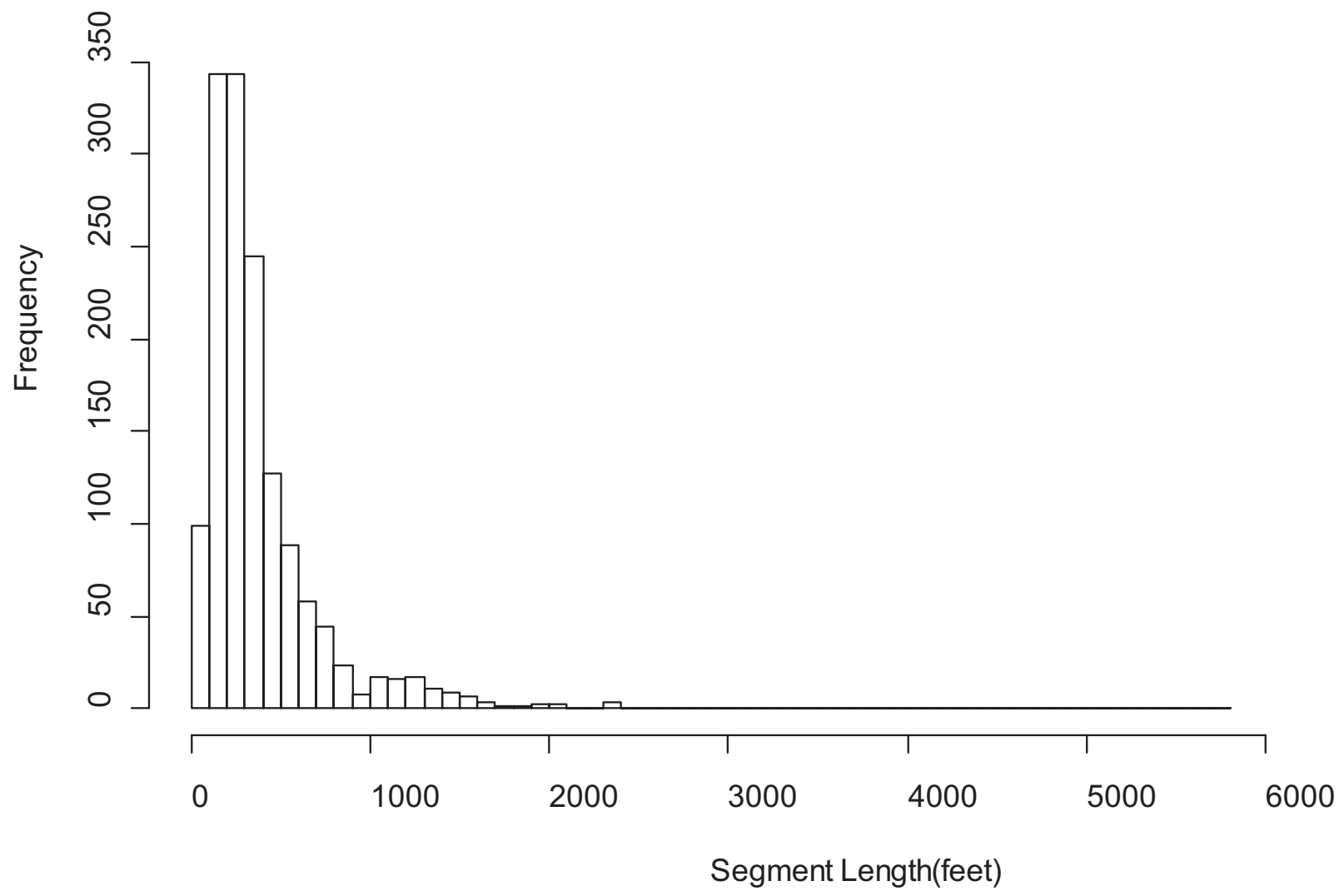

Figure 5.1: Histogram of Urban Arterial Segment Length

Upon completion of the roadway site segmentation effort, the project team then used these newly defined segment boundaries for crash assignment. The next section reviews the crash assignment effort for both the segments and the study intersections.

\subsection{CRASH ASSIGNMENT}

The HSM SPFs are divided into segment and intersection predictive methods; therefore, it is important to carefully assign crashes to these two categories. In the vicinity of intersections there may be crashes that geographically occur on the segment but that are a direct result of intersection conditions and so it is important to clearly distinguish between intersection-related and segment crashes. The project team next assigned crashes to the segments and intersections using a systematic procedure. The methods use by the project team for assigning crashes to roadway segments and intersection sites are presented in Section 5.2.1 (segments) and Section 5.2.2 (intersections). 


\subsubsection{Assigning Crashes to Roadway Segments}

As an initial step, the project team identified all crashes for the 2004 to 2006 study period that occurred within the limits of the individual study segments. The crashes were next evaluated to determine if they met the HSM roadway-related criteria. The steps for this evaluation process are shown as follows:

1. If the crash data indicated that the crash occurred within the limits of an intersection, the crash was not assigned to the segment.

2. If the crash reporting indicated that the crash was considered intersection-related, the crash was not assigned to the segment.

3. If the crash was shown as driveway-related, the crash was assigned to the segment.

4. For the higher speed rural locations, if the crash was a rear-end crash and the crash occurred at the approach to an intersection, the crash was not assigned to the segment.

5. All other crashes were assigned to the segment.

Following crash assignment, the project team tallied the annual number of crashes at each segment location and this value represented the total observed crashes for a particular roadway type for a given year.

\subsubsection{Assigning Crashes to Intersection Sites}

For each intersection type, the research team identified all reported crashes that occurred during the study period (2004 to 2006) within the physical intersection limits as well as those that occurred on the intersection approaches (approximately $250 \mathrm{ft}$ from the center of each intersection). Next, team members analyzed each crash in the vicinity of an intersection to determine if that crash may also have been associated with intersection operations. The steps for this evaluation process are shown as follows:

1. If the crash data indicated that the crash happened within the limits of an intersection, the crash was assigned to that intersection.

2. If the crash reporting indicated that the crash was considered intersection-related, the crash was assigned to that intersection.

3. If the crash was shown as driveway-related, the crash was not assigned to the intersection.

4. For the higher speed rural locations, if the crash was a rear-end crash and the crash occurred at the approach to an intersection, the crash was assigned to that intersection.

5. All other crashes were not assigned to the intersection. 
Following crash assignment, the project team tallied the annual number of crashes at each intersection location and this value represented the total observed crashes for a particular intersection type for a given year.

\subsection{MINOR AADT ESTIMATION MODEL-RURAL}

Often a data collection effort will result in the identification of data elements that are incomplete or unavailable. For the calibration effort, the project team was not always able to locate a value for the AADT for minor roads at rural intersections. Since the major and minor AADT value are critical input values into the intersection SPFs, the project team developed an AADT estimation model to address this gap in available data. Due to the large number of sites and the lengthy data collection procedure, it was not practical for the project team to physically collect all unknown AADT data. As a result, this section of the report reviews AADT estimation models developed by the project team that were generated from known AADT of minor roads. The project team developed the AADT estimation model using multiple linear regression techniques in a manner similarly reviewed for those developed for Indiana (see Section 2.3). The following sections, therefore, review the candidate variables, correlation between these variables, selected variables, and final AADT estimation model.

\subsubsection{Response Variable and Independent Variables}

The response variable (also known as the dependent variable) is the target data element for this modeling effort and, for this analysis, was the AADT of the minor road. The authors evaluated a variety of variables and identified 12 variables which appeared to contribute to an expected rural-location traffic volume. These candidate variables are listed in Table 5.1.

Table 5.1: Independent Variables for Minor AADT Estimation Models

\begin{tabular}{l|l}
\hline Variable & Description \\
\hline CtPop & County population \\
\hline CityPop & Population of nearest city \\
\hline Income & Average per capita income of the region \\
\hline Distance & Distance to the nearest freeway (miles $)$ \\
\hline MIA & Is the cross street a minor arterial? $(1=$ yes, $0=$ no $)$ \\
\hline MAC & Is the cross street a major collector? $(1=$ yes, $0=$ no $)$ \\
\hline CityLimit & Is the intersection located within a city limit? $(1=$ yes, $0=$ no $)$ \\
\hline Right & Is a right-turn lane present on the minor road? $(1=$ yes, $0=$ no $)$ \\
\hline LandUse & Does the major road have a right-turn lane? $(1=$ yes, $0=$ no $)$ \\
\hline Centerline & Is the adjacent land developed? $(1=$ yes, $0=$ no $)$ \\
\hline Edgeline & Is a centerline present on the minor road? $(1=$ yes, $0=$ no $)$ \\
\hline
\end{tabular}

The first four independent variables are continuous variables (values on a scale and that do not fit a yes versus no category). To minimize the unequal variance, the project team applied a $\log 10$ transformation to both the response and the independent continuous variables. This transformation helped to center the variables and reduce potential multi-collinearity issues (Mohamad et al. 1998). All of the independent continuous variables were further centered by subtracting all individual observations of the variables from the mean of all observations. 


\subsubsection{Correlation between Variables}

When the model includes too many variables, there can be a loss in precision because the variables might be correlated to each other. One important assumption of linear regression is that all variables should be independent of each other. Therefore, the project team calculated the variance inflation factor (VIF) to test to see if there was a strong correlation between any of the candidate variables. Table 5.2 shows VIFs for all of the candidate variables. When the value of the VIF is less than ten, there is no serious correlation problem (Rawlings et al. 1998). Table 5.2 shows that all of the VIF values are very small, and therefore all variables could be assumed to be independent.

Table 5.2: Variance Inflation Factors for Independent Variables

\begin{tabular}{c|c}
\hline Variable & VIF \\
\hline CtPop & 1.576 \\
\hline CityPop & 1.311 \\
\hline Income & 1.198 \\
\hline Distance & 1.289 \\
\hline MIA & 1.410 \\
\hline MAC & 1.278 \\
\hline City Limit & 1.282 \\
\hline Right & 1.199 \\
\hline RightCross & 1.267 \\
\hline LandUse & 1.269 \\
\hline Centerline & 1.435 \\
\hline Edgeline & 1.663 \\
\hline
\end{tabular}

\subsubsection{Variable Selection}

For the model development, the project team identified variables by selecting the best model from all possible subset models. To perform this analysis, the team first selected the best model for each number of parameters and developed an associated $\mathrm{Cp}$ plot for the models. The $\mathrm{Cp}$ plot shows the relationship between the Cp statistic of each best model and $\mathrm{p}$-- Number of Parameters (the intercept and variables). Figure 5.2 shows the Cp plot. The line is the condition when $\mathrm{Cp}$ equals $\mathrm{p}$. The $\mathrm{Cp}$ of a model which has no bias should be approximately equal to $\mathrm{p}$ (Ramsey and Schafer 2002). When the value of Cp is above the line, this indicates that the model is biased. When the value of $\mathrm{Cp}$ is below the line it can be assumed that the model does not produce bias. To avoid unnecessary independent variables, the model with the smallest number of parameters when the $\mathrm{Cp}$ drops below the $\mathrm{Cp}=\mathrm{p}$ line should be selected. The figure indicates that the appropriate AADT estimation model, therefore, is the best model when the number of parameters equals 10. This model includes the following predictor variables: Distance, MIA, MAC, CityLimit, Right, RightCross, LandUse, Centerline and Edgeline. The Intercept is the tenth parameter in the model. 


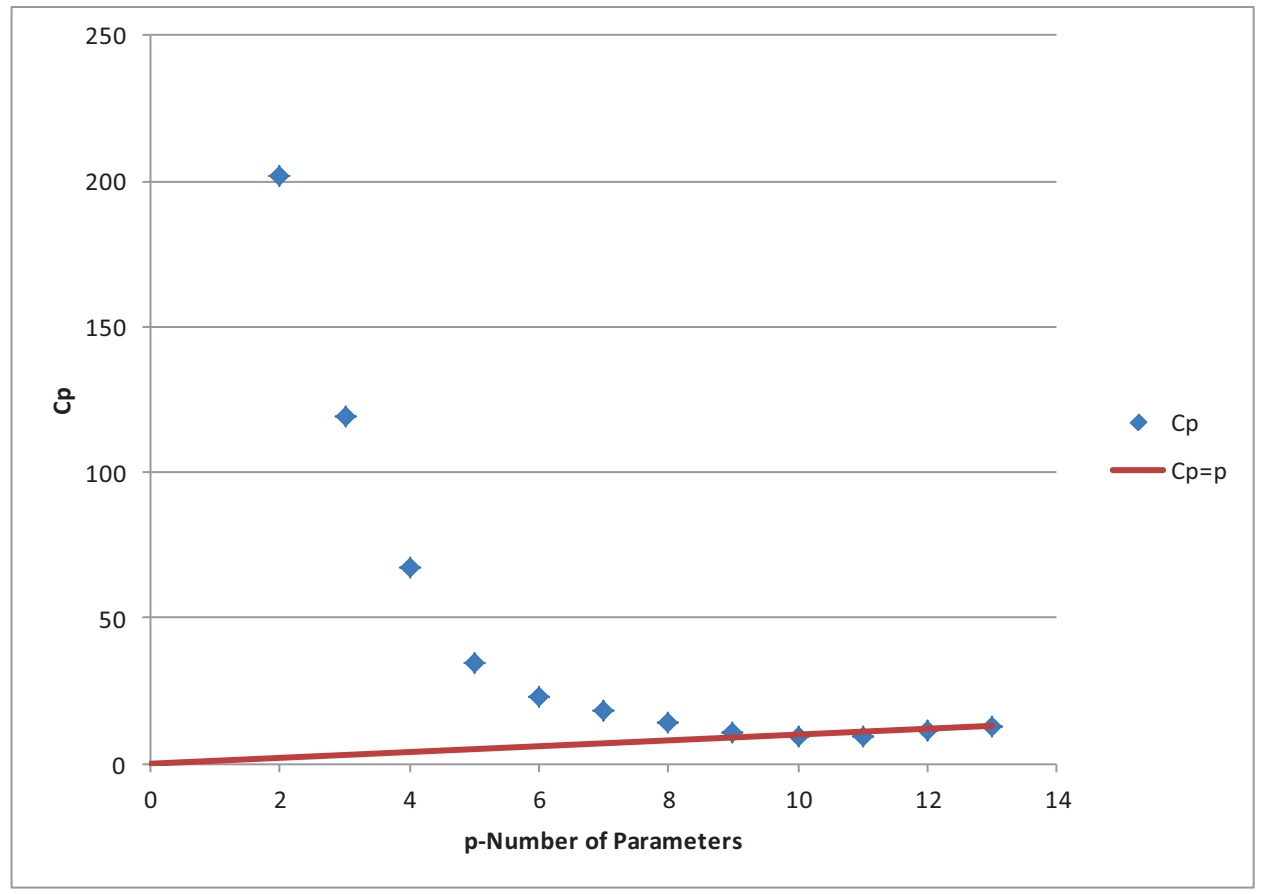

Figure 5.2: $\mathrm{C}_{\mathrm{p}}$ Plot

\subsubsection{Final AADT Estimation Model}

For the calibration effort, the project team generated two final AADT estimation models. The first model is to estimate the AADT for the minor roads for all intersection types except for MR4SG. The second model is to estimate AADT of minor roads of MR4SG. The regression results for the best nine-variable (ten-parameter) models for the final two AADT estimation models is shown in Table 5.3 (see Table 5.1 for variable definitions).

Model-1 and Model-2 have the same variables and similar values for each parameter. These two models can be written in equation format as follows:

\section{Model-1 (except for MR4SG):}

$$
\begin{gathered}
\log _{10} \text { AADT }=2.0281-0.112 \times\left(\log _{10} \text { Distance }-1.174634\right)+0.68(\mathrm{MIA})+ \\
0.4148(\mathrm{MAC})+0.1391(\text { CityLimit })+0.1761(\text { Right })+0.2060(\text { RightCross })+ \\
0.2125(\text { LandUse })+0.3028(\text { Centerline })+0.1268(\text { Edgeline })
\end{gathered}
$$




\section{Model-2 (MR4SG):}

$$
\begin{gathered}
\log _{10} \mathrm{AADT}=2.0246-0.1064 \times\left(\log _{10} \text { Distance }-1.177515\right)+0.6634(\mathrm{MIA})+ \\
0.4132(\mathrm{MAC})+0.1427(\text { CityLimit })+0.1987(\text { Right })+0.2073(\text { RightCross })+ \\
0.2229(\text { LandUse })+0.2988(\text { Centerline })+0.1381(\text { Edgeline })
\end{gathered}
$$

"1.174634" in Model-1 and "1.177515" in Model-2 represent the means of the $\log 10$ transformed Distance variable.

Table 5.3: Regression for Candidate Models

\begin{tabular}{l|c|c|c|c}
\hline \multirow{2}{*}{ Models: } & \multicolumn{2}{c}{$\begin{array}{c}\text { Model-1 Applies to Intersection } \\
\text { R3ST, R4ST,R4SG, MR3ST, and } \\
\text { MR4ST] }\end{array}$} & \multicolumn{2}{c}{$\begin{array}{c}\text { Model-2 [Applies to Intersection } \\
\text { MR4SG] }\end{array}$} \\
\hline R-Square: & \multicolumn{2}{|c|}{0.6231} & \multicolumn{2}{c}{0.6395} \\
\hline Variable Name & Value & \multicolumn{2}{c}{ Pr $(>|\mathrm{t}|)$} & \multicolumn{2}{c}{ Value $(>|\mathrm{t}|)$} \\
\hline Intercept & 2.0281 & 0.0000 & 2.0246 & 0.0000 \\
\hline $\begin{array}{l}\text { Distance (transformed and } \\
\text { centered) }\end{array}$ & -0.1120 & 0.0136 & -0.1064 & 0.0170 \\
\hline MIA & 0.6810 & 0.0000 & 0.6634 & 0.0000 \\
\hline MAC & 0.4148 & 0.0000 & 0.4132 & 0.0000 \\
\hline CityLimit & 0.1391 & 0.0732 & 0.1427 & 0.0580 \\
\hline Right & 0.1761 & 0.0266 & 0.1987 & 0.0093 \\
\hline RightCross & 0.2060 & 0.0036 & 0.2073 & 0.0025 \\
\hline LandUse & 0.2125 & 0.0001 & 0.2229 & 0.0000 \\
\hline Centerline & 0.3028 & 0.0001 & 0.2988 & 0.0001 \\
\hline Edgeline & 0.1268 & 0.0451 & 0.1381 & 0.0281 \\
\hline
\end{tabular}

As a final step, the project team performed an additional inspection of the model results and noted that the R-Squared values were both greater than 0.6 and that the values for all of the parameters resulted in expected plus or minus signs (logical increases and decreases based on the variable definition). As previously reviewed, the models also did not include any variables with strong correlations.

\subsection{MINOR AADT ESTIMATION - URBAN}

Since it is much more likely to have counts on urban minor highways and there are many more signalized intersections to sample, the selection process included a screen for minor approaches with at least one year of reported volume. If minor volume counts were missing for any of the analysis years, the project team estimated the unknown volume by multiplying the $\mathrm{AADT}_{\text {major }}$ (which is known for each year) by the ratio of $\left(\mathrm{AADT}_{\text {major }} / \mathrm{AADT}_{\text {minor }}\right.$ ) for the year where the minor AADT is known.

\subsection{DEVELOPING CALIBRATION FACTORS}

Upon identification of all required data and completion of the estimation for missing data values, the research team then proceeded to develop the calibration factors. To perform this analysis, first the HSM procedures for predicted crashes must be applied. As an initial step, the predictive methods for each road type are incorporated for each segment and intersection location. This 
evaluation will result in unadjusted predicted crashes. These predicted crashes are then contrasted to observed crashes to ultimately identify the calibration factors. If a jurisdiction generally experiences dramatically different driving behavior or reporting thresholds than the nationally expected values, the locally-derived crash type and severity distributions should be inspected and considered in the overall calibration effort. The following sections outline this calibration procedure.

\subsubsection{Unadjusted Predicted Crashes}

To calculate the unadjusted predicted crashes for each homogeneous segment or intersection, the research team first calculated the number of crashes under base condition using a base model equation or SPF included in the HSM. For example, base conditions for a rural two-lane, twoway road segment are:

- Lane widths of 12 feet,

- Paved shoulder widths of six feet,

- Roadway hazard ratings of three,

- $\quad$ Five driveways per mile,

- Level vertical conditions,

- No horizontal curves,

- No supplemental lanes,

- No rumble strips,

- $\quad$ No lighting, and

- $\quad$ No automated speed enforcement.

$N_{s p f}$ is then the value of the predicted total crash frequency for base conditions and can be calculated using the associated SPF equation.

To calculate the unadjusted predicted number of crashes at each location, the $N_{\text {spf }}$ value can then be multiplied by the CMFs that represent non-base conditions at each location. Equation 5-3 demonstrates this calculation:

$\mathrm{N}_{\text {predicted(unadjusted) }}=\mathrm{N}_{s p f} \times\left(\mathrm{CMF}_{1} \times \mathrm{CMF}_{2} \ldots \mathrm{CMF}_{n}\right)$

For a site where all conditions adhere to the base condition, the CMF value would be equal to one. Similarly, for any base conditions present that specific CMF has a value of one. For site features expected to result in a decreased number of crashes the CMF should be less than one. 
For features that would likely contribute to an increase in crashes, the CMF for that feature is then greater than one. Section 5.5.2 demonstrates an example calculation for unadjusted predicted crashes.

\subsubsection{Example of predicted crash calculations}

A multilane rural undivided segment is depicted as Site 3 in the following example. This location is Highway 35 from mile point 15.93 to mile point 17.93 . The study year shown in this example is 2005 .

Table 5.4 shows site characteristic data for a portion of this corridor (mile points 16.85 to 17.11). In Table 5.4, the location of mile point 16.85 is the end of a previous homogenous roadway segment (Segment 4). A new segment (Segment 5) begins at this location. The table indicates that at milepoint 16.89, the side slope for one side of the road changes from 1:2 to 1:6. Using the strict definition of homogeneous segments, therefore, Segment 5 should end at milepoint 16.89. The HSM recommends, however, that a minimum segment length of 0.1 miles be used. Since Segment 5, if ended at this change in side slope location, would result in a segment considerably smaller than 0.1 miles the project team chose to continue Segment 5 until the segment length reaches this minimum length. Therefore, Segment 5 extends from milepoint16.85 to 16.95 with the length of 0.1 miles, and the next homogenous segment in this site is from MP16.95 to MP 17.11 (Segment 6). There are a total of 11 homogenous segments at Site 3. The change in physical properties within this not-quite-homogeneous segment can be resolved by either using a segment average value for the side slope or using weighted CMF values to capture this side slope differential.

Table 5.5 shows a portion of the "predicted crash" calibration spreadsheet used for this analysis. The content shown in this table is for the Site 3 MRU segments depicted in Table 5.4. The predicted number of crashes for the base condition for the Segment 5 was 0.235 and 0.376 for the Segment 6. Following the application of the CMFs for each segment, the unadjusted predicted number crashes for Segment 5 equates to 0.238 (0.387 for Segment 6). Following this site-by-site calculation for the unadjusted predicted crash frequencies, the total predicted number

of crashes for this site can be determined by adding the values for each segment. For the example shown, the total predicted crash frequency for site 3 is equal to 5.416. 
Table 5.4: Example Road Characteristic Data for Segments

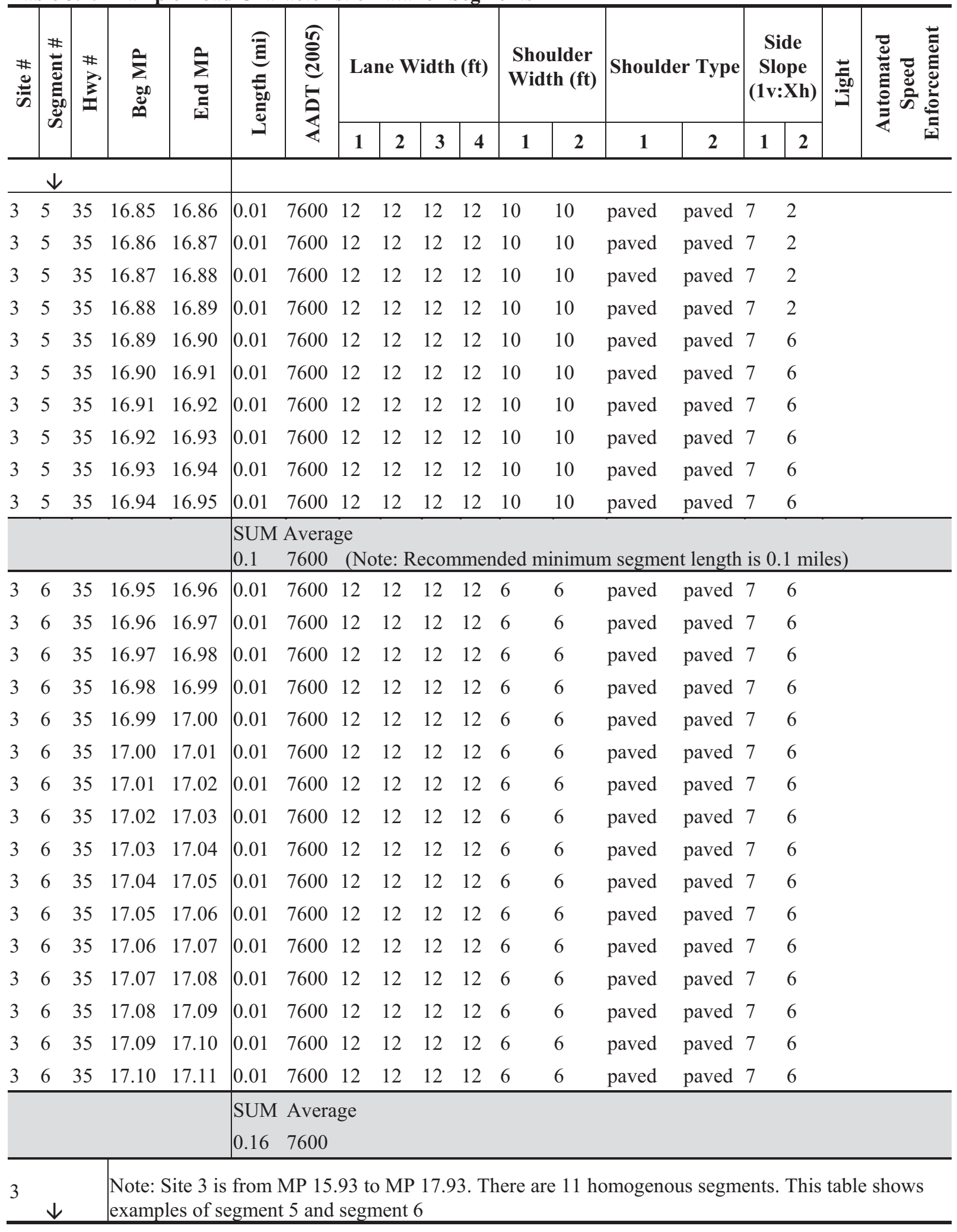


Table 5.5: Example of Calculation Spreadsheet for Estimating Predicted Crashes

\begin{tabular}{|c|c|c|c|c|c|c|c|c|c|c|c|c|c|}
\hline \multirow[b]{2}{*}{ Site \# } & \multirow[b]{2}{*}{$\begin{array}{c}\text { Segmen } \\
\mathrm{t} \#\end{array}$} & \multirow[b]{2}{*}{$\begin{array}{c}\text { Hwy } \\
\#\end{array}$} & \multirow[b]{2}{*}{$\begin{array}{l}\text { Beg } \\
\text { MP }\end{array}$} & \multirow[b]{2}{*}{$\begin{array}{l}\text { End } \\
\text { MP }\end{array}$} & \multirow[b]{2}{*}{$\begin{array}{c}\text { Length } \\
\text { (mi) }\end{array}$} & \multirow[b]{2}{*}{$\begin{array}{l}\text { AADT } \\
(2005)\end{array}$} & \multirow[b]{2}{*}{ Nspf } & \multicolumn{5}{|c|}{ CMFs } & \multirow[b]{2}{*}{ Npredic } \\
\hline & & & & & & & & 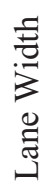 & 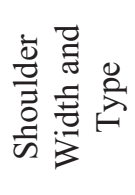 & $\begin{array}{l}0 \\
\frac{0}{0} \\
\frac{\pi}{2} \\
\frac{0}{0} \\
\tilde{n}\end{array}$ & 些 & 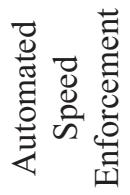 & \\
\hline & $\downarrow$ & & & & & & & & & & & & $\downarrow$ \\
\hline 3 & 5 & 35 & 16.85 & 16.86 & 0.01 & 7600 & & 1 & 0.96 & 1.09 & 1 & 1 & \\
\hline 3 & 5 & 35 & 16.86 & 16.87 & 0.01 & 7600 & & 1 & 0.96 & 1.09 & 1 & 1 & \\
\hline 3 & 5 & 35 & 16.87 & 16.88 & 0.01 & 7600 & & 1 & 0.96 & 1.09 & 1 & 1 & \\
\hline 3 & 5 & 35 & 16.88 & 16.89 & 0.01 & 7600 & & 1 & 0.96 & 1.09 & 1 & 1 & \\
\hline 3 & 5 & 35 & 16.89 & 16.90 & 0.01 & 7600 & & 1 & 0.96 & 1.03 & 1 & 1 & \\
\hline 3 & 5 & 35 & 16.90 & 16.91 & 0.01 & 7600 & & 1 & 0.96 & 1.03 & 1 & 1 & \\
\hline 3 & 5 & 35 & 16.91 & 16.92 & 0.01 & 7600 & & 1 & 0.96 & 1.03 & 1 & 1 & \\
\hline 3 & 5 & 35 & 16.92 & 16.93 & 0.01 & 7600 & & 1 & 0.96 & 1.03 & 1 & 1 & \\
\hline 3 & 5 & 35 & 16.93 & 16.94 & 0.01 & 7600 & & 1 & 0.96 & 1.03 & 1 & 1 & \\
\hline \multirow[t]{2}{*}{3} & 5 & 35 & 16.94 & 16.95 & 0.01 & 7600 & & 1 & 0.96 & 1.03 & 1 & 1 & \\
\hline & & & & & $\begin{array}{c}\text { SUM } \\
0.1\end{array}$ & $\begin{array}{c}\text { Averag } \\
\text { e } \\
7600\end{array}$ & 0.235 & 1 & 0.96 & 1.054 & 1 & 1 & 0.238 \\
\hline 3 & 6 & 35 & 16.95 & 16.96 & 0.01 & 7600 & & 1 & 1 & 1.03 & 1 & 1 & \\
\hline 3 & 6 & 35 & 16.96 & 16.97 & 0.01 & 7600 & & 1 & 1 & 1.03 & 1 & 1 & \\
\hline 3 & 6 & 35 & 16.97 & 16.98 & 0.01 & 7600 & & 1 & 1 & 1.03 & 1 & 1 & \\
\hline 3 & 6 & 35 & 16.98 & 16.99 & 0.01 & 7600 & & 1 & 1 & 1.03 & 1 & 1 & \\
\hline 3 & 6 & 35 & 16.99 & 17.00 & 0.01 & 7600 & & 1 & 1 & 1.03 & 1 & 1 & \\
\hline 3 & 6 & 35 & 17.00 & 17.01 & 0.01 & 7600 & & 1 & 1 & 1.03 & 1 & 1 & \\
\hline 3 & 6 & 35 & 17.01 & 17.02 & 0.01 & 7600 & & 1 & 1 & 1.03 & 1 & 1 & \\
\hline 3 & 6 & 35 & 17.02 & 17.03 & 0.01 & 7600 & & 1 & 1 & 1.03 & 1 & 1 & \\
\hline 3 & 6 & 35 & 17.03 & 17.04 & 0.01 & 7600 & & 1 & 1 & 1.03 & 1 & 1 & \\
\hline 3 & 6 & 35 & 17.04 & 17.05 & 0.01 & 7600 & & 1 & 1 & 1.03 & 1 & 1 & \\
\hline 3 & 6 & 35 & 17.05 & 17.06 & 0.01 & 7600 & & 1 & 1 & 1.03 & 1 & 1 & \\
\hline 3 & 6 & 35 & 17.06 & 17.07 & 0.01 & 7600 & & 1 & 1 & 1.03 & 1 & 1 & \\
\hline 3 & 6 & 35 & 17.07 & 17.08 & 0.01 & 7600 & & 1 & 1 & 1.03 & 1 & 1 & \\
\hline 3 & 6 & 35 & 17.08 & 17.09 & 0.01 & 7600 & & 1 & 1 & 1.03 & 1 & 1 & \\
\hline 3 & 6 & 35 & 17.09 & 17.10 & 0.01 & 7600 & & 1 & 1 & 1.03 & 1 & 1 & \\
\hline \multirow[t]{2}{*}{3} & 6 & 35 & 17.10 & 17.11 & 0.01 & 7600 & & 1 & 1 & 1.03 & 1 & 1 & \\
\hline & & & & & $\begin{array}{c}\text { SUM } \\
0.16\end{array}$ & $\begin{array}{c}\text { Averag } \\
\text { e } \\
7600\end{array}$ & 0.376 & 1 & 1 & 1.03 & 1 & 1 & 0.387 \\
\hline 3 & $\downarrow$ & & & & & & & & & & & & $\downarrow$ \\
\hline & & & & & & & & & & & & SUM: & 5.416 \\
\hline
\end{tabular}




\subsubsection{Calculation of Calibration Factors}

Following the calculation of the unadjusted predicted crashes and identification of the total observed crashes for each study site, the calibration factor can then be determined. The HSM provides the following equation for calculation of the calibration factor:

$$
\mathrm{C}=\frac{\sum_{\text {allsites }} \mathrm{N}_{\text {observed }}}{\sum_{\text {allsites }} \mathrm{N}_{\text {predicted (unadjusted) }}}
$$

Where: $\mathrm{N}_{\text {observed }}$ observed crash frequency of each site,

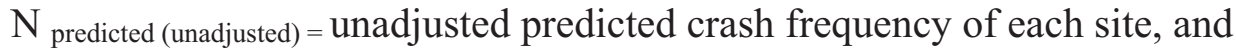

$\mathrm{C}=$ calibration factor.

Based on the example shown in Section 5.5.2, the total predicted crash frequency for site 3 was 5.416 for the year 2005. During the same year, this site experienced a total of 5 crashes (observed). Therefore the calculated calibration factor for this site for the year 2005 is shown as follows:

$$
\mathrm{C}_{\text {Site 3(2005) }}=\frac{5}{5.416}=0.92
$$

This basic calibration procedure should be applied to all study road and intersection types. Note that the example evaluated a single year; however, due to know regression-to-the-mean tendencies in crash data, the calibration factor should be developed for at least a three year period. For the example shown, then, the calibration factor could be calculated in two ways. First, the value for each year could be calculated and then the three values averaged. A second approach is that the crashes (predicted and observed) for three years should be added and then a single calibration value calculated. The project team evaluated both approaches for this research effort and determined that they gave similar results.

\subsubsection{Locally-Derived Values}

Table 5.6 lists the 24 HSM tables or factors that can be calibrated to local conditions based on proportions. The HSM uses default crash and severity types for select CMF and crash type estimates. The basis for the HSM default distribution values is the states used in the development of the SPFs. For example, for the rural two-lane, two-way roads the default distribution for severity and for collision type at segment locations evolved from State of Washington data for the years 2002 to 2006. Similarly, default values for intersection distributions were developed from California data for the years 2002 to 2006. A similar default distribution is included for the proportion of nighttime crashes (for use with the street lighting CMFs). It is possible, therefore, that the inclusion of these default values in the development of the predicted (unadjusted) crashes may introduce a bias that does not apply to the State of 
Oregon. Since this information is then used for calculating calibration factors, the project team felt that the use of default values versus locally-derived values merited consideration in this analysis.

Development of the local-derived proportions was performed using the full statewide crash data base whenever possible. Some proportions had to be developed using the calibration data base rather than the full database. For example, in order to determine $p_{n r}$ (proportion of total crashes for unlighted roadway segments that occur at night) for use in the segment lighting CMF, whether a segment is lighted or unlighted must be known. Lighting is not kept in the state inventory file, so it was necessary for the research team to estimate the values based on the calibration segments where the presence of lighting was collected. 
Table 5.6: HSM Tables or Equations for Which Local Calibration is Possible

\begin{tabular}{|c|c|c|c|c|c|}
\hline Chapter & $\begin{array}{l}\text { Table or } \\
\text { Type of } \\
\text { Roadway } \\
\text { Element in } \\
\text { the HSM }\end{array}$ & 递 & 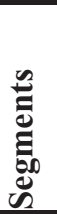 & 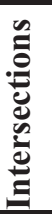 & Local Calibration Value \\
\hline \multirow{7}{*}{$\begin{array}{l}\text { 10- Rural } \\
\text { Two-Lane } \\
\text { Highways }\end{array}$} & Table $10-3$ & 1 & $\mathrm{X}$ & & Crash severity by facility type for roadway segments \\
\hline & Table $10-4$ & 1 & $\mathrm{X}$ & & Collision type by facility type for roadway segments \\
\hline & Table 10-5 & 1 & & $\mathrm{X}$ & Crash severity by facility type for intersections \\
\hline & Table 10-6 & 1 & & $\mathrm{X}$ & Collision type by facility type for intersections \\
\hline & Eq 10-18 & 1 & $\mathrm{X}$ & & Driveway-related accidents as a proportion of total accidents $\left(\mathrm{p}_{\mathrm{d}}\right)$ \\
\hline & Table $10-12$ & 2 & $\mathrm{X}$ & & Nighttime accidents as a proportion of total accidents by severity level \\
\hline & Table $10-15$ & 2 & & $\mathrm{X}$ & $\begin{array}{l}\text { Nighttime accidents as a proportion of total accidents by severity level } \\
\text { and by intersection type }\end{array}$ \\
\hline \multirow{6}{*}{$\begin{array}{l}11 \text { - Rural } \\
\text { multilane } \\
\text { highways }\end{array}$} & Table 11-4 & 1 & $\mathrm{X}$ & & Crash severity and collision type for undivided segments \\
\hline & Table 11-6 & 1 & $\mathrm{X}$ & & Crash severity and collision type for divided segments \\
\hline & Table 11-9 & 1 & & $\mathrm{X}$ & Crash severity and collision type by intersection type \\
\hline & Table 11-15 & 2 & $\mathrm{X}$ & & $\begin{array}{l}\text { Nighttime accidents as a proportion of total accidents by severity level } \\
\text { and by roadway segment type for undivided roadway segments }\end{array}$ \\
\hline & Table 11-19 & 2 & & $\mathrm{X}$ & $\begin{array}{l}\text { Nighttime accidents as a proportion of total accidents by severity level } \\
\text { and by roadway segment type for divided roadway segments }\end{array}$ \\
\hline & Table 11-24 & 2 & & $\mathrm{X}$ & $\begin{array}{l}\text { Nighttime accidents as a proportion of total accidents by severity level } \\
\text { and by intersection type }\end{array}$ \\
\hline \multirow{13}{*}{$\begin{array}{l}12 \text { - Urban } \\
\text { and } \\
\text { Suburban } \\
\text { Arterials }\end{array}$} & Table $12-4$ & 1 & $\mathrm{X}$ & & $\begin{array}{l}\text { Crash severity and collision type for multiple-vehicle non-driveway } \\
\text { collisions by roadway segment type }\end{array}$ \\
\hline & Table $12-10$ & 1 & $\mathrm{X}$ & & $\begin{array}{l}\text { Crash severity and collision type for single-vehicle accidents by } \\
\text { roadway segment type }\end{array}$ \\
\hline & Table $12-6$ & 1 & $\mathrm{X}$ & & $\begin{array}{l}\text { Crash severity for driveway-related collisions by roadway segment } \\
\text { type }\end{array}$ \\
\hline & Table 12-7 & 1 & $\mathrm{X}$ & & Pedestrian accident adjustment factor by roadway segment type \\
\hline & Table $12-8$ & 1 & $\mathrm{X}$ & & Bicycle accident adjustment factor by roadway segment type \\
\hline & Table 12-9 & 1 & $\mathrm{X}$ & & $\begin{array}{l}\text { Proportion of fixed object collisions (not listed as option in HSM and } \\
\text { not included in the Oregon calibration effort) }\end{array}$ \\
\hline & Table 12-11 & 1 & & $\mathrm{X}$ & $\begin{array}{l}\text { Crash severity and collision type for multiple-vehicle collisions by } \\
\text { intersection type }\end{array}$ \\
\hline & Eq 12-27 & 1 & & $\mathrm{X}$ & ST \\
\hline & Table $12-13$ & 1 & & $\mathrm{X}$ & $\begin{array}{l}\text { Crash severity and collision type for single-vehicle accidents by } \\
\text { intersection type }\end{array}$ \\
\hline & Table 12-16 & 1 & & $\mathrm{X}$ & $\begin{array}{l}\text { Pedestrian accident adjustment factor by intersection type for STOP- } \\
\text { controlled intersections }\end{array}$ \\
\hline & Table $12-17$ & 1 & $\mathrm{X}$ & & Bicycle accident adjustment factor by intersection type \\
\hline & Table 12-23 & 2 & $\mathrm{X}$ & & $\begin{array}{l}\text { Nighttime accidents as a proportion of total accidents by severity level } \\
\text { and by roadway segment type }\end{array}$ \\
\hline & Table 12-27 & 2 & & $X$ & $\begin{array}{l}\text { Nighttime crashes as a proportion of total crashes by severity level and } \\
\text { by intersection type }\end{array}$ \\
\hline
\end{tabular}

Source: (1) 2004-06 Statewide Databases (Crash and ITIS), (2) Segments Collected for Calibration 
As part of the calibration effort, therefore, the project team developed two types of locallyderived values. The first type represents locally-derived values for each crash study year. The second type then incorporated the average locally-derived values as derived from crash data for all three study years (2004 to 2006). Table 5.7 through Table 5.13 each show the comparisons between default proportion and Oregon-derived values based on the three-year crash data for the rural two-lane two-way roadway segments and urban suburban facilities. Oregon-derived values for all facilities are included in Appendix B.

Table 5.7: HSM-Default Crash Severity Levels versus Oregon Levels (2004-2006) for Rural Two-Lane, TwoWay Roads

\begin{tabular}{c|c|c}
\hline \multirow{2}{*}{ Crash Severity Level } & \multicolumn{2}{|c}{ Percentage of total roadway segment crashes } \\
\cline { 2 - 3 } & HSM-Provided Values & Oregon-Derived Values \\
\hline Fatal & 1.3 & 3.1 \\
\hline Incapacitating Injury & 5.4 & 2.7 \\
\hline Non-incapacitating Injury & 10.9 & 18.0 \\
\hline Possible Injury & 14.5 & 54.0 \\
\hline Total Fatal Plus Injury & 32.1 & 46.0 \\
\hline Property Damage Only & 67.9 & 100.0 \\
\hline \hline TOTAL & 100.0 & 25.1 \\
\hline
\end{tabular}

Table 5.8: HSM-Default Collision Distributions versus Oregon Distributions (2004 -2006) for Rural Two-Lane, Two-Way Roads

\begin{tabular}{|c|c|c|c|c|c|c|}
\hline \multirow[b]{3}{*}{ Collision Type } & \multicolumn{6}{|c|}{ Percentage of total roadway segment crashes by crash severity level } \\
\hline & \multicolumn{3}{|c|}{ HSM-Provided Values } & \multicolumn{3}{|c|}{ Oregon-Derived Values } \\
\hline & $\begin{array}{c}\text { Total } \\
\text { fatal and } \\
\text { injury }\end{array}$ & $\begin{array}{c}\text { Property } \\
\text { damage } \\
\text { only }\end{array}$ & $\begin{array}{c}\text { TOTAL (all } \\
\text { severity levels } \\
\text { combined) }\end{array}$ & $\begin{array}{c}\text { Total } \\
\text { fatal and } \\
\text { injury }\end{array}$ & $\begin{array}{c}\text { Property } \\
\text { damage } \\
\text { only }\end{array}$ & $\begin{array}{l}\text { TOTAL (all } \\
\text { severity levels } \\
\text { combined) }\end{array}$ \\
\hline \multicolumn{7}{|l|}{ SINGLE-VEHICLE CRASHES } \\
\hline Collision with animal & 3.8 & 18.4 & 12.1 & 3.1 & 12.0 & 7.2 \\
\hline Collision with bicycle & 0.4 & 0.1 & 0.2 & 0.6 & 0.0 & 0.3 \\
\hline Collision with pedestrian & 0.7 & 0.1 & 0.3 & 0.8 & 0.0 & 0.4 \\
\hline Overturned & 3.7 & 1.5 & 2.5 & 8.6 & 3.8 & 6.4 \\
\hline Run-off-road & 54.5 & 50.5 & 52.1 & 47.1 & 39.1 & 43.5 \\
\hline Other single-vehicle crash & 0.7 & 2.9 & 2.1 & 1.7 & 1.3 & 1.5 \\
\hline Total single-vehicle crashes & 63.8 & 73.5 & 69.3 & 62.0 & 56.2 & 59.3 \\
\hline \multicolumn{7}{|c|}{ MULTIPLE-VEHICLE CRASHES } \\
\hline Angle collision & 10 & 7.2 & 8.5 & 0.8 & 0.7 & 0.8 \\
\hline Head-on collision & 3.4 & 0.3 & 1.6 & 5.8 & 1.0 & 3.6 \\
\hline Rear-end collision & 16.4 & 12.2 & 14.2 & 18.8 & 21.4 & 20.0 \\
\hline Sideswipe collision & 3.8 & 3.8 & 3.7 & 4.4 & 7.1 & 5.6 \\
\hline Other multiple-vehicle collision & 2.6 & 3.0 & 2.7 & 8.2 & 13.5 & 10.6 \\
\hline Total multiple-vehicle crashes & 36.2 & 26.5 & 30.7 & 38.0 & 43.8 & 40.7 \\
\hline TOTAL CRASHES & 100.0 & 100.0 & 100.0 & 100.0 & 100.0 & 100.0 \\
\hline
\end{tabular}


Table 5.9: HSM-Default Nighttime Proportions versus Oregon Proportions (2004 - 2006) for Rural TwoLane, Two-Way Roads

\begin{tabular}{|c|c|c|c|}
\hline \multirow{8}{*}{$\begin{array}{l}\text { Roadway } \\
\text { Type }(2 \mathrm{U})\end{array}$} & \multicolumn{3}{|c|}{ HSM Default Values } \\
\hline & \multicolumn{2}{|c|}{$\begin{array}{c}\text { Proportion of total nighttime crashes } \\
\text { by severity level }\end{array}$} & $\begin{array}{c}\text { Proportion of crashes that } \\
\text { occur at night }\end{array}$ \\
\hline & Fatal and Injury $p_{\text {inr }}$ & PDO $p_{\text {pnr }}$ & $\mathbf{p}_{\mathrm{nr}}$ \\
\hline & 0.382 & 0.618 & 0.37 \\
\hline & \multicolumn{3}{|c|}{ Oregon-Derived Values } \\
\hline & \multicolumn{2}{|c|}{$\begin{array}{c}\text { Proportion of total nighttime crashes } \\
\text { by severity level }\end{array}$} & $\begin{array}{c}\text { Proportion of crashes that } \\
\text { occur at night }\end{array}$ \\
\hline & Fatal and Injury $p_{\text {inr }}$ & PDO $p_{\text {pnr }}$ & $\mathbf{p}_{\mathrm{nr}}$ \\
\hline & 0.54 & 0.46 & 0.28 \\
\hline
\end{tabular}

Table 5.10: Nighttime Crash Proportions for Unlighted Urban Roadway Segments (2004 -2006)

\begin{tabular}{c|c|c|c}
\hline \multirow{2}{*}{ Road Type } & \multicolumn{3}{c}{ HSM Default Values } \\
\cline { 2 - 4 } & \multicolumn{2}{|c}{$\begin{array}{c}\text { Proportion of total nighttime crashes by severity } \\
\text { level }\end{array}$} & $\begin{array}{c}\text { Proportion of crashes that } \\
\text { occur at night }\end{array}$ \\
\hline \multirow{2}{*}{$2 \mathrm{U}$} & 0.424 & 0.576 & $\mathbf{p}_{\mathbf{n r}}$ \\
\hline $3 \mathrm{~T}$ & 0.429 & 0.571 & 0.316 \\
\hline $4 \mathrm{U}$ & 0.517 & 0.483 & 0.304 \\
\hline $4 \mathrm{D}$ & 0.364 & 0.636 & 0.365 \\
\hline $5 \mathrm{~T}$ & 0.432 & 0.568 & 0.410 \\
\hline & \multicolumn{2}{|c|}{ Oregon-Derived Values } & 0.274 \\
\hline 2U & 0.606 & 0.394 & 0.215 \\
\hline 3T & 0.286 & 0.714 & 0.118 \\
\hline $4 \mathrm{U}$ & 0.385 & 0.615 & 0.234 \\
\hline $4 \mathrm{D}$ & 0.800 & 0.2 & 0.225 \\
\hline $5 \mathrm{~T}$ & 0.474 & 0.526 & 0.228 \\
\hline
\end{tabular}


Table 5.11: Distribution of Multiple-Vehicle Nondriveway Collisions for Roadway Segments by Manner of Collision Type (2004 -2006)

\begin{tabular}{|c|c|c|c|c|c|c|c|c|c|c|}
\hline \multirow{3}{*}{ Collision type } & \multicolumn{10}{|c|}{ HSM Default Values } \\
\hline & \multicolumn{2}{|c|}{$2 \mathrm{U}$} & \multicolumn{2}{|c|}{$3 T$} & \multicolumn{2}{|c|}{$4 \mathrm{U}$} & \multicolumn{2}{|c|}{ 4D } & \multicolumn{2}{|c|}{$5 \mathrm{~T}$} \\
\hline & FI & PDO & FI & PDO & FI & PDO & FI & PDO & FI & PDO \\
\hline Rear-end collision & 0.730 & 0.778 & 0.845 & 0.842 & 0.511 & 0.506 & 0.832 & 0.662 & 0.846 & 0.651 \\
\hline Head-on collision & 0.068 & 0.004 & 0.034 & 0.020 & 0.077 & 0.004 & 0.020 & 0.007 & 0.021 & 0.004 \\
\hline Angle collision & 0.085 & 0.079 & 0.069 & 0.020 & 0.181 & 0.130 & 0.040 & 0.036 & 0.050 & 0.059 \\
\hline $\begin{array}{l}\text { Sideswipe, same } \\
\text { direction }\end{array}$ & 0.015 & 0.031 & 0.001 & 0.078 & 0.093 & 0.249 & 0.050 & 0.223 & 0.061 & 0.248 \\
\hline $\begin{array}{l}\text { Sideswipe, opposite } \\
\text { direction }\end{array}$ & 0.073 & 0.055 & 0.017 & 0.020 & 0.082 & 0.031 & 0.010 & 0.001 & 0.004 & 0.009 \\
\hline $\begin{array}{l}\text { Other multiple- } \\
\text { vehicle collision }\end{array}$ & 0.029 & 0.053 & 0.034 & 0.020 & 0.056 & 0.080 & 0.048 & 0.071 & 0.018 & 0.029 \\
\hline \multirow{3}{*}{ Collision type } & \multicolumn{10}{|c|}{ Locally-Derived Values } \\
\hline & \multicolumn{2}{|c|}{$2 \mathrm{U}$} & \multicolumn{2}{|c|}{$3 T$} & \multicolumn{2}{|c|}{$4 \mathrm{U}$} & \multicolumn{2}{|c|}{ 4D } & \multicolumn{2}{|c|}{$5 T$} \\
\hline & FI & PDO & FI & PDO & FI & PDO & FI & PDO & FI & PDO \\
\hline Rear-end collision & 0.709 & 0.680 & 0.818 & 0.636 & 0.658 & 0.548 & 0.783 & 0.646 & 0.606 & 0.524 \\
\hline Head-on collision & 0.029 & 0.009 & 0.016 & 0.004 & 0.029 & 0.004 & 0.006 & 0.000 & 0.018 & 0.011 \\
\hline Angle collision & 0.013 & 0.049 & 0.000 & 0.025 & 0.015 & 0.016 & 0.019 & 0.008 & 0.020 & 0.015 \\
\hline $\begin{array}{l}\text { Sideswipe, same } \\
\text { direction }\end{array}$ & 0.010 & 0.037 & 0.000 & 0.075 & 0.060 & 0.205 & 0.038 & 0.142 & 0.053 & 0.156 \\
\hline $\begin{array}{l}\text { Sideswipe, opposite } \\
\text { direction }\end{array}$ & 0.039 & 0.020 & 0.000 & 0.014 & 0.022 & 0.008 & 0.013 & 0.004 & 0.005 & 0.004 \\
\hline $\begin{array}{l}\text { Other multiple- } \\
\text { vehicle collision }\end{array}$ & 0.201 & 0.206 & 0.166 & 0.246 & 0.216 & 0.219 & 0.140 & 0.200 & 0.298 & 0.289 \\
\hline
\end{tabular}

Table 5.12: Proportion of Pedestrian Accidents by Roadway Segment Type (2004-2006)

\begin{tabular}{c|c|c|c|c}
\hline \multirow{2}{*}{ Road type } & \multicolumn{4}{|c}{ Pedestrian Crash Adjustment Factor $\left(\mathbf{f}_{\text {pedr }}\right)$} \\
\cline { 2 - 5 } & HSM-Default Values & \multicolumn{2}{c}{ Locally-Derived Values } \\
\cline { 2 - 5 } & $\begin{array}{c}\text { Posted Speed 30 mph } \\
\text { or Lower }\end{array}$ & $\begin{array}{c}\text { Posted Speed Greater } \\
\text { than 30 mph }\end{array}$ & $\begin{array}{c}\text { Posted Speed 30 mph } \\
\text { or Lower }\end{array}$ & $\begin{array}{c}\text { Posted Speed Greater } \\
\text { than 30 mph }\end{array}$ \\
\hline $2 \mathrm{U}$ & 0.036 & 0.005 & 0.034 & 0.012 \\
\hline $3 \mathrm{~T}$ & 0.041 & 0.013 & 0.020 & 0.014 \\
\hline $4 \mathrm{U}$ & 0.022 & 0.009 & 0.016 & 0.004 \\
\hline 4D & 0.067 & 0.019 & 0.048 & 0.013 \\
\hline 5T & 0.030 & 0.023 & 0.010 & 0.021 \\
\hline
\end{tabular}


Table 5.13: Local Proportions of Crashes by Intersection Type (2004-2006)

\begin{tabular}{|c|c|c|}
\hline \multirow{2}{*}{ Intersection Type } & HSM-Default Values & Locally-Derived Values \\
\hline & \multicolumn{2}{|c|}{ Proportion of Single Vehicle Crashes that are Fatal and Injury ( $\left.f_{\text {bisv }}\right)$} \\
\hline $3 \mathrm{ST}$ & 0.310 & 0.900 \\
\hline \multirow[t]{2}{*}{$4 \mathrm{ST}$} & 0.280 & 0.880 \\
\hline & \multicolumn{2}{|c|}{ Proportion of Total Crashes that are Pedestrian Fatal and Injury Crashes $\left(f_{p e d i}\right)$} \\
\hline $3 \mathrm{ST}$ & 0.021 & 0.025 \\
\hline \multirow[t]{2}{*}{$4 \mathrm{ST}$} & 0.022 & 0.016 \\
\hline & \multicolumn{2}{|c|}{ Proportion of Total Crashes that are Bicycle Fatal and Injury Crashes $\left(f_{b i k e i}\right)$} \\
\hline $3 \mathrm{SG}$ & 0.011 & 0.016 \\
\hline $3 \mathrm{ST}$ & 0.016 & 0.022 \\
\hline $4 \mathrm{SG}$ & 0.015 & 0.023 \\
\hline $4 \mathrm{ST}$ & 0.018 & 0.028 \\
\hline
\end{tabular}

The research team next tested the statistical differences for the total predicted crash frequency by facility types for Oregon to those represented by the HSM default values. In addition, the project team compared the "by year" values to the "combined year" values. The results and how they affected the overall calibration procedure are further addressed in Section 6.2 of this report.

As shown in Table 5.7 the authors also noted an obvious difference in crash severity level between default values and the Oregon-derived values. The Oregon-derived values depicted a larger proportion of fatal and injury level crashes from the larger reported crash population. The difference may be associated with the Oregon self-reporting crash rules or may also be due to the various reporting thresholds ( $\$ 1500$ for an Oregon PDO compared to $\$ 700$ and $\$ 750$ in the neighboring states - coincidentally the states used for the HSM default values). As a result of this disparity in crash severity reporting, the authors elected to develop calibration factors for the fatal and injury level in addition to those for total crashes. The results of this analysis are presented in Section 6.3.

\subsection{SUMMARY OF DATA ANALYSIS}

In this section, the authors reviewed the methods for determining homogeneous segments, assignment of historic crash data, estimation for rural road minor AADT values, calculation of calibration factors, and the potential influence of using the HSM locally-derived factors for the calibration process. Upon completion of these steps, the procedures as identified must then be applied to the larger-scale calibration effort for the State of Oregon. Section 6.0 reviews the results of this overall process. 


\subsection{CALIBRATION RESULTS}

Section 5.0 demonstrated the steps required to perform the large-scale effort for the Oregon calibration of the HSM predictive methods. In this section, the research team provides the overall results for this calibration effort. In addition, the authors demonstrate statistical comparisons between using default proportions and using locally-derived values for crash severity and crash type as a part of the analysis effort.

\subsection{CALIBRATION FACTORS BASED ON DEFAULT PROPORTIONS}

To effectively use the HSM predictive methods in a local setting, it is necessary to develop calibration factors for all facility types. Previously this report reviewed the process to develop calibration factors and further identified a basic assumption in the HSM that default proportions for crash types and severity could influence the calibration results. Table 6.1: Estimated Calibration Factors for Oregon (based on HSM default crash proportions) depicts the calibration results developed using the default distribution values included in the HSM. The table demonstrates that for most facility types, the calibration factors have values smaller than 1.0 except for urban 4-leg signalized intersections and urban 4-lane divided facilities.

The calibration factor (1.43) for the urban four-lane divided facility merits additional discussion since it is so much different than the other facilities. In Oregon urban areas, the four-lane divided facility on state highway is not common. The research team identified only 5.87 miles to be used in the calibration data statewide. Many of these segments became divided after the installation of access management medians (prior to 2004); facilities designed as "true" divided sections were a small subset of the calibration data. Thus, this calibration factor likely reflects 1) the small sample size, and 2) the difference between the higher design standards of the four-lane divided facilities in the HSM SPFs data set and the segments in the Oregon calibration set. When using the HSM for future facilities, it is not recommended that the calculated Oregon calibration factor be used for these urban four-lane divided segments. This approach would introduce scenarios where the four-lane divided facility appears less safe than undivided facilities. It would be reasonable to apply the calibration factor estimate for the other multi-lane facilities $(0.64$ or 0.65$)$ in this case.

One optimistic explanation for the generally low (less than 1.0) results could be that the Oregon highways are much safer than other states due to a different, possibly more conservative driving population and less inclement weather. It is likely, however, that the drivers in Oregon are similar to those in other states and the reasons for the observed disparity are due to a much more obvious issue.

The State of Oregon is a self-reporting state. Therefore, in the State of Oregon, when a person is involved in a crash which does not have injuries, the involved drivers are not legally required to report the crash. If a person is involved in a crash which causes injury, death, more than $\$ 1,500$ 
damage to vehicles, or more than $\$ 1,500$ damage to vehicles and towing of another vehicle, the person is required to file an Oregon Traffic Accident and Insurance Report within 72 hours. The police will also file reports if they respond to an injury crash, but it is likely that many propertydamage-only (PDO) crashes are simply never reported in Oregon. It can then be expected that if the total crash population is further subdivided into severity levels, the PDO proportion is quite likely to be much smaller in Oregon than in neighboring states. Similarly, this would cause the proportion of fatal and injury crashes (out of the total crashes) to be a much larger value. Table 5.7 confirms this unbalanced proportion of PDO crashes as compared to the HSM default values (based on the State of Washington).

An additional issue that will likely influence the comparison of crash proportions is the actual reporting threshold. The State of Oregon has a \$1500 reporting threshold for PDO crashes while our neighboring states of Washington and California have PDO reporting thresholds of $\$ 700$ and $\$ 750$ respectively. This substantial difference in crash reporting thresholds would mean that crashes that must be reported in Washington and California (above $\$ 700$ or $\$ 750$ in damage but below $\$ 1500$ ) would not be reported in Oregon. As a result, the project team evaluated calibration of the HSM predictive methods with the use of default values and also with locallydeveloped Oregon values. The use of the values shown in Table 6.1, therefore, should be used cautiously since the default values directly influence select CMFs used in the calibration process. 
Table 6.1: Estimated Calibration Factors for Oregon (based on HSM default crash proportions)

\begin{tabular}{|c|c|c|c|c|c|c|c|c|c|c|c|c|c|c|}
\hline \multirow{3}{*}{\multicolumn{2}{|c|}{ Facility Type }} & \multirow{3}{*}{$\mathbf{n}$} & \multicolumn{8}{|c|}{ Observed (O) and Predicted (P) Crashes } & \multicolumn{4}{|c|}{ Calibration Factor } \\
\hline & & & \multicolumn{2}{|c|}{2004} & \multicolumn{2}{|c|}{2005} & \multicolumn{2}{|c|}{2006} & \multicolumn{2}{|c|}{$\begin{array}{c}2004- \\
2006 \\
\end{array}$} & \multirow{2}{*}{$\begin{array}{r}2004 \\
C_{2004}\end{array}$} & \multirow{2}{*}{$\begin{array}{r}2005 \\
C_{2005}\end{array}$} & \multirow{2}{*}{$\begin{array}{r}2006 \\
C_{2006}\end{array}$} & \multirow{2}{*}{$\begin{array}{r}\mathbf{2 0 0 4 -} \\
\mathbf{2 0 0 6} \\
\mathrm{C}_{04-06} \\
\end{array}$} \\
\hline & & & $\mathrm{O}$ & $\mathrm{P}$ & $\mathrm{O}$ & $\mathrm{P}$ & $\mathrm{O}$ & $\mathrm{P}$ & $\mathrm{O}$ & $\mathrm{P}$ & & & & \\
\hline \multicolumn{15}{|c|}{ SEGMENTS } \\
\hline \multicolumn{15}{|c|}{ Rural Two Lane } \\
\hline $\mathrm{R} 2$ & 2-lane undivided & 75 & 123 & 180 & 139 & 176 & 132 & 177 & 394 & 533 & 0.68 & 0.79 & 0.75 & 0.74 \\
\hline \multicolumn{15}{|c|}{ Rural Multilane } \\
\hline MRU & Undivided & 50 & 111 & 337 & 138 & 332 & 115 & 334 & 364 & 1003 & 0.33 & 0.42 & 0.34 & 0.36 \\
\hline MRD & Divided & 19 & 17 & 25 & 15 & 25 & 26 & 25 & 58 & 75 & 0.69 & 0.60 & 1.03 & 0.78 \\
\hline \multicolumn{15}{|c|}{ Urban and Suburban Arterials } \\
\hline $\mathrm{U} 2 \mathrm{U}$ & 2-lane undivided & 491 & 126 & 201 & 98 & 200 & 153 & 200 & 377 & 602 & 0.63 & 0.49 & 0.76 & 0.63 \\
\hline U3T & $\begin{array}{c}\text { 3-lane with } \\
\text { TWLTL }\end{array}$ & 205 & 74 & 89 & 70 & 86 & 71 & 87 & 215 & 262 & 0.83 & 0.81 & 0.81 & 0.82 \\
\hline U4D & 4-lane divided & 86 & 43 & 37 & 60 & 38 & 58 & 38 & 161 & 113 & 1.16 & 1.60 & 1.53 & 1.43 \\
\hline $\mathrm{U} 4 \mathrm{U}$ & 4-lane undivided & 375 & 153 & 266 & 167 & 262 & 186 & 256 & 506 & 783 & 0.58 & 0.64 & 0.73 & 0.65 \\
\hline U5T & $\begin{array}{l}\text { 5-lane with } \\
\text { TWLTL }\end{array}$ & 323 & 273 & 402 & 259 & 405 & 240 & 400 & 772 & 1207 & 0.68 & 0.64 & 0.60 & 0.64 \\
\hline \multicolumn{15}{|c|}{ INTERSECTIONS } \\
\hline \multicolumn{15}{|c|}{ Rural Two Lane } \\
\hline R3ST & 3-leg, minor STOP & 200 & 31 & 115 & 43 & 113 & 34 & 114 & 108 & 342 & 0.27 & 0.38 & 0.30 & 0.32 \\
\hline R4ST & 4-leg, minor STOP & 200 & 67 & 220 & 59 & 216 & 78 & 216 & 204 & 652 & 0.31 & 0.27 & 0.36 & 0.31 \\
\hline R4SG & 4-leg, signalized & 25 & 38 & 99 & 51 & 99 & 53 & 102 & 142 & 300 & 0.38 & 0.51 & 0.52 & 0.47 \\
\hline \multicolumn{15}{|c|}{ Rural Multilane } \\
\hline MR3ST & 3-leg, minor STOP & 100 & 16 & 80 & 10 & 78 & 11 & 78 & 37 & 236 & 0.20 & 0.13 & 0.14 & 0.16 \\
\hline MR4ST & 4-leg, minor STOP & 107 & 48 & 150 & 58 & 149 & 72 & 148 & 178 & 446 & 0.32 & 0.39 & 0.49 & 0.40 \\
\hline MR4SG & 4-leg, signalized & 34 & 51 & 352 & 49 & 352 & 57 & 349 & 157 & 1053 & 0.14 & 0.14 & 0.16 & 0.15 \\
\hline \multicolumn{15}{|c|}{ Urban and Suburban Arterials } \\
\hline U3ST & 3-leg, minor STOP & 73 & 42 & 101 & 31 & 96 & 30 & 98 & 103 & 296 & 0.41 & 0.32 & 0.31 & 0.35 \\
\hline U4ST & 4-leg, minor STOP & 48 & 39 & 81 & 29 & 76 & 37 & 80 & 105 & 237 & 0.48 & 0.38 & 0.46 & 0.44 \\
\hline U3SG & 3-leg, signalized & 49 & 109 & 143 & 103 & 144 & 109 & 140 & 321 & 427 & 0.76 & 0.72 & 0.78 & 0.75 \\
\hline U4SG & 4-leg, signalized & 57 & 232 & 209 & 235 & 209 & 223 & 207 & 690 & 625 & 1.11 & 1.13 & 1.08 & 1.10 \\
\hline
\end{tabular}




\subsection{DEFAULT PROPORTIONS VERSUS LOCALLY-DERIVED PROPORTIONS}

It is important to understand if there is a difference in the total predicted crash frequencies of all sites between using default proportions and locally-derived proportions. The project team used annual as well and multi-year comparisons to evaluate the influence of the use of locally-derived proportions on the overall number of predicted crashes. A straightforward comparison method for evaluating values calculated using the default proportions and values determined using locally-derived proportions is the paired t-test. Table 6.2, Table 6.3, and Table 6.4 show the t-test results for three comparison tests (annual comparison, comparison of three year average, and comparison of annual values then averaged) for the rural facilities. The rural multilane four-leg signalized intersection is not included in this analysis since the HSM SPF for this particular facility does not include base conditions (so there are not any CMFs applied to this facility that could be affected by the default versus locally-derived question).

Table 6.2: Initial Comparison: HSM Default Proportions versus Locally-Derived Proportions (for each year) - Rural Facilities

\begin{tabular}{|c|c|c|c|c|c|}
\hline \multirow{2}{*}{ Facility Type } & \multicolumn{2}{|c|}{ HSM Default Proportions } & \multicolumn{2}{|c|}{ Locally-Derived Proportions (each year) } & \multirow{2}{*}{ Outputs } \\
\hline & Total Crashes & Sample size & Total Crashes & Sample size & \\
\hline $\mathrm{R} 2$ & 532.82 & 75 & 527.15 & 75 & \multirow{8}{*}{$\begin{array}{c}\mathrm{p} \text {-value } \\
0.3027 \\
\mathrm{~T} \\
-1.1124 \\
\mathrm{df} \\
7 \\
\text { Confidence Interval } \\
(-9.50,3.42)\end{array}$} \\
\hline R3ST & 342.15 & 200 & 343.39 & 200 & \\
\hline R4ST & 651.54 & 200 & 656.17 & 200 & \\
\hline R4SG & 299.96 & 25 & 317.51 & 25 & \\
\hline MRU & 1003.12 & 50 & 997.25 & 50 & \\
\hline MRD & 74.77 & 19 & 74.97 & 19 & \\
\hline MR3ST & 235.95 & 100 & 238.92 & 100 & \\
\hline MR4ST & 446.09 & 107 & 455.36 & 107 & \\
\hline
\end{tabular}

Table 6.3: Second Comparison: HSM Default Proportions versus Locally-Derived Proportions (average of three years) - Rural Facilities

\begin{tabular}{|c|c|c|c|c|c|}
\hline \multirow{2}{*}{ Facility Type } & \multicolumn{2}{|c|}{$\begin{array}{l}\text { HSM Default } \\
\text { Proportions }\end{array}$} & \multicolumn{2}{|c|}{$\begin{array}{c}\text { Locally-Derived Proportions (average three } \\
\text { years) }\end{array}$} & \multirow{2}{*}{ Outputs } \\
\hline & $\begin{array}{c}\text { Total } \\
\text { Crashes } \\
\end{array}$ & Sample size & Total Crashes & Sample size & \\
\hline $\mathrm{R} 2$ & 532.82 & 75 & 528.81 & 75 & \multirow{8}{*}{$\begin{array}{c}\mathrm{p} \text {-value } \\
0.3216 \\
\mathrm{~T} \\
-1.0665 \\
\mathrm{df} \\
7 \\
\text { Confidence Interval } \\
(-9.26,3.50)\end{array}$} \\
\hline R3ST & 342.15 & 200 & 343.52 & 200 & \\
\hline $\mathrm{R} 4 \mathrm{ST}$ & 651.54 & 200 & 655.01 & 200 & \\
\hline R4SG & 299.96 & 25 & 317.51 & 25 & \\
\hline MRU & 1003.12 & 50 & 995.82 & 50 & \\
\hline MRD & 74.77 & 19 & 75.01 & 19 & \\
\hline MR3ST & 235.95 & 100 & 239.16 & 100 & \\
\hline MR4ST & 446.09 & 107 & 454.58 & 107 & \\
\hline
\end{tabular}


Table 6.4: Third Comparison: HSM Default Proportions versus Locally-Derived Proportions (three years then averaged) - Rural Facilities

\begin{tabular}{|c|c|c|c|c|c|}
\hline \multirow{2}{*}{ Facility Type } & \multicolumn{2}{|c|}{$\begin{array}{c}\text { Derived Proportions (each } \\
\text { year) }\end{array}$} & \multicolumn{2}{|c|}{$\begin{array}{l}\text { Locally-Derived Proportions } \\
\text { (average three years) }\end{array}$} & \multirow{2}{*}{ Outputs } \\
\hline & Total Crashes & Sample size & Total Crashes & Sample size & \\
\hline $\mathrm{R} 2$ & 527.15 & 75 & 528.81 & 75 & \multirow{8}{*}{$\begin{array}{c}\text { p-value } \\
0.6486 \\
\mathrm{~T} \\
0.476 \\
\mathrm{df} \\
7 \\
\text { nfidence Interval } \\
(-0.65,0.98)\end{array}$} \\
\hline R3ST & 343.39 & 200 & 343.52 & 200 & \\
\hline R4ST & 656.17 & 200 & 655.01 & 200 & \\
\hline R4SG & 317.51 & 25 & 317.51 & 25 & \\
\hline MRU & 997.25 & 50 & 995.82 & 50 & \\
\hline MRD & 74.97 & 19 & 75.01 & 19 & \\
\hline MR3ST & 238.92 & 100 & 239.16 & 100 & \\
\hline MR4ST & 455.36 & 107 & 454.58 & 107 & \\
\hline
\end{tabular}

Table 6.5: Fourth Comparison: HSM Default Proportions versus Locally-Derived Proportions (three years) Urban and Suburban Facilities

\begin{tabular}{|c|c|c|c|c|c|}
\hline \multirow{2}{*}{ Facility Type } & \multicolumn{2}{|c|}{$\begin{array}{l}\text { HSM Default } \\
\text { Proportions }\end{array}$} & \multicolumn{2}{|c|}{$\begin{array}{l}\text { Locally-Derived Proportions } \\
\text { (three years) }\end{array}$} & \multirow{2}{*}{ Outputs } \\
\hline & $\begin{array}{c}\text { Total } \\
\text { Crashes }\end{array}$ & $\begin{array}{c}\text { Sample } \\
\text { size }\end{array}$ & Total Crashes & Sample size & \\
\hline U3ST & 295.60 & 73 & 290.57 & 73 & \multirow{9}{*}{$\begin{array}{c}\mathrm{p} \text {-value } \\
0.068169 \\
\mathrm{~T} \\
1.859548 \\
\mathrm{df} \\
8\end{array}$} \\
\hline U4ST & 237.15 & 48 & 231.19 & 48 & \\
\hline U3SG & 426.60 & 49 & 438.77 & 49 & \\
\hline U4SG & 625.29 & 57 & 654.37 & 57 & \\
\hline $\mathrm{U} 2 \mathrm{U}$ & 601.50 & 491 & 609.77 & 491 & \\
\hline U3T & 262.19 & 73 & 266.63 & 73 & \\
\hline U4D & 112.51 & 86 & 114.04 & 86 & \\
\hline $\mathrm{U} 4 \mathrm{U}$ & 783.30 & 375 & 802.51 & 375 & \\
\hline U5T & 1207.15 & 323 & 1214.38 & 323 & \\
\hline
\end{tabular}

These three analysis tables (Table 6.2: , Table 6.3 and, Table 6.4: ) show that p-values for all three comparisons are larger than 0.05 . This indicates that there is no significant difference between the three methods. Table 6.5 shows the results of this comparison for the urban and suburban facilities. In an aggregate sense, the difference in estimating total crashes of using the HSM defaults of the locally derived proportions is not statistically significant $(p=0.068)$. Note however, that the difference for the urban models is greater than for any of the comparisons completed for the rural sections.

If agencies do not have available data to generate locally-derived values, they can confidently use default values to estimate total crashes. If however, the interest is in specific distributions of 
crash types (e.g. single vehicle crashes by type), then the agency would be advised to use the locally-derived proportions.

For Oregon calculations, the research team recommends the use of the local proportions provided in the Appendix.

\subsection{CALIBRATION FACTORS FOR TOTAL CRASHES VERSUS FATAL PLUS INJURY CRASHES}

Since the Oregon-derived severity levels are significantly different than the HSM default proportions, the authors next considered if calibration factors for total crashes should be used in Oregon or if a more accurate approach would be the use of Oregon fatal plus injury crashes when predicting crashes. The HSM predictive method chapters vary based on the time of initial development and method evolution. For example, the rural two-lane two-way chapter (Chapter 10 of the HSM) includes models that can only predict total crashes. The urban and suburban chapter (Chapter 12 of the HSM) includes a variety of severity-level models.

Based on the previous comparison for the fatal plus injury crashes in Oregon compared to the HSM default values, the project team pursued the option that a more accurate way to apply the HSM predictive methods to the State of Oregon (particularly for the rural two-lane roads) may be to develop calibration factors specifically for the fatal plus injury crashes. Table 6.6 depicts the fatal plus injury calibration factors for the rural two-lane two-way roads. Since the values shown for fatal plus injury are less likely to be subjected to the self-report and reporting threshold issues previously identified for Oregon, the project team anticipates that the use at some future time of these severity models as they will more accurately reflect expected crash conditions in Oregon. The current HSM calibration sampling technique is based on total crashes, so the severity calibration values used in this analysis for fatal and injury crashes is shown for the purposes of demonstrating this future need for severity model calibration methods.

Table 6.6: Calibration Comparison for Total Crashes versus Fatal plus Injury (Rural Two-Lane, Two-Way Roads) Using HSM-Proportional Values

\begin{tabular}{l|c|c|c|c}
\hline Rural Two-Lane, Two-Way Facility & R2 & R3ST & R4ST & R4SG \\
\hline Sample Size (Sites) & 75 & 200 & 200 & 25 \\
\hline Observed Crashes (Total for 2004 to 2006) & 394 & 108 & 204 & 142 \\
\hline Observed Crashes (Fatal and Injury) & 196 & 58 & 135 & 73 \\
\hline Predicted Crashes (Total for 2004 to 2006) & 533 & 342 & 652 & 300 \\
\hline Predicted (Adjusted by Local Proportions) & 171 & 142 & 281 & 108 \\
\hline Calibration Factor (Total) & 0.74 & 0.32 & 0.31 & 0.47 \\
\hline Calibration Factor (Fatal and Injury) & 1.15 & 0.41 & 0.48 & 0.67 \\
\hline
\end{tabular}

Table 6.6 indicates that for rural two-lane, two-way roads in Oregon, the calibration factors for fatal and injury crashes are larger than calibration factors for total crashes. Similarly, Table 6.7 compares the values of fatal and injury calibration factors for the rural multilane facilities to those for total crashes. For rural multilane highways, the difference between calibrations factors of total crashes and fatal plus injury crashes is not significant. 
Table 6.7: Calibration Comparison for Total Crashes versus Fatal plus Injury (Rural Multilane Highways) Using HSM-Proportional Values

\begin{tabular}{l|c|c|c|c|c}
\hline Rural Multilane Facility & MRU & MRD & MR3ST & MR4ST & MR4SG \\
\hline Sample Size (Sites) & 50 & 19 & 100 & 107 & 34 \\
\hline Observed Crashes (Total for 2004 to 2006) & 364 & 58 & 37 & 178 & 157 \\
\hline Observed Crashes (Fatal and Injury) & 153 & 25 & 20 & 96 & 76 \\
\hline Predicted Crashes (Total for 2004 to 2006) & 1003 & 75 & 236 & 446 & 1053 \\
\hline Predicted (Using SPFs for fatal and injury) & 579 & 37 & 89 & 199 & 452 \\
\hline Calibration Factor (Total) & 0.36 & 0.78 & 0.16 & 0.40 & 0.15 \\
\hline Calibration Factor (Fatal and Injury) & 0.26 & 0.68 & 0.23 & 0.48 & 0.17 \\
\hline
\end{tabular}

The urban and suburban chapter includes models for total, fatal and injury, and PDO crashes. The predictive procedures, however, only call for use of one calibration factor per facility generated from total crashes. The calibration procedure can be analyzed to produce calibration factors for each severity level. Table 6.8 and Table 6.9 show the results of the analysis to produce calibration factors for each severity level. Factors are produced for both HSM-defaults and local proportions. Like the rural two-lane, two-way facilities there are significant differences in calibration factors by severity level, particularly for segments. If as suggested in the HSM procedures, the total calibration factor is applied to all severity models the result will be to underestimate the number of crashes in the fatal and injury category. The tables indicate that some severity models predict Oregon crashes (calibration factor approximately equal to one). The primary gap is in PDO predictions. These differences are explained by the underreporting issue described earlier.

When the interest is in predicting severity-level crashes, it is feasible that an Oregon agency could use the calibration factor for each severity level; however, this should be performed with caution as the sample size used for the HSM method is based on total crashes (so the Oregon severity level crashes may not represent an adequate study sample size). When severity models are present for the HSM predictive procedure, such as for the urban models, a rebalancing equation should be applied to confirm that the predicted total crashes are the sum of fatal and injury plus PDO. This rebalancing equation is applied prior to the calibration factor application but before the CMF application and calibration factor. To apply separate severity calibration factors, the HSM procedures need to be modified to apply the rebalancing equation after the severity-specific calibration factors. 
Table 6.8: Calibration Comparison for Total Crashes versus Fatal plus Injury (Urban and Suburban Intersections)

\begin{tabular}{l|l|r|r|r|r}
\hline \multicolumn{1}{l}{$\begin{array}{l}\text { Urban and Suburban Arterials, } \\
\text { Intersections }\end{array}$} & \multicolumn{1}{l|}{ U3ST } & \multicolumn{1}{l}{ U4ST } & \multicolumn{1}{l}{ U3SG } & \multicolumn{1}{l}{ U4SG } \\
\hline & Sample Size (Sites) & 73 & 48 & 49 & 57 \\
\hline \multirow{2}{*}{$\begin{array}{l}\text { Observed } \\
\text { Crashes }\end{array}$} & Total & 103 & 105 & 321 & 690 \\
\cline { 2 - 6 } & Fatal and Injury & 55 & 50 & 161 & 328 \\
\cline { 2 - 6 } & PDO & 48 & 55 & 160 & 362 \\
\hline $\begin{array}{l}\text { Predicted, HSM } \\
\text { Defaults }\end{array}$ & Total & 295.60 & 237.15 & 426.60 & 625.29 \\
\cline { 2 - 6 } & Fatal and Injury & 108.30 & 92.48 & 150.79 & 241.76 \\
\cline { 2 - 6 } & PDO & 187.29 & 144.66 & 275.81 & 383.53 \\
\hline $\begin{array}{l}\text { Predicted, Local } \\
\text { Derived }\end{array}$ & Total & 290.57 & 231.19 & 438.77 & 654.37 \\
\cline { 2 - 6 } & Fatal and Injury & 118.13 & 98.30 & 156.17 & 254.85 \\
\cline { 2 - 6 } & PDO & 172.35 & 132.88 & 282.45 & 399.14 \\
\hline $\begin{array}{l}\text { Calibration } \\
\text { Factor, HSM } \\
\text { Defaults }\end{array}$ & Total & 0.348 & 0.443 & 0.752 & 1.103 \\
\cline { 2 - 6 } & Fatal and Injury & 0.508 & 0.541 & 1.068 & 1.357 \\
\cline { 2 - 6 } & PDO & 0.256 & 0.380 & 0.580 & 0.944 \\
\hline $\begin{array}{l}\text { Calibration } \\
\text { Factor, Local } \\
\text { Derived }\end{array}$ & Total & 0.354 & 0.454 & 0.732 & 1.054 \\
\cline { 2 - 6 } & Fatal and Injury & 0.466 & 0.509 & 1.068 & 1.287 \\
\cline { 2 - 6 } & PDO & 0.279 & 0.414 & 0.566 & 0.907 \\
\hline
\end{tabular}

Table 6.9: Calibration Comparison for Total Crashes versus Fatal plus Injury (Urban and Suburban Arterials)

\begin{tabular}{l|l|r|r|r|r|r}
\hline \multicolumn{1}{l|}{ Urban and Suburban Arterials, Segments } & \multicolumn{1}{l|}{ U2U } & \multicolumn{1}{l}{ U3T } & \multicolumn{1}{l}{ U4D } & \multicolumn{1}{l}{ U4U } & \multicolumn{1}{l}{ U5T } \\
\hline \multirow{2}{*}{$\begin{array}{l}\text { Observed } \\
\text { Crashes }\end{array}$} & Tomple Size (Sites) & 491 & 73 & 86 & 375 & 323 \\
\cline { 2 - 7 } & Fatal and Injury & 177 & 215 & 161 & 506 & 772 \\
\cline { 2 - 7 } & PDO & 200 & 127 & 98 & 235 & 323 \\
\hline $\begin{array}{l}\text { Predicted, HSM } \\
\text { Defaults }\end{array}$ & Total & 601.50 & 262.19 & 112.51 & 783.30 & 1207.15 \\
\cline { 2 - 7 } & Fatal and Injury & 177.58 & 75.87 & 32.09 & 245.38 & 350.08 \\
\cline { 2 - 7 } & PDO & 423.89 & 186.30 & 80.42 & 537.93 & 857.11 \\
\hline $\begin{array}{l}\text { Predicted, Local } \\
\text { Derived }\end{array}$ & Total & 609.77 & 266.63 & 114.04 & 802.51 & 1214.38 \\
\cline { 2 - 7 } & Fatal and Injury & 216.83 & 89.84 & 35.77 & 274.25 & 434.75 \\
\cline { 2 - 7 } & PDO & 392.98 & 176.81 & 78.29 & 528.28 & 779.63 \\
\hline $\begin{array}{l}\text { Calibration } \\
\text { Factor, HSM } \\
\text { Defaults }\end{array}$ & Total & 0.627 & 0.820 & 1.431 & 0.646 & 0.640 \\
\cline { 2 - 7 } & Fatal and Injury & 0.997 & 1.160 & 1.932 & 0.958 & 0.923 \\
\cline { 2 - 7 } & PDO & 0.472 & 0.682 & 1.231 & 0.504 & 0.524 \\
\hline $\begin{array}{l}\text { Calibration } \\
\text { Factor, Local } \\
\text { Derived }\end{array}$ & Total & 0.618 & 0.806 & 1.412 & 0.631 & 0.636 \\
\cline { 2 - 7 } & Fatal and Injury & 0.816 & 0.979 & 1.734 & 0.857 & 0.743 \\
\cline { 2 - 7 } & PDO & 0.509 & 0.718 & 1.265 & 0.513 & 0.576 \\
\hline
\end{tabular}




\subsection{CALIBRATION FACTORS FOR TOTAL CRASHES BY GEOGRAPHIC REGION}

Given Oregon's diverse climate and geography, the research team explored the differences if the calibration factor was calculated for the state's different geographic regions. In previous work, the research team divided Oregon's geography into nine climate zones based on the mean annual days of measurable snowfall exceeding $0.25 \mathrm{~cm}(0.1 \mathrm{in})$ and the mean annual days when the temperature fell below freezing (Monsere et al. 2008). These data were obtained from the 2002 National Oceanic and Atmospheric Administration's (NOAA) Climate Atlas of the United States. These zones are shown in Figure 6.1. Though this work was based on examining speed and ice related crashes, it accurately captures the primary geographic and weather differences in the state.

The research team conducted this exploratory analysis only for urban and suburban segments and the results are shown in Table 6.10. The table shows the facility type, the climate zone, the statewide calibration factor, a calibration factor that estimated only segments in each zone, the difference between the zones, and the number of segments and observed crashes. For all of the facility types, the largest sample of segments and crashes is in zone 2, which represents the Willamette Valley. The statewide calibration factor most closely matches the zone 2 calibration factor. While the calibration factors for each zone do differ from the statewide estimate, none of the other zones are close to having the minimum number of crashes per facility type (100 crashes per year for three years or 300 total crashes) required of the calibration procedure. Zone 1 (which is essentially all of the coastal urbanized areas along US101) has the next highest sample. However, even inclusion of an additional two years of data or aggregation of other zones does not bring the samples up to the necessary minimum. Thus, the authors' conclusion is that data collection efforts and sample size limit the calibration factor to one statewide value. When the predictive models are applied with the EB procedure, additional local differences will be accounted for by the inclusion of site-specific historical crash data.

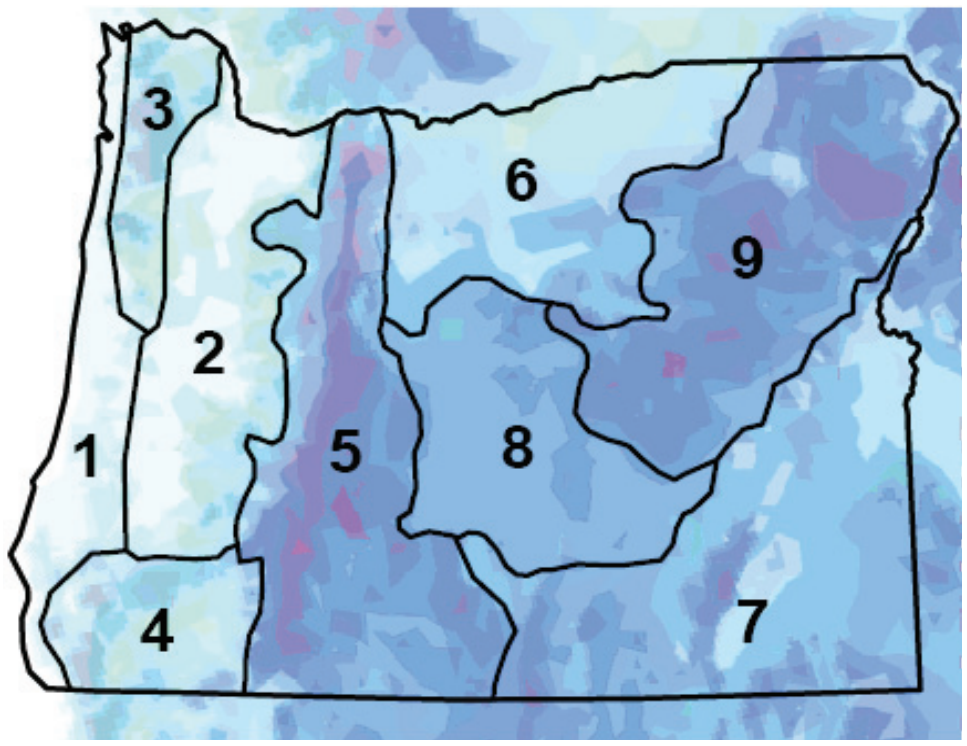

Figure 6.1: Climate Zones, Oregon 
Table 6.10: Calibration Comparison for Total Crashes by Climate Zone (Urban and Suburban Arterials) Using HSM-Default Values

\begin{tabular}{|c|c|c|c|c|c|c|}
\hline \multirow{2}{*}{$\begin{array}{l}\text { Climate } \\
\text { Zone }\end{array}$} & \multirow[t]{2}{*}{ Facility } & \multicolumn{2}{|c|}{ Crash Calibration Factor, 2004-2006 } & \multirow{2}{*}{$\begin{array}{l}\text { Difference } \\
\text { (B-A) }\end{array}$} & \multirow{2}{*}{$\begin{array}{l}\text { Sample } \\
\text { Size }\end{array}$} & \multirow{2}{*}{$\begin{array}{l}\text { 3-Year Observed } \\
\text { Crash Count }\end{array}$} \\
\hline & & Statewide (A) & By Climate Zone (B) & & & \\
\hline 1 & $2 \mathrm{U}$ & 0.627 & 0.517 & -0.11 & 156 & 34 \\
\hline 2 & $2 \mathrm{U}$ & & 0.615 & -0.01 & 927 & 283 \\
\hline 4 & $2 \mathrm{U}$ & & 0.955 & 0.33 & 147 & 26 \\
\hline 6 & $2 \mathrm{U}$ & & 0.904 & 0.28 & 75 & 17 \\
\hline 8 & $2 \mathrm{U}$ & & 0.659 & 0.03 & 78 & 12 \\
\hline 9 & $2 \mathrm{U}$ & & 0.434 & -0.19 & 90 & 5 \\
\hline 1 & $3 \mathrm{~T}$ & 0.820 & 0.660 & -0.16 & 198 & 59 \\
\hline 2 & $3 \mathrm{~T}$ & & 1.075 & 0.25 & 240 & 120 \\
\hline 4 & $3 \mathrm{~T}$ & & 0.167 & -0.65 & 24 & 4 \\
\hline 6 & $3 \mathrm{~T}$ & & 0.411 & -0.41 & 39 & 3 \\
\hline 8 & $3 \mathrm{~T}$ & & 1.484 & 0.66 & 12 & 5 \\
\hline 9 & $3 \mathrm{~T}$ & & 0.906 & 0.09 & 102 & 24 \\
\hline 1 & $4 \mathrm{D}$ & 1.431 & 2.311 & 0.88 & 24 & 8 \\
\hline 2 & $4 \mathrm{D}$ & & 1.500 & 0.07 & 171 & 107 \\
\hline 4 & $4 \mathrm{D}$ & & 3.147 & 1.72 & 18 & 10 \\
\hline 8 & $4 \mathrm{D}$ & & 1.042 & -0.39 & 45 & 36 \\
\hline 1 & $4 \mathrm{U}$ & 0.646 & 0.994 & 0.35 & 123 & 90 \\
\hline 2 & $4 \mathrm{U}$ & & 0.630 & -0.02 & 723 & 367 \\
\hline 4 & $4 \mathrm{U}$ & & 0.533 & -0.11 & 75 & 27 \\
\hline 5 & $4 \mathrm{U}$ & & 0.387 & -0.26 & 15 & 2 \\
\hline 6 & $4 \mathrm{U}$ & & 0.577 & -0.07 & 81 & 12 \\
\hline 8 & $4 \mathrm{U}$ & & 0.259 & -0.39 & 15 & 4 \\
\hline 9 & $4 \mathrm{U}$ & & 0.218 & -0.43 & 87 & 4 \\
\hline 1 & $5 \mathrm{~T}$ & 0.640 & 0.811 & 0.17 & 63 & 58 \\
\hline 2 & $5 \mathrm{~T}$ & & 0.653 & 0.01 & 786 & 626 \\
\hline 4 & $5 \mathrm{~T}$ & & 0.401 & -0.24 & 30 & 23 \\
\hline 5 & $5 \mathrm{~T}$ & & 0.553 & -0.09 & 84 & 65 \\
\hline 8 & $5 \mathrm{~T}$ & & 0.000 & -0.64 & 6 & 0 \\
\hline
\end{tabular}

\subsection{SUMMARY OF CALIBRATION RESULTS}

As shown in this section, there are a wide variety of ways to develop the calibration factors for the HSM procedures. The method for incorporating the locally-derived severity and crash type proportions can vary; however, analysis shows that the resulting values are not statistically different. As a result, an agency can use the HSM default values without creating substantially different results when considering total crashes. A second issue associated with using the calibration factors in conjunction with the HSM default values is that the rural two-lane road models were developed only for total crashes. The inclusion of severity based methods requires the use of the default values and for the HSM Chapter 10 models, the resulting fatal plus injury calibration factors do substantially differ. 


\subsection{CONCLUSIONS}

This report summarizes the results of the efforts to generate calibration factors for the predictive models in the HSM. Though the adaptation of the HSM calibration method is a straightforward procedure, this report highlights a few key issues identified during the creation of the Oregon calibration factors.

\subsection{DATA COLLECTION ISSUES}

The data set can be time consuming to develop and the HSM recommended sample size of 100 crashes per year does not apply to all facilities. It is reasonable to adjust sample size expectations for under-represented facility types by basing an assumption on average crash history for similar facilities. The most difficult data variables to acquire for this effort were urban intersection pedestrian volumes, minor-road signal phasing, and minor road AADT values for rural intersection locations. If possible, efforts should be made to modify data inventories to include:

- Minor road AADT,

- Signal phasing information in urban areas,

- Presence of lighting,

- Presence of centerline rumble strips, and

- Urban intersection pedestrian volumes.

Though the following information would be useful, it would be much harder to systematically collect. These elements would be recommended for a lower priority of data collection:

- Driveway density and type,

- Presence and type of parking,

- Roadside hazard rating,

- Side slope,

- Roadside fixed object density, and

- Average offset to fixed objects. 
The acquisition of these high and lower priority inventory items would allow HSM predictive procedures to be applied on a network-level for screening and other purposes. This report provides recommendations and assumptions to overcome these potential data deficiencies. Since it is not likely that pedestrian counts will be obtained on a wide-scale, some effort should be made to model or adapt other models based on land-use to predict pedestrian volumes.

\subsection{CALIBRATION FACTORS}

The primary observation from this analysis is that Oregon calibration factors for total crashes highlight that the current Oregon crash reporting procedures and thresholds introduce a significant difference in observed crash proportions. As a result, the use of severity-based calibration factors or Oregon-specific fatal plus injury SPFs seems more appropriate for costbenefit based decisions. The calibration factor for the urban four-lane divided facility should be used with care. This calibration factor likely reflects 1) the small sample size, and 2) the difference between the higher designs of the four-lane divided facilities in the HSM SPFs data set and the segments in the Oregon calibration set. When using the HSM for future urban fourlane divided facilities, it is not recommended that the calculated Oregon calibration factor be used. The use of this factor would introduce scenarios where the four-lane divided facility appears less safe than undivided facilities. It would be reasonable to apply the calibration factor estimate for the other multi-lane facilities (0.64) in this case.

Though the report did not review this, it is important to note that the road characteristic data developed for the purposes of calibration can be preserved and calibration factors can be updated for future years (with future observed crashes and updated AADT values) with minimal additional effort. However, after some time, it is likely that improvements or modifications have been made to some of the calibration intersections or segments and the data will need to be recollected.

To enhance precision, the research team recommends the use of the HSM calibration factors developed with local proportions and the use of local proportions in all calculations. These recommended calibration factors are summarized in Table 7.1. The actual locally derived crash type proportions are included in the Appendix of the report. 
Table 7.1: Recommended Oregon HSM Calibration Factors (based on locally derived crash proportions)

\begin{tabular}{|c|c|c|c|c|}
\hline \multicolumn{2}{|c|}{ Facility Type } & $\begin{array}{c}\text { Observed } \\
\text { Crashes }\end{array}$ & $\begin{array}{c}\text { Predicted } \\
\text { Crashes } \\
\end{array}$ & $\begin{array}{c}\text { Calibration } \\
\text { Factor, } \mathrm{C}\end{array}$ \\
\hline \multicolumn{5}{|c|}{ SEGMENTS } \\
\hline \multicolumn{5}{|c|}{ Rural Two-Lane } \\
\hline R2 & 2-lane undivided & 394 & 529 & 0.74 \\
\hline \multicolumn{5}{|c|}{ Rural Multilane } \\
\hline MRU & Undivided & 364 & 996 & 0.37 \\
\hline MRD & Divided & 58 & 75 & 0.77 \\
\hline \multicolumn{5}{|c|}{ Urban and Suburban Arterials } \\
\hline $\mathrm{U} 2 \mathrm{U}$ & 2-lane undivided & 377 & 610 & 0.62 \\
\hline U3T & 3-lane with TWLTL & 215 & 267 & 0.81 \\
\hline U4D & 4-lane divided & 161 & 114 & 1.411 \\
\hline $\mathrm{U} 4 \mathrm{U}$ & 4-lane undivided & 506 & 803 & 0.63 \\
\hline U5T & 5-lane with TWLTL & 772 & 1214 & 0.64 \\
\hline \multicolumn{5}{|c|}{ INTERSECTIONS } \\
\hline \multicolumn{5}{|c|}{ Rural Two-Lane } \\
\hline R3ST & 3-leg, minor STOP & 108 & 344 & 0.31 \\
\hline R4ST & 4-leg, minor STOP & 204 & 655 & 0.31 \\
\hline R4SG & 4-leg, signalized & 142 & 318 & 0.45 \\
\hline \multicolumn{5}{|c|}{ Rural Multilane } \\
\hline MR3ST & 3-leg, minor STOP & 37 & 239 & 0.15 \\
\hline MR4ST & 4-leg, minor STOP & 178 & 455 & 0.39 \\
\hline MR4SG & 4-leg, signalized & 157 & 1053 & 0.15 \\
\hline \multicolumn{5}{|c|}{ Urban and Suburban Arterials } \\
\hline U3ST & 3-leg, minor STOP & 103 & 291 & 0.35 \\
\hline U4ST & 4-leg, minor STOP & 105 & 231 & 0.45 \\
\hline U3SG & 3-leg, signalized & 321 & 439 & 0.73 \\
\hline U4SG & 4-leg, signalized & 690 & 654 & 1.05 \\
\hline
\end{tabular}

1 Use with caution (see discussion in text). If using the SPFs to evaluate future facilities use calibration factor of 0.64

\subsection{FUTURE WORK}

The use of the HSM predictive methods creates a promising procedure for quantitative safety evaluations; however, the calibration application for Oregon crash conditions highlights several issues with the procedure that should be addressed. These include ways to address variability in reporting thresholds, methods for developing critical variable information that is not available in state databases (such as minor road AADT values), and alternative procedures for sample size estimation at facilities with historically low crash conditions. In addition, it appears a logical next step in the evolution of this calibration process would be to examine the functional form of the SPFs and determine if the local SPFs reflect a similar form since the current calibration procedure assumes a linear relationship based simply on a proportional adjustment. 
Two future efforts that the authors recommend ODOT should pursue includes:

- Monitor improvements and crash conditions for the calibration sites used for this project. It is advisable to periodically update the calibration factors for these locations as crash conditions change over time.

- Though the HSM calibration procedure targets total crashes and the sample sizes are based on this overall crash summary, evidence from this calibration effort suggests that future evaluation of severity model calibration factors is advisable for Oregon databases.

This research effort identified several recommendations that should be considered for future editions of the HSM. First, the one-size-fits-all sample size does not appear to be appropriate for all facility types and should be enhanced. In addition, the calibration of severity-level models requires additional consideration. The HSM severity-model rebalancing procedure should be incorporated into the calibration process and sample size techniques appropriate for the severitylevel models are needed. The calibration factors developed for this effort are suitable for evaluations within a jurisdiction, but the overall HSM calibration techniques should address the severity-level and sample size considerations before comparing predicted, calibrated crash frequencies between different jurisdictions that have varying reporting thresholds or procedures. 


\subsection{REFERENCES}

American Association of State Transportation Officials. Highway Safety Manual. AASHTO, Washington, D.C., 2010.

California Department of Motor Vehicles. 2011. http://dmv.ca.gov/forms/sr/ sr1.htm. Accessed on January 11, 2011.

Dixon, K. K., and J. Rohani. Methodologies for Estimating Curve Speeds on Oregon Highways. SPR 641, FHWA-OR-RD-08-04, Oregon Department of Transportation, Salem, Oregon, 2008.

Mohamad, D., K.C. Sinha, T. Kuczek, and C.F. Scholer. 1998. Annual Average Daily Traffic Prediction Model for County Roads. In Transportation Research Record, No. 1617, Transportation Research Board. National Research Council. Washington, D.C., 1968, pp. 69-77.

Monsere, C., and D. Chi. A Strategy for Reducing the Impact of Driving Under Influence of Intoxicants in Portland, Oregon. Portland State University, Intelligent Transportation Systems Lab, Research Report CSTSP 08-01, March 2008

Monsere, C.M, P.G. Bosa, R.L. Bertini. Combining Climate, Crash, and Highway Data for Improved Ranking of Speed and Winter-Weather Related Crash Locations in Oregon. Journal of Transportation Engineering, Vol. 134(7), 2008, pp. 287-296.

Ramsey, F.L., and D.W. Schafer. The Statistical Sleuth-A Course in Methods of Data Analysis, Second Edition. Duxbury Thomson Learning, Pacific Grove, California, 2002.

Rawlings, J.O., S.G. Pantula, and D.A. Dickey. Applied Regression Analysis - A Research Tool, Second Edition. Springer-Verlag, New York, 1998.

Washington State Patrol. Police Traffic Collision Report Instruction Manual, 7th edition. Located at http://www.wsp.wa.gov/publications/forms/pctrmanl.pdf, Revised July 2006. 

APPENDIX A - ABBREVIATION TABLE 

Table A.1: Abbreviations Used in Report

\begin{tabular}{|c|c|}
\hline Abbreviation & Term \\
\hline $2 \mathrm{U}$ & Two-Lane Undivided \\
\hline $3 \mathrm{~T}$ & Three-Lane includes a Two-Way Left-Turn Lane \\
\hline $4 \mathrm{D}$ & Four-Lane Divided \\
\hline $4 \mathrm{U}$ & Four-Lane Undivided \\
\hline$\overline{5 T}$ & Five-Lane includes a Two-Way Left-Turn Lane \\
\hline AADT & Annual Average Daily Traffic \\
\hline AASHTO & American Association of State Highway and Transportation Officials \\
\hline $\mathrm{C}$ & Calibration factor \\
\hline CDS & Crash Data System \\
\hline $\mathrm{CMF}$ & Crash Modification Factor (Function) \\
\hline DVL & Digital Video Log \\
\hline $\mathrm{ft}$ & feet \\
\hline GIS & Geographic Information Systems \\
\hline HSM & Highway Safety Manual \\
\hline Hwy & Highway \\
\hline ITIS & Integrated Transportation Information System \\
\hline ITS & Intelligent Transportation System \\
\hline MAC & Major Collector \\
\hline MIA & Minor Arterial \\
\hline MP & Milepoint \\
\hline MR3ST & Rural Multilane Three-Leg Stop Controlled Intersection \\
\hline MR4SG & Rural Multilane Four-Leg Signalized Intersections \\
\hline MR4ST & Rural Multilane Four-Leg Stop Controlled Intersection \\
\hline MRD & Rural Multilane Divided Segment \\
\hline MRU & Rural Multilane Undivided Segment \\
\hline NOAA & National Oceanic and Atmospheric Administration \\
\hline Nspf & Total predicted crash frequency for a base condition \\
\hline ODOT & Oregon Department of Transportation \\
\hline OTREC & Oregon Transportation Research and Education Consortium \\
\hline $\mathrm{PDO}$ & Property-Damage-Only \\
\hline R2 & Rural Two-Lane, Two-Way Undivided Segment \\
\hline R3ST & Rural Two-Lane, Two-Way Three-Leg Stop Controlled Intersection \\
\hline R4SG & Rural Two-Lane, Two-Way Four-Leg Signalized Intersections \\
\hline R4ST & Rural Two-Lane, Two-Way Four-Leg Stop Controlled Intersection \\
\hline SPF & Safety Performance Function \\
\hline TWLTL & Two-Way Left-Turn Lane \\
\hline U3SG & Urban Three-Leg Signalized Intersection \\
\hline $\mathrm{U} 3 \mathrm{ST}$ & Urban Three-Leg Stop-controlled Intersection \\
\hline U4SG & Urban Four-Leg Signalized Intersection \\
\hline U4ST & Urban Four-Leg Stop-controlled Intersection \\
\hline VIF & Variance Inflation Factor \\
\hline
\end{tabular}





\section{APPENDIX B - LOCALLY-DERIVED VALUES}





\section{RURAL TWO-LANE, TWO-WAY ROADWAY SEGMENTS LOCALLY- DERIVED VALUES}

Table B.1: 2004 R2 Locally-Derived Crash Severity Values

\begin{tabular}{l|c}
\hline Crash Severity Level & Locally-Derived Values \\
\hline Fatal & 3.3 \\
\hline Incapacitating Injury & 6.2 \\
\hline Non-incapacitating Injury & 25.5 \\
\hline Possible Injury & 17.2 \\
\hline Total Fatal Plus Injury & 52.2 \\
\hline Property Damage Only & 47.8 \\
\hline TOTAL & 100.0 \\
\hline
\end{tabular}

Table B.2: 2004 R2 Locally-Derived Collision Types

\begin{tabular}{|c|c|c|c|}
\hline \multirow[b]{2}{*}{ Collision Type } & \multicolumn{3}{|c|}{ Locally-Derived Values } \\
\hline & $\begin{array}{c}\text { Total fatal and } \\
\text { injury }\end{array}$ & $\begin{array}{c}\text { Property damage } \\
\text { only }\end{array}$ & $\begin{array}{l}\text { TOTAL (all severity } \\
\text { levels combined) }\end{array}$ \\
\hline \multicolumn{4}{|c|}{ SINGLE-VEHICLE CRASHES } \\
\hline Collision with animal & 3.8 & 12.0 & 7.7 \\
\hline Collision with bicycle & 0.4 & 0.0 & 0.2 \\
\hline Collision with pedestrian & 0.8 & 0.0 & 0.4 \\
\hline Overturned & 10.4 & 3.2 & 7.0 \\
\hline Ran off road & 42.1 & 35.6 & 39.0 \\
\hline Other single-vehicle crash & 1.4 & 0.6 & 1.0 \\
\hline Total single-vehicle crashes & 58.9 & 51.4 & 55.3 \\
\hline \multicolumn{4}{|c|}{ MULTIPLE-VEHICLE CRASHES } \\
\hline Angle collision & 0.8 & 1.1 & 0.9 \\
\hline Head-on collision & 6.8 & 1.4 & 4.2 \\
\hline Rear-end collision & 18.9 & 23.0 & 20.9 \\
\hline Sideswipe collision & 5.0 & 7.3 & 6.1 \\
\hline Other multiple-vehicle collision & 9.6 & 15.9 & 12.6 \\
\hline Total multiple-vehicle crashes & 41.1 & 48.6 & 44.7 \\
\hline TOTAL CRASHES & 100.0 & 100.0 & 100.0 \\
\hline
\end{tabular}

Table B.3: 2004 R2 Locally-Derived Values for Nighttime Crashes

\begin{tabular}{c|c|c}
\hline \multicolumn{3}{c}{ Locally-Derived Values } \\
\hline Proportion of total nighttime crashes by severity level & Proportion of crashes that occur at night \\
\hline Fatal and Injury $\mathrm{p}_{\mathrm{inr}}$ & PDO $\mathrm{p}_{\mathrm{pnr}}$ & $\mathbf{p}_{\mathrm{nr}}$ \\
\hline 0.5 & 0.5 & 0.27 \\
\hline
\end{tabular}


Table B.4: 2005 R2 Locally-Derived Crash Severity Values

\begin{tabular}{l|c}
\hline \multicolumn{1}{c|}{ Crash Severity Level } & Locally-Derived Values \\
\hline Fatal & 3.1 \\
\hline Incapacitating Injury & 7.6 \\
\hline Non-incapacitating Injury & 24.5 \\
\hline Possible Injury & 19.5 \\
\hline Total Fatal Plus Injury & 54.6 \\
\hline Property Damage Only & 45.4 \\
\hline \hline TOTAL & 100.0 \\
\hline
\end{tabular}

Table B.5: 2005 R2 Locally-Derived Collision Types

\begin{tabular}{l|c|c||c}
\hline \multirow{2}{*}{ Collision Type } & \multicolumn{3}{c}{ Locally-Derived Values } \\
\cline { 2 - 4 } & $\begin{array}{c}\text { Total fatal and } \\
\text { injury }\end{array}$ & $\begin{array}{c}\text { Property damage } \\
\text { only }\end{array}$ & $\begin{array}{c}\text { TOTAL (all severity } \\
\text { levels combined) }\end{array}$ \\
\hline \multicolumn{2}{c}{ SINGLE-VEHICLE CRASHES } \\
\hline Collision with animal & 3.2 & 10.4 & 6.4 \\
\hline Collision with bicycle & 0.6 & 0.0 & 0.3 \\
\hline Collision with pedestrian & 0.6 & 0.0 & 0.3 \\
\hline Overturned & 7.4 & 3.3 & 5.6 \\
\hline Run-off-road & 48.0 & 41.9 & 45.3 \\
\hline Other single-vehicle crash & 1.5 & 2.1 & 1.7 \\
\hline Total single-vehicle crashes & 61.3 & 57.6 & 59.7 \\
\hline & MULTIPLE-VEHICLE CRASHES & 0.8 \\
\hline Angle collision & 0.9 & 0.5 & 3.7 \\
\hline Head-on collision & 5.7 & 1.0 & 20.1 \\
\hline Rear-end collision & 19.5 & 20.7 & 6.0 \\
\hline Sideswipe collision & 4.2 & 8.3 & 40.3 \\
\hline Other multiple-vehicle collision & 8.4 & 11.8 & 100.0 \\
\hline Total multiple-vehicle crashes & 38.7 & 42.4 & \\
\hline
\end{tabular}

Table B.6: 2005 R2 Locally-Derived Values for Nighttime Crashes Locally-Derived Values

\begin{tabular}{c|c|c}
\hline \multicolumn{2}{c|}{ Proportion of total nighttime crashes by severity level } & Proportion of crashes that occur at night \\
\hline Fatal and Injury $\mathbf{p}_{\text {inr }}$ & PDO $\mathbf{p}_{\mathbf{p n r}}$ & $\mathbf{p}_{\mathbf{n r}}$ \\
\hline 0.57 & 0.43 & 0.29 \\
\hline
\end{tabular}

Table B.7: 2006 R2 Locally-Derived Crash Severity Values

\begin{tabular}{l|c}
\hline \multicolumn{1}{c}{ Crash Severity Level } & Locally-Derived Values \\
\hline Fatal & 3.0 \\
\hline Incapacitating Injury & 9.3 \\
\hline Non-incapacitating Injury & 25.6 \\
\hline Possible Injury & 17.1 \\
\hline Total Fatal Plus Injury & 54.9 \\
\hline Property Damage Only & 45.1 \\
\hline \hline TOTAL & 100.0 \\
\hline
\end{tabular}


Table B.8: 2006 R2 Locally-Derived Collision Types

\begin{tabular}{l|c|c|c}
\hline \multirow{2}{*}{ Collision Type } & \multicolumn{3}{c}{ Locally-Derived Values } \\
\cline { 2 - 4 } & $\begin{array}{c}\text { Total fatal and } \\
\text { injury }\end{array}$ & Property damage only & $\begin{array}{c}\text { TOTAL (all severity } \\
\text { levels combined) }\end{array}$ \\
\hline \multicolumn{4}{c}{ SINGLE-VEHICLE CRASHES } \\
\hline Collision with animal & 2.5 & 13.7 & 7.6 \\
\hline Collision with bicycle & 0.7 & 0.0 & 0.4 \\
\hline Collision with pedestrian & 1.0 & 0.0 & 0.5 \\
\hline Overturned & 8.4 & 5.1 & 6.9 \\
\hline Run-off-road & 50.5 & 39.5 & 45.6 \\
\hline Other single-vehicle crash & 2.3 & 1.0 & 1.7 \\
\hline Total single-vehicle crashes & 65.4 & 59.4 & 62.7 \\
\hline & MULTIPLE-VEHICLE CRASHES & 0.6 \\
\hline Angle collision & 0.7 & 0.4 & 3.1 \\
\hline Head-on collision & 5.0 & 0.7 & 19.1 \\
\hline Rear-end collision & 17.8 & 20.6 & 4.9 \\
\hline Sideswipe collision & 4.2 & 5.7 & 3.7 \\
\hline Other multiple-vehicle collision & 6.8 & 13.2 & 100.0 \\
\hline Total multiple-vehicle crashes & 34.6 & 40.6 & \\
\hline \hline
\end{tabular}

Table B.9: 2006 R2 Locally-Derived Values for Nighttime Crashes

Locally-Derived Values

\begin{tabular}{c|c|c}
\hline \multicolumn{2}{c|}{ Proportion of total nighttime crashes by severity level } & Proportion of crashes that occur at night \\
\hline Fatal and Injury $\mathbf{p}_{\mathrm{inr}}$ & PDO $\mathbf{p}_{\mathrm{pnr}}$ & $\mathbf{p}_{\mathbf{n r}}$ \\
\hline 0.54 & 0.46 & 0.29 \\
\hline
\end{tabular}

Table B.10: 2004 -2006 (Three years) R2 Locally-Derived Crash Severity Values

\begin{tabular}{l|c}
\hline Crash Severity Level & Locally-Derived Values \\
\hline Fatal & 3.1 \\
\hline Incapacitating Injury & 7.7 \\
\hline Non-incapacitating Injury & 25.1 \\
\hline Possible Injury & 18.0 \\
\hline Total Fatal Plus Injury & 54.0 \\
\hline Property Damage Only & 46.0 \\
\hline TOTAL & 100.0 \\
\hline
\end{tabular}


Table B.11: 2004-2006 (Three years) R2 Locally-Derived Collision Types

\begin{tabular}{|c|c|c|c|}
\hline \multirow[b]{2}{*}{ Collision Type } & \multicolumn{3}{|c|}{ Locally-Derived Values } \\
\hline & $\begin{array}{c}\text { Total fatal and } \\
\text { injury }\end{array}$ & $\begin{array}{c}\text { Property damage } \\
\text { only }\end{array}$ & $\begin{array}{l}\text { TOTAL (all severity } \\
\text { levels combined) }\end{array}$ \\
\hline \multicolumn{4}{|c|}{ SINGLE-VEHICLE CRASHES } \\
\hline Collision with animal & 3.1 & 12.0 & 7.2 \\
\hline Collision with bicycle & 0.6 & 0.0 & 0.3 \\
\hline Collision with pedestrian & 0.8 & 0.0 & 0.4 \\
\hline Overturned & 8.6 & 3.8 & 6.4 \\
\hline Run-off-road & 47.1 & 39.1 & 43.5 \\
\hline Other single-vehicle crash & 1.7 & 1.3 & 1.5 \\
\hline Total single-vehicle crashes & 62.0 & 56.2 & 59.3 \\
\hline \multicolumn{4}{|c|}{ MULTIPLE-VEHICLE CRASHES } \\
\hline Angle collision & 0.8 & 0.7 & 0.8 \\
\hline Head-on collision & 5.8 & 1.0 & 3.6 \\
\hline Rear-end collision & 18.8 & 21.4 & 20.0 \\
\hline Sideswipe collision & 4.4 & 7.1 & 5.6 \\
\hline Other multiple-vehicle collision & 8.2 & 13.5 & 10.6 \\
\hline Total multiple-vehicle crashes & 38.0 & 43.8 & 40.7 \\
\hline TOTAL CRASHES & 100.0 & 100.0 & 100.0 \\
\hline
\end{tabular}

Table B.12: 2004-2006 (Three Years) R2 Locally-Derived Values for Nighttime Crashes

\begin{tabular}{|c|c|c|}
\hline \multicolumn{3}{|c|}{ Locally-Derived Values } \\
\hline Proportion of total nig & s by severity level & Proportion of crashes that occur at night \\
\hline Fatal and Injury $p_{\text {inr }}$ & PDO $p_{p n r}$ & $\mathbf{p}_{\mathrm{nr}}$ \\
\hline 0.54 & 0.46 & 0.28 \\
\hline
\end{tabular}




\section{RURAL TWO-LANE, TWO-WAY INTERSECTIONS LOCALLY- DERIVED VALUES}

Table B.13: 2004 R3ST, R4ST, and R4SG Locally-Derived Crash Severity Values

\begin{tabular}{l|c|c|c}
\hline \multirow{2}{*}{\multicolumn{1}{c}{ Collision Type }} & \multicolumn{2}{c}{ Locally-Derived Values } \\
\cline { 2 - 4 } & R3ST & R4ST & R4SG \\
\hline Fatal & 2.1 & 2.0 & 0.0 \\
\hline Incapacitating injury & 4.6 & 6.7 & 2.6 \\
\hline Non-incapacitating injury & 21.0 & 19.0 & 20.5 \\
\hline Possible injury & 23.5 & 21.0 & 32.8 \\
\hline Total fatal plus injury & 51.2 & 48.7 & 64.1 \\
\hline Property damage only & 48.8 & 51.3 & 100.0 \\
\hline \hline TOTAL & 100.0 & 100.0 & \\
\hline
\end{tabular}

Table B.14: 2004 R3ST, R4ST, and R4SG Locally-Derived Collision Type

\begin{tabular}{|c|c|c|c|c|c|c|c|c|c|}
\hline \multicolumn{10}{|c|}{ Percentage of severity and total crashes by collision type (Locally-Derived Values) } \\
\hline \multirow[b]{2}{*}{ Collision Type } & \multicolumn{3}{|c|}{$\begin{array}{c}\text { Three-leg stop-controlled } \\
\text { intersections }\end{array}$} & \multicolumn{3}{|c|}{$\begin{array}{l}\text { Four-leg stop-controlled } \\
\text { intersections }\end{array}$} & \multicolumn{3}{|c|}{$\begin{array}{c}\text { Four-leg signalized } \\
\text { intersections }\end{array}$} \\
\hline & $\begin{array}{c}\text { Fatal } \\
\text { and } \\
\text { Injury }\end{array}$ & \begin{tabular}{|c|} 
Property \\
damage \\
only
\end{tabular} & Total & $\begin{array}{c}\text { Fatal } \\
\text { and } \\
\text { injury }\end{array}$ & \begin{tabular}{|c} 
Property \\
damage \\
only
\end{tabular} & Total & $\begin{array}{c}\text { Fatal } \\
\text { and } \\
\text { injury }\end{array}$ & \begin{tabular}{|c|} 
Property \\
damage \\
only
\end{tabular} & Total \\
\hline \multicolumn{10}{|c|}{ SINGLE-VEHICLE CRASHES } \\
\hline Collision with animal & 0.0 & 0.0 & 0.0 & 0.0 & 0.8 & 0.4 & 0.0 & 0.0 & 0.0 \\
\hline Collision with bicycle & 0.8 & 0.0 & 0.4 & 2.4 & 0.0 & 1.2 & 0.0 & 0.0 & 0.0 \\
\hline Collision with pedestrian & 0.0 & 0.0 & 0.0 & 1.6 & 0.0 & 0.8 & 0.0 & 0.0 & 0.0 \\
\hline Overturned & 3.3 & 0.9 & 2.1 & 0.8 & 0.0 & 0.4 & 0.0 & 0.0 & 0.0 \\
\hline Run-off-road & 12.3 & 12.9 & 12.6 & 3.3 & 3.9 & 3.6 & 0.0 & 0.0 & 0.0 \\
\hline Other single-vehicle crash & 0.0 & 0.0 & 0.0 & 0.8 & 0.0 & 0.4 & 0.0 & 0.0 & 0.0 \\
\hline Total single-vehicle crashes & 16.4 & 13.8 & 15.1 & 8.9 & 4.7 & 6.7 & 0.0 & 0.0 & 0.0 \\
\hline \multicolumn{10}{|c|}{ MULTIPLE-VEHICLE CRASHES } \\
\hline Angle collision & 4.1 & 10.3 & 7.1 & 42.3 & 34.9 & 38.5 & 21.4 & 24.0 & 23.1 \\
\hline Head-on collision & 2.5 & 0.0 & 1.3 & 0.0 & 0.0 & 0.0 & 0.0 & 0.0 & 0.0 \\
\hline Rear-end collision & 36.9 & 35.3 & 36.1 & 22.0 & 14.7 & 18.3 & 50.0 & 44.0 & 46.2 \\
\hline Sideswipe collision & 1.6 & 0.9 & 1.3 & 0.0 & 0.0 & 0.0 & 0.0 & 0.0 & 0.0 \\
\hline $\begin{array}{l}\text { Other multiple-vehicle } \\
\text { collision }\end{array}$ & 38.5 & 39.7 & 39.1 & 26.8 & 45.7 & 36.5 & 28.6 & 32.0 & 30.8 \\
\hline Total multiple-vehicle crashes & 83.6 & 86.2 & 84.9 & 91.1 & 95.3 & 93.3 & 100.0 & 100.0 & 100.0 \\
\hline TOTAL CRASHES & 100.0 & 100.0 & 100.0 & 100.0 & 100.0 & 100.0 & 100.0 & 100.0 & 100.0 \\
\hline
\end{tabular}

Table B.15: 2004 R3ST, R4ST, and R4SG Locally-Derived Values for Nighttime Crashes

\begin{tabular}{c|c}
\hline \multicolumn{2}{c}{ Proportion of crashes that occur at night, $\mathbf{p}_{\mathbf{n i}}$} \\
\hline Intersection Type & Locally-Derived Values \\
\hline 3ST & 0.189 \\
\hline 4ST & 0.143 \\
\hline 4SG & 0.103 \\
\hline
\end{tabular}


Table B.16: 2005 R3ST, R4ST, and R4SG Locally-Derived Crash Severity Values

\begin{tabular}{l|c|c|c}
\hline \multirow{2}{*}{ Collision type } & \multicolumn{3}{|c}{ Locally-Derived Values } \\
\cline { 2 - 4 } & R3ST & R4ST & R4SG \\
\hline Fatal & 0.9 & 0.9 & 2.6 \\
\hline Incapacitating injury & 4.1 & 7.1 & 0.0 \\
\hline Non-incapacitating injury & 20.5 & 20.4 & 28.7 \\
\hline Possible injury & 26.5 & 24.8 & 38.5 \\
\hline Total fatal plus injury & 52.1 & 53.1 & 61.5 \\
\hline Property damage only & 47.9 & 46.9 & 100.0 \\
\hline TOTAL & 100.0 & 100.0 & \\
\hline
\end{tabular}

Table B.17: 2005 R3ST, R4ST, and R4SG Locally-Derived Collision Type Percentage of total crashes by collision type (Locally-Derived Values)

\begin{tabular}{l|c|c|c|c|c|c|c|c|c|c}
\hline \multirow{2}{*}{ Collision Type } & $\begin{array}{c}\text { Three-leg stop-controlled } \\
\text { intersections }\end{array}$ & \multicolumn{2}{c}{$\begin{array}{c}\text { Four-leg stop-controlled } \\
\text { intersections }\end{array}$} & \multicolumn{2}{c}{$\begin{array}{c}\text { Four-leg signalized } \\
\text { intersections }\end{array}$} \\
\cline { 2 - 13 } & $\begin{array}{c}\text { Fatal } \\
\text { and } \\
\text { Injury }\end{array}$ & $\begin{array}{c}\text { Property } \\
\text { damage } \\
\text { only }\end{array}$ & Total & $\begin{array}{c}\text { Fatal } \\
\text { and } \\
\text { injury }\end{array}$ & $\begin{array}{c}\text { Property } \\
\text { damage } \\
\text { only }\end{array}$ & Total & $\begin{array}{c}\text { Fatal } \\
\text { and } \\
\text { injury }\end{array}$ & $\begin{array}{c}\text { Property } \\
\text { damage } \\
\text { only }\end{array}$ & Total \\
\hline \multicolumn{7}{|c|}{ SINGLE-VEHICLE CRASHES } \\
\hline Collision with animal & 0.0 & 0.0 & 0.0 & 0.0 & 0.0 & 0.0 & 0.0 & 0.0 & 0.0 \\
\hline Collision with bicycle & 0.0 & 0.0 & 0.0 & 0.8 & 0.0 & 0.4 & 5.9 & 0.0 & 2.6 \\
\hline Collision with pedestrian & 0.0 & 0.0 & 0.0 & 0.8 & 0.0 & 0.4 & 0.0 & 0.0 & 0.0 \\
\hline Overturned & 1.7 & 0.0 & 0.9 & 1.6 & 1.0 & 1.3 & 0.0 & 0.0 & 0.0 \\
\hline Run-off-road & 11.7 & 16.2 & 13.7 & 0.8 & 3.1 & 1.8 & 0.0 & 0.0 & 0.0 \\
\hline Other single-vehicle crash & 0.0 & 1.0 & 0.5 & 1.6 & 0.0 & 0.9 & 5.9 & 0.0 & 2.6 \\
\hline Total single-vehicle crashes & 13.3 & 17.2 & 15.1 & 5.5 & 4.1 & 4.9 & 11.8 & 0.0 & 5.1 \\
\hline & \multicolumn{7}{|c|}{ MULTIPLE-VEHICLE CRASHES } & & & \\
\hline Angle collision & 5.0 & 3.0 & 4.1 & 47.7 & 28.6 & 39.4 & 23.5 & 31.8 & 28.2 \\
\hline Head-on collision & 0.0 & 0.0 & 0.0 & 0.8 & 0.0 & 0.4 & 0.0 & 0.0 & 0.0 \\
\hline Rear-end collision & 32.5 & 31.3 & 32.0 & 19.5 & 17.3 & 18.6 & 35.3 & 40.9 & 38.5 \\
\hline Sideswipe collision & 1.7 & 4.0 & 2.7 & 0.8 & 0.0 & 0.4 & 0.0 & 0.0 & 0.0 \\
\hline $\begin{array}{l}\text { Other multiple-vehicle } \\
\text { collision }\end{array}$ & 47.5 & 44.4 & 46.1 & 25.8 & 50.0 & 36.3 & 29.4 & 27.3 & 28.2 \\
\hline Total multiple-vehicle crashes & 86.7 & 82.8 & 84.9 & 94.5 & 95.9 & 95.1 & 88.2 & 100.0 & 94.9 \\
\hline \hline TOTAL CRASHES & 100.0 & 100.0 & 100.0 & 100.0 & 100.0 & 100.0 & 100.0 & 100.0 & 100.0 \\
\hline
\end{tabular}

Table B.18: 2005 R3ST, R4ST, and R4SG Locally-Derived Values for Nighttime Crashes

\begin{tabular}{c|c}
\hline \multicolumn{2}{c}{ Proportion of crashes that occur at night, $\mathbf{p}_{\mathbf{n i}}$} \\
\hline Locally-Derived Values \\
\hline Intersection Type & 0.142 \\
\hline SST & 0.137 \\
\hline 4SG & 0.154 \\
\hline
\end{tabular}


Table B.19: 2006 R3ST, R4ST, and R4SG Locally-Derived Crash Severity Values

\begin{tabular}{l|c|c|c}
\hline \multirow{2}{*}{\multicolumn{1}{c|}{ Collision Type }} & \multicolumn{3}{c}{ Locally-Derived Values } \\
\cline { 2 - 4 } & R3ST & R4ST & R4SG \\
\hline Fatal & 0.9 & 1.5 & 0.0 \\
\hline Incapacitating injury & 6.4 & 6.3 & 4.4 \\
\hline Non-incapacitating injury & 22.8 & 25.4 & 13.3 \\
\hline Possible injury & 26.9 & 20.2 & 33.3 \\
\hline Total fatal plus injury & 57.1 & 53.3 & 48.1 \\
\hline Property damage only & 42.9 & 46.7 & 100.0 \\
\hline TOTAL & 100.0 & 100.0 & \\
\hline
\end{tabular}

Table B.20: 2006 R3ST, R4ST, and R4SG Locally-Derived Collision Type

Percentage of total crashes by collision type (Locally-Derived Values)

\begin{tabular}{|c|c|c|c|c|c|c|c|c|c|}
\hline \multirow[b]{2}{*}{ Collision type } & \multicolumn{3}{|c|}{$\begin{array}{c}\text { Three-leg stop-controlled } \\
\text { intersections }\end{array}$} & \multicolumn{3}{|c|}{$\begin{array}{c}\text { Four-leg stop-controlled } \\
\text { intersections }\end{array}$} & \multicolumn{3}{|c|}{$\begin{array}{l}\text { Four-leg signalized } \\
\text { intersections }\end{array}$} \\
\hline & $\begin{array}{c}\text { Fatal } \\
\text { and } \\
\text { Injury } \\
\end{array}$ & \begin{tabular}{|c|}
$\begin{array}{c}\text { Property } \\
\text { damage } \\
\text { only }\end{array}$ \\
\end{tabular} & Total & \begin{tabular}{|c|} 
Fatal \\
and \\
injury \\
\end{tabular} & \begin{tabular}{|c} 
Property \\
damage \\
only
\end{tabular} & Total & $\begin{array}{c}\text { Fatal } \\
\text { and } \\
\text { injury }\end{array}$ & \begin{tabular}{|c|}
$\begin{array}{c}\text { Property } \\
\text { damage } \\
\text { only }\end{array}$ \\
\end{tabular} & Total \\
\hline \multicolumn{10}{|c|}{ SINGLE-VEHICLE CRASHES } \\
\hline Collision with animal & 0.0 & 0.0 & 0.0 & 0.0 & 0.0 & 0.0 & 0.0 & 0.0 & 0.0 \\
\hline Collision with bicycle & 1.6 & 0.0 & 0.9 & 2.8 & 0.0 & 1.5 & 0.0 & 0.0 & 0.0 \\
\hline Collision with pedestrian & 0.8 & 0.0 & 0.5 & 2.8 & 0.0 & 1.5 & 4.3 & 0.0 & 2.2 \\
\hline Overturned & 2.4 & 2.1 & 2.3 & 1.4 & 0.8 & 1.1 & 0.0 & 0.0 & 0.0 \\
\hline Run-off-road & 10.4 & 12.8 & 11.4 & 4.8 & 10.2 & 7.4 & 0.0 & 0.0 & 0.0 \\
\hline Other single-vehicle crash & 1.6 & 1.1 & 1.4 & 0.0 & 0.0 & 0.0 & 0.0 & 0.0 & 0.0 \\
\hline Total single-vehicle crashes & 16.8 & 16.0 & 16.4 & 11.7 & 11.0 & 11.4 & 4.3 & 0.0 & 2.2 \\
\hline \multicolumn{10}{|c|}{ MULTIPLE-VEHICLE CRASHES } \\
\hline Angle collision & 4.8 & 3.2 & 4.1 & 37.2 & 22.8 & 30.5 & 30.4 & 18.2 & 24.4 \\
\hline Head-on collision & 0.8 & 0.0 & 0.5 & 1.4 & 0.8 & 1.1 & 0.0 & 0.0 & 0.0 \\
\hline Rear-end collision & 30.4 & 33.0 & 31.5 & 12.4 & 28.3 & 19.9 & 43.5 & 31.8 & 37.8 \\
\hline Sideswipe collision & 1.6 & 1.1 & 1.4 & 0.7 & 0.0 & 0.4 & 0.0 & 4.5 & 2.2 \\
\hline $\begin{array}{l}\text { Other multiple-vehicle } \\
\text { collision }\end{array}$ & 45.6 & 46.8 & 46.1 & 36.6 & 37.0 & 36.8 & 21.7 & 45.5 & 33.3 \\
\hline Total multiple-vehicle crashes & 83.2 & 84.0 & 83.6 & 88.3 & 89.0 & 88.6 & 95.7 & 100.0 & 97.8 \\
\hline TOTAL CRASHES & 100.0 & 100.0 & 100.0 & 100.0 & 100.0 & 100.0 & 100.0 & 100.0 & 100.0 \\
\hline
\end{tabular}

Table B.21: 2006 R3ST, R4ST, and R4SG Locally-Derived Values for Nighttime Crashes

\begin{tabular}{c|c}
\hline \multicolumn{2}{c}{ Proportion of crashes that occur at night, $\mathbf{p}_{\mathbf{n i}}$} \\
\hline Intersection Type & Locally-Derived Values \\
\hline 3ST & 0.215 \\
\hline 4ST & 0.228 \\
\hline 4SG & 0.133 \\
\hline
\end{tabular}


Table B.22: 2004 to 2006 (Three Years) R3ST, R4ST, and R4SG Locally-Derived Crash Severity Values

\begin{tabular}{l|c|c|c}
\hline \multirow{2}{*}{\multicolumn{1}{c|}{ Collision type }} & \multicolumn{3}{c}{ Locally-Derived Values } \\
\cline { 2 - 4 } & & & R4ST \\
\hline Fatal & 1.3 & 1.5 & R4SG \\
\hline Incapacitating injury & 5.0 & 6.7 & 0.8 \\
\hline Non-incapacitating injury & 21.4 & 21.7 & 13.8 \\
\hline Possible injury & 25.6 & 21.9 & 25.2 \\
\hline Total fatal plus injury & 53.4 & 51.7 & 42.3 \\
\hline Property damage only & 46.6 & 48.3 & 57.7 \\
\hline TOTAL & 100.0 & 100.0 & 100.0 \\
\hline
\end{tabular}

Table B.23: 2004 to 2006 (Three Years) R3ST, R4ST, and R4SG Locally-Derived Collision Type

\begin{tabular}{|c|c|c|c|c|c|c|c|c|c|}
\hline \multicolumn{10}{|c|}{ Percentage of total crashes by collision type (Locally-Derived Values) } \\
\hline \multirow[b]{2}{*}{ Collision Type } & \multicolumn{3}{|c|}{$\begin{array}{c}\text { Three-leg stop-controlled } \\
\text { intersections }\end{array}$} & \multicolumn{3}{|c|}{$\begin{array}{c}\text { Four-leg stop-controlled } \\
\text { intersections }\end{array}$} & \multicolumn{3}{|c|}{$\begin{array}{c}\text { Four-leg signalized } \\
\text { intersections }\end{array}$} \\
\hline & \begin{tabular}{|c|} 
Fatal \\
and \\
Injury
\end{tabular} & \begin{tabular}{|c}
$\begin{array}{c}\text { Property } \\
\text { damage } \\
\text { only }\end{array}$ \\
\end{tabular} & \begin{tabular}{|l|} 
Total \\
\\
\end{tabular} & $\begin{array}{c}\text { Fatal } \\
\text { and } \\
\text { injury }\end{array}$ & \begin{tabular}{|c}
$\begin{array}{c}\text { Property } \\
\text { damage } \\
\text { only }\end{array}$ \\
\end{tabular} & Total & \begin{tabular}{|c} 
Fatal \\
and \\
injury
\end{tabular} & $\begin{array}{c}\text { Property } \\
\text { damage } \\
\text { only }\end{array}$ & Total \\
\hline \multicolumn{10}{|c|}{ SINGLE-VEHICLE CRASHES } \\
\hline Collision with animal & 0.0 & 0.0 & 0.0 & 0.0 & 0.3 & 0.1 & 0.0 & 0.0 & 0.0 \\
\hline Collision with bicycle & 0.8 & 0.0 & 0.4 & 2.0 & 0.0 & 1.1 & 1.9 & 0.0 & 0.8 \\
\hline Collision with pedestrian & 0.3 & 0.0 & 0.1 & 1.8 & 0.0 & 0.9 & 1.9 & 0.0 & 0.8 \\
\hline Overturned & 2.5 & 1.0 & 1.8 & 1.3 & 0.6 & 0.9 & 0.0 & 0.0 & 0.0 \\
\hline Run-off-road & 11.4 & 13.9 & 12.6 & 3.0 & 5.9 & 4.4 & 0.0 & 0.0 & 0.0 \\
\hline Other single-vehicle crash & 0.5 & 0.6 & 0.6 & 0.8 & 0.0 & 0.4 & 1.9 & 0.0 & 0.8 \\
\hline Total single-vehicle crashes & 15.5 & 15.5 & 15.5 & 8.8 & 6.8 & 7.9 & 5.6 & 0.0 & 2.4 \\
\hline \multicolumn{10}{|c|}{ MULTIPLE-VEHICLE CRASHES } \\
\hline Angle collision & 4.6 & 5.8 & 5.2 & 42.2 & 28.8 & 35.9 & 25.9 & 24.6 & 25.2 \\
\hline Head-on collision & 1.1 & 0.0 & 0.6 & 0.8 & 0.3 & 0.5 & 0.0 & 0.0 & 0.0 \\
\hline Rear-end collision & 33.2 & 33.3 & 33.3 & 17.7 & 20.3 & 18.9 & 42.6 & 39.1 & 40.7 \\
\hline Sideswipe collision & 1.6 & 1.9 & 1.8 & 0.5 & 0.0 & 0.3 & 0.0 & 1.4 & 0.8 \\
\hline Other multiple-vehicle collision & 43.9 & 43.4 & 43.6 & 30.1 & 43.8 & 36.5 & 25.9 & 34.8 & 30.9 \\
\hline Total multiple-vehicle crashes & 84.5 & 84.5 & 84.5 & 91.2 & 93.2 & 92.1 & 94.4 & 100.0 & 97.6 \\
\hline TOTAL CRASHES & 100.0 & 100.0 & 100.0 & 100.0 & 100.0 & 100.0 & 100.0 & 100.0 & 100.0 \\
\hline
\end{tabular}

Table B.24: 2004 to 2006 (Three Year) R3ST, R4ST, and R4SG Locally-Derived Values for Nighttime Crashes

\begin{tabular}{c|c}
\hline \multicolumn{2}{c}{ Proportion of crashes that occur at night, $\mathbf{p}_{\mathbf{n i}}$} \\
\hline Intersection Type & Locally-Derived Values \\
\hline 3ST & 0.182 \\
\hline 4ST & 0.172 \\
\hline 4SG & 0.130 \\
\hline
\end{tabular}




\section{RURAL MULTILANE SEGMENT LOCALLY-DERIVED VALUES}

Table B.25: 2004 MRU Locally-Derived Crash Severity Values

\begin{tabular}{|c|c|c|c|c|}
\hline \multirow[b]{2}{*}{ Collision Type } & \multicolumn{4}{|c|}{ Locally-Derived Values } \\
\hline & Total & Fatal and injury & Fatal and injury & PDO \\
\hline Head-on & 0.036 & 0.056 & 0.074 & 0.019 \\
\hline Sideswipe & 0.183 & 0.132 & 0.173 & 0.228 \\
\hline Rear-end & 0.359 & 0.368 & 0.185 & 0.352 \\
\hline Angle & 0.010 & 0.007 & 0.012 & 0.012 \\
\hline Single & 0.294 & 0.319 & 0.370 & 0.272 \\
\hline Other & 0.118 & 0.118 & 0.185 & 0.117 \\
\hline Single Vehicle run-off-road, Head-on, Sideswipe & 0.399 & & & \\
\hline
\end{tabular}

Table B.26: 2004 MRU Locally-Derived Values for Nighttime Crashes

$$
\text { Locally-Derived Values }
$$

Proportion of total night-time crashes by severity level

Fatal and injury, $\mathrm{p}_{\text {inr }}$

0.571
PDO, $\mathrm{p}_{\mathrm{pnr}}$

Proportion of crashes that occur at night

$\mathrm{p}_{\mathrm{nr}}$

0.206

Table B.27: 2004 MRD Locally-Derived Crash Severity Values

\begin{tabular}{|c|c|c|c|c|}
\hline \multirow[b]{2}{*}{ Collision Type } & \multicolumn{4}{|c|}{ Locally-Derived Values } \\
\hline & Total & $\begin{array}{l}\text { Fatal and } \\
\text { injury }\end{array}$ & $\begin{array}{c}\text { Fatal and } \\
\text { injury }^{\text {a }}\end{array}$ & PDO \\
\hline Head-on & 0.055 & 0.067 & 0.067 & 0.047 \\
\hline Sideswipe & 0.123 & 0.100 & 0.133 & 0.140 \\
\hline Rear-end & 0.356 & 0.333 & 0.133 & 0.372 \\
\hline Angle & 0.000 & 0.000 & 0.000 & 0.000 \\
\hline Single & 0.411 & 0.467 & 0.600 & 0.372 \\
\hline Other & 0.055 & 0.033 & 0.067 & 0.070 \\
\hline Single Vehicle run-off-road, Head-on, Sideswipe & 0.493 & & & \\
\hline
\end{tabular}

Table B.28: 2004 MRD Locally-Derived Values for Nighttime Crashes

Locally-Derived Values

\begin{tabular}{c|c|c}
\hline \multicolumn{2}{c|}{ Proportion of total night-time crashes by severity level } & Proportion of crashes that occur at night \\
\hline Fatal and injury, $\mathrm{p}_{\mathrm{inr}}$ & PDO, $\mathrm{p}_{\mathrm{pnr}}$ & $\mathrm{p}_{\mathrm{nr}}$ \\
\hline 0.550 & 0.450 & 0.274 \\
\hline
\end{tabular}


Table B.29: 2005 MRU Locally-Derived Crash Severity Values

\begin{tabular}{|c|c|c|c|c|}
\hline \multirow[b]{2}{*}{ Collision Type } & \multicolumn{4}{|c|}{ Locally-Derived Values } \\
\hline & Total & Fatal and Injury & Fatal and Injury & PDO \\
\hline Head-on & 0.049 & 0.092 & 0.155 & 0.012 \\
\hline Sideswipe & 0.146 & 0.096 & 0.100 & 0.188 \\
\hline Rear-end & 0.329 & 0.367 & 0.200 & 0.297 \\
\hline Angle & 0.019 & 0.028 & 0.036 & 0.012 \\
\hline Single & 0.344 & 0.339 & 0.436 & 0.348 \\
\hline Other & 0.114 & 0.078 & 0.073 & 0.145 \\
\hline Single Vehicle run-off-road, Head-on, Sideswipe & 0.435 & & & \\
\hline
\end{tabular}

Table B.30: 2005 MRU Locally-Derived Values for Nighttime Crashes

\section{Locally-Derived Values}

\begin{tabular}{c|c|c} 
Proportion of total night-time crashes by severity level & Proportion of crashes that occur at night \\
\hline Fatal and injury, $\mathrm{p}_{\mathrm{inr}}$ & $\mathrm{PDO}, \mathrm{p}_{\mathrm{pnr}}$ & $\mathrm{p}_{\mathrm{nr}}$ \\
\hline 0.518 & 0.482 & 0.241 \\
\hline
\end{tabular}

Table B.31: 2005 MRD Locally-Derived Crash Severity Values

\begin{tabular}{|c|c|c|c|c|}
\hline \multirow[b]{2}{*}{ Collision Type } & \multicolumn{4}{|c|}{ Locally-Derived Values } \\
\hline & Total & Fatal and injury & Fatal and injury ${ }^{\mathrm{a}}$ & $\mathrm{PDO}$ \\
\hline Head-on & 0.000 & 0.000 & 0.000 & 0.000 \\
\hline Sideswipe & 0.206 & 0.080 & 0.091 & 0.289 \\
\hline Rear-end & 0.397 & 0.440 & 0.455 & 0.368 \\
\hline Angle & 0.000 & 0.000 & 0.000 & 0.000 \\
\hline Single & 0.365 & 0.480 & 0.455 & 0.289 \\
\hline Other & 0.032 & 0.000 & 0.000 & 0.053 \\
\hline Single Vehicle run-off-road, Head-on, Sideswipe & 0.492 & & & \\
\hline
\end{tabular}

Table B.32: 2005 MRD Locally-Derived Values for Nighttime Crashes

\begin{tabular}{c|c|c}
\hline \multicolumn{3}{c}{ Locally-Derived Values } \\
\hline \multicolumn{2}{c}{ Proportion of total night-time crashes by severity level } & Proportion of crashes that occur at night \\
\hline Fatal and injury, $\mathrm{p}_{\mathrm{inr}}$ & $\mathrm{PDO}, \mathrm{p}_{\mathrm{pnr}}$ & $\mathrm{p}_{\mathrm{nr}}$ \\
\hline 0.389 & 0.611 & 0.286 \\
\hline
\end{tabular}


Table B.33: 2006 MRU Locally-Derived Crash Severity Values

\begin{tabular}{|c|c|c|c|c|}
\hline \multirow[b]{2}{*}{ Collision Type } & \multicolumn{4}{|c|}{ Locally-Derived Values } \\
\hline & Total & Fatal and injury & Fatal and injury ${ }^{a}$ & PDO \\
\hline Head-on & 0.040 & 0.083 & 0.118 & 0.012 \\
\hline Sideswipe & 0.148 & 0.101 & 0.097 & 0.178 \\
\hline Rear-end & 0.305 & 0.339 & 0.194 & 0.283 \\
\hline Angle & 0.014 & 0.024 & 0.032 & 0.008 \\
\hline Single & 0.390 & 0.375 & 0.473 & 0.399 \\
\hline Other & 0.103 & 0.077 & 0.086 & 0.120 \\
\hline Single Vehicle run-off-road, Head-on, Sideswipe & 0.458 & & & \\
\hline
\end{tabular}

Table B.34: 2006 MRU Locally-Derived Values for Nighttime Crashes

\section{Locally-Derived Values}

\begin{tabular}{c|c|c} 
Proportion of total night-time crashes by severity level & Proportion of crashes that occur at night \\
\hline Fatal and injury, $\mathrm{p}_{\mathrm{inr}}$ & $\mathrm{PDO}, \mathrm{p}_{\mathrm{pnr}}$ & $\mathrm{p}_{\mathrm{nr}}$ \\
\hline 0.357 & 0.643 & 0.263 \\
\hline
\end{tabular}

Table B.35: 2006 MRD Locally-Derived Crash Severity Values

\begin{tabular}{|c|c|c|c|c|}
\hline \multirow[b]{2}{*}{ Collision type } & \multicolumn{4}{|c|}{ Locally-Derived Values } \\
\hline & Total & Fatal and injury & Fatal and injury ${ }^{a}$ & PDO \\
\hline Head-on & 0.021 & 0.059 & 0.067 & 0.000 \\
\hline Sideswipe & 0.128 & 0.000 & 0.000 & 0.200 \\
\hline Rear-end & 0.170 & 0.235 & 0.200 & 0.133 \\
\hline Angle & 0.021 & 0.059 & 0.067 & 0.000 \\
\hline Single & 0.574 & 0.588 & 0.600 & 0.567 \\
\hline Other & 0.085 & 0.059 & 0.067 & 0.100 \\
\hline Single Vehicle run-off-road, Head-on, Sideswipe & 0.574 & & & \\
\hline
\end{tabular}

Table B.36: 2006 MRD Locally-Derived Values for Nighttime Crashes

\begin{tabular}{|c|c|c|}
\hline \multicolumn{3}{|c|}{ Locally-Derived Values } \\
\hline \multicolumn{2}{|c|}{ Proportion of total night-time crashes by severity level } & \multirow{2}{*}{$\begin{array}{c}\text { Proportion of crashes that occur at night } \\
\mathrm{p}_{\mathrm{nr}}\end{array}$} \\
\hline Fatal and injury, $\mathrm{p}_{\text {inr }}$ & $\mathrm{PDO}, \mathrm{p}_{\mathrm{pnr}}$ & \\
\hline 0.412 & 0.588 & 0.362 \\
\hline
\end{tabular}


Table B.37: 2004 to 2006 (Three Years) MRU Locally-Derived Crash Severity Values

\begin{tabular}{|c|c|c|c|c|}
\hline \multirow[b]{2}{*}{ Collision Type } & \multicolumn{4}{|c|}{ Locally-Derived Values } \\
\hline & Total & Fatal and injury & Fatal and injury ${ }^{a}$ & PDO \\
\hline Head-on & 0.040 & 0.083 & 0.118 & 0.012 \\
\hline Sideswipe & 0.148 & 0.101 & 0.097 & 0.178 \\
\hline Rear-end & 0.305 & 0.339 & 0.194 & 0.283 \\
\hline Angle & 0.014 & 0.024 & 0.032 & 0.008 \\
\hline Single & 0.390 & 0.375 & 0.473 & 0.399 \\
\hline Other & 0.103 & 0.077 & 0.086 & 0.120 \\
\hline Single Vehicle run-off-road, Head-on, Sideswipe & 0.458 & & & \\
\hline
\end{tabular}

Table B.38: 2004 to 2006 (Three Years) MRU Locally-Derived Values for Nighttime Crashes Locally-Derived Values

Proportion of total night-time crashes by severity level

Proportion of crashes that occur at night

\begin{tabular}{c|c|c}
\hline Fatal and injury, $\mathrm{p}_{\mathrm{inr}}$ & PDO, $\mathrm{p}_{\mathrm{pnr}}$ & $\mathrm{p}_{\mathrm{nr}}$ \\
\hline 0.357 & 0.643 & 0.263 \\
\hline
\end{tabular}

Table B.39: 2004 to 2006 (Three Years) MRD Locally-Derived Crash Severity Values

\begin{tabular}{|c|c|c|c|c|}
\hline \multirow[b]{2}{*}{ Collision type } & \multicolumn{4}{|c|}{ Locally-Derived Values } \\
\hline & Total & Fatal and injury & Fatal and injury ${ }^{a}$ & PDO \\
\hline Head-on & 0.027 & 0.042 & 0.049 & 0.018 \\
\hline Sideswipe & 0.153 & 0.069 & 0.073 & 0.207 \\
\hline Rear-end & 0.322 & 0.347 & 0.244 & 0.306 \\
\hline Angle & 0.005 & 0.014 & 0.024 & 0.000 \\
\hline Single & 0.437 & 0.500 & 0.561 & 0.396 \\
\hline Other & 0.055 & 0.028 & 0.049 & 0.072 \\
\hline Single Vehicle run-off-road, Head-on, Sideswipe & 0.514 & & & \\
\hline
\end{tabular}

Table B.40: 2004 to 2006 (Three Years) MRD Locally-Derived Values for Nighttime Crashes

\begin{tabular}{c|c|c}
\hline \multicolumn{2}{|c}{ Locally-Derived Values } \\
\hline \multicolumn{2}{l}{ Proportion of total night-time crashes by severity level } & Proportion of crashes that occur at night \\
\hline Fatal and injury, $\mathrm{p}_{\mathrm{inr}}$ & PDO, $\mathrm{p}_{\mathrm{pnr}}$ & $\mathrm{p}_{\mathrm{nr}}$ \\
\hline 0.455 & 0.545 & 0.301 \\
\hline
\end{tabular}




\section{RURAL MULTILANE INTERSECTIONS LOCALLY-DERIVED VALUES}

Table B.41: 2004 MR3ST Locally-Derived Crash Severity Values

Collision Type

\begin{tabular}{|c|c|c|c|}
\hline \multicolumn{4}{|c|}{ Locally-Derived Values } \\
\hline Total & Fatal and injury & Fatal and injury & \\
PDO
\end{tabular}

Three-leg intersections with minor road stop control

\begin{tabular}{l|c|c|c|c}
\hline Head-on & 0.009 & 0.008 & 0.014 & 0.011 \\
\hline Sideswipe & 0.005 & 0.000 & 0.000 & 0.011 \\
\hline Rear-end & 0.269 & 0.320 & 0.155 & 0.202 \\
\hline Angle & 0.041 & 0.064 & 0.099 & 0.011 \\
\hline Single & 0.137 & 0.152 & 0.183 & 0.117 \\
\hline Other & 0.539 & 0.456 & 0.549 & 0.649 \\
\hline Single Vehicle run-off-road, Head-on, Sideswipe & 0.114 & & & \\
\hline
\end{tabular}

Table B.42: 2004 MR4ST Locally-Derived Collision Type

\begin{tabular}{|c|c|c|c|c|}
\hline \multirow[b]{2}{*}{ Collision Type } & \multicolumn{4}{|c|}{ Locally-Derived Values } \\
\hline & Total & Fatal and injury & Fatal and injury ${ }^{a}$ & PDO \\
\hline \multicolumn{5}{|c|}{ Four-leg intersections with minor road stop control } \\
\hline Head-on & 0.005 & 0.009 & 0.014 & 0.000 \\
\hline Sideswipe & 0.005 & 0.000 & 0.000 & 0.011 \\
\hline Rear-end & 0.156 & 0.159 & 0.086 & 0.152 \\
\hline Angle & 0.405 & 0.469 & 0.529 & 0.326 \\
\hline Single & 0.054 & 0.018 & 0.014 & 0.098 \\
\hline Other & 0.376 & 0.345 & 0.357 & 0.413 \\
\hline Single Vehicle run-off-road, Head-on, Sideswipe & 0.059 & & & \\
\hline
\end{tabular}

Table B.43: 2004 MR3ST and MR4ST Locally-Derived Values for Nighttime Crashes

\begin{tabular}{c|c|c|c}
\hline \multirow{2}{*}{ Roadway Type } & \multicolumn{2}{|c}{ Locally-Derived Values } \\
\cline { 2 - 4 } & \multicolumn{2}{|c}{$\begin{array}{c}\text { Proportion of total night-time } \\
\text { crashes by severity level }\end{array}$} & $\begin{array}{c}\text { Proportion of crashes that } \\
\text { occur at night }\end{array}$ \\
\hline & Fatal and & PDO, $\mathrm{p}_{\mathrm{pnr}}$ & $\mathrm{p}_{\mathrm{nr}}$ \\
\hline injury, $\mathrm{p}_{\mathrm{inr}}$ & 0.515 & 0.485 & 0.151 \\
\hline 4ST & 0.553 & 0.447 & 0.174 \\
\hline
\end{tabular}


Table B.44: 2005 MR3ST Locally-Derived Crash Severity Values

\begin{tabular}{|c|c|c|c|c|}
\hline \multirow[b]{2}{*}{ Collision Type } & \multicolumn{4}{|c|}{ Locally-Derived Values } \\
\hline & Total & Fatal and injury & Fatal and injury ${ }^{a}$ & PDO \\
\hline \multicolumn{5}{|c|}{ Three-leg intersections with minor road stop control } \\
\hline Head-on & 0.012 & 0.020 & 0.031 & 0.000 \\
\hline Sideswipe & 0.006 & 0.010 & 0.000 & 0.000 \\
\hline Rear-end & 0.193 & 0.192 & 0.109 & 0.189 \\
\hline Angle & 0.064 & 0.121 & 0.125 & 0.014 \\
\hline Single & 0.105 & 0.101 & 0.109 & 0.108 \\
\hline Other & 0.620 & 0.556 & 0.625 & 0.689 \\
\hline Single Vehicle run-off-road, Head-on, Sideswipe & 0.094 & & & \\
\hline
\end{tabular}

Table B.45: 2005 MR4ST Locally-Derived Collision Type

\begin{tabular}{|c|c|c|c|c|}
\hline \multirow[b]{2}{*}{ Collision Type } & \multicolumn{4}{|c|}{ Locally-Derived Values } \\
\hline & Total & Fatal and injury & Fatal and injury ${ }^{a}$ & $\mathrm{PDO}$ \\
\hline \multicolumn{5}{|c|}{ Four-leg intersections with minor road stop control } \\
\hline Head-on & 0.010 & 0.016 & 0.025 & 0.000 \\
\hline Sideswipe & 0.010 & 0.000 & 0.000 & 0.024 \\
\hline Rear-end & 0.124 & 0.128 & 0.074 & 0.119 \\
\hline Angle & 0.411 & 0.440 & 0.457 & 0.369 \\
\hline Single & 0.043 & 0.056 & 0.049 & 0.024 \\
\hline Other & 0.402 & 0.360 & 0.395 & 0.464 \\
\hline Single Vehicle run-off-road, Head-on, Sideswipe & 0.038 & & & \\
\hline
\end{tabular}

Table B.46: 2005 MR3ST and MR4ST Locally-Derived Values for Nighttime Crashes

\begin{tabular}{c|c|c|c}
\hline \multirow{2}{*}{ Roadway Type } & \multicolumn{2}{|c}{ Locally-Derived Values } \\
\cline { 2 - 4 } & $\begin{array}{c}\text { Proportion of total night-time } \\
\text { crashes by severity level }\end{array}$ & $\begin{array}{c}\text { Proportion of crashes that } \\
\text { occur at night }\end{array}$ \\
\hline & $\begin{array}{c}\text { Fatal and } \\
\text { injury, } \mathrm{p}_{\mathrm{inr}}\end{array}$ & PDO, $\mathrm{p}_{\mathrm{pnr}}$ & $\mathrm{p}_{\mathrm{nr}}$ \\
\hline 3ST & 0.615 & 0.385 & 0.152 \\
\hline 4ST & 0.538 & 0.462 & 0.152 \\
\hline
\end{tabular}


Table B.47: 2006 MR3ST Locally-Derived Crash Severity Values

\begin{tabular}{|c|c|c|c|c|}
\hline \multirow[b]{2}{*}{ Collision Type } & \multicolumn{4}{|c|}{ Locally-Derived Values } \\
\hline & Total & Fatal and injury & Fatal and injury ${ }^{\mathrm{a}}$ & PDO \\
\hline \multicolumn{5}{|c|}{ Three-leg intersections with minor road stop control } \\
\hline Head-on & 0.000 & 0.000 & 0.000 & 0.000 \\
\hline Sideswipe & 0.021 & 0.017 & 0.027 & 0.028 \\
\hline Rear-end & 0.265 & 0.265 & 0.227 & 0.264 \\
\hline Angle & 0.032 & 0.034 & 0.013 & 0.028 \\
\hline Single & 0.111 & 0.094 & 0.093 & 0.139 \\
\hline Other & 0.571 & 0.590 & 0.640 & 0.542 \\
\hline Single Vehicle run-off-road, Head-on, Sideswipe & 0.090 & & & \\
\hline
\end{tabular}

Table B.48: 2006 MR4ST Locally-Derived Collision Type

\begin{tabular}{|c|c|c|c|c|}
\hline \multirow[b]{2}{*}{ Collision Type } & \multicolumn{4}{|c|}{ Locally-Derived Values } \\
\hline & Total & Fatal and injury & Fatal and injury ${ }^{\mathrm{a}}$ & $\mathrm{PDO}$ \\
\hline \multicolumn{5}{|c|}{ Four-leg intersections with minor road stop control } \\
\hline Head-on & 0.000 & 0.000 & 0.000 & 0.000 \\
\hline Sideswipe & 0.013 & 0.016 & 0.014 & 0.010 \\
\hline Rear-end & 0.166 & 0.168 & 0.100 & 0.163 \\
\hline Angle & 0.327 & 0.376 & 0.414 & 0.265 \\
\hline Single & 0.067 & 0.080 & 0.100 & 0.051 \\
\hline Other & 0.426 & 0.360 & 0.371 & 0.510 \\
\hline Single Vehicle run-off-road, Head-on, Sideswipe & 0.058 & & & \\
\hline
\end{tabular}

Table B.49: 2006 MR3ST and MR4ST Locally-Derived Values for Nighttime Crashes

\begin{tabular}{c|c|c|c}
\hline \multirow{2}{*}{ Roadway Type } & \multicolumn{2}{|c}{ Locally-Derived Values } \\
\cline { 2 - 4 } & \multicolumn{2}{|c}{$\begin{array}{c}\text { Proportion of total night-time } \\
\text { crashes by severity level }\end{array}$} & $\begin{array}{c}\text { Proportion of crashes that } \\
\text { occur at night }\end{array}$ \\
\hline & $\begin{array}{c}\text { Fatal and } \\
\text { injury, } \mathrm{p}_{\mathrm{inr}}\end{array}$ & PDO, $\mathrm{p}_{\mathrm{pnr}}$ & $\mathrm{p}_{\mathrm{nr}}$ \\
\hline 3ST & 0.600 & 0.400 & 0.132 \\
\hline 4ST & 0.710 & 0.290 & 0.164 \\
\hline
\end{tabular}


Table B.50: 2004 to 2006 (Three Years) MR3ST Locally-Derived Crash Severity Values

\begin{tabular}{|c|c|c|c|c|}
\hline \multirow[b]{2}{*}{ Collision Type } & \multicolumn{4}{|c|}{ Locally-Derived Values } \\
\hline & Total & Fatal and injury & Fatal and injury ${ }^{a}$ & PDO \\
\hline \multicolumn{5}{|c|}{ Three-leg intersections with minor road stop control } \\
\hline Head-on & 0.007 & 0.009 & 0.014 & 0.004 \\
\hline Sideswipe & 0.010 & 0.009 & 0.010 & 0.013 \\
\hline Rear-end & 0.245 & 0.264 & 0.167 & 0.217 \\
\hline Angle & 0.045 & 0.070 & 0.076 & 0.017 \\
\hline Single & 0.119 & 0.117 & 0.129 & 0.121 \\
\hline Other & 0.573 & 0.531 & 0.605 & 0.629 \\
\hline Single Vehicle run-off-road, Head-on, Sideswipe & 0.100 & & & \\
\hline
\end{tabular}

Table B.51: 2004 to 2006 (Three Years) MR4ST Locally-Derived Collision Type

\begin{tabular}{|c|c|c|c|c|}
\hline \multirow[b]{2}{*}{ Collision Type } & \multicolumn{4}{|c|}{ Locally-Derived Values } \\
\hline & Total & $\begin{array}{l}\text { Fatal and } \\
\text { injury }\end{array}$ & $\begin{array}{l}\text { Fatal and } \\
\text { injury }^{\mathrm{a}}\end{array}$ & $\mathrm{PDO}$ \\
\hline \multicolumn{5}{|c|}{ Four-leg intersections with minor road stop control } \\
\hline Head-on & 0.005 & 0.008 & 0.014 & 0.000 \\
\hline Sideswipe & 0.009 & 0.006 & 0.005 & 0.015 \\
\hline Rear-end & 0.149 & 0.152 & 0.086 & 0.146 \\
\hline Angle & 0.380 & 0.427 & 0.466 & 0.318 \\
\hline Single & 0.055 & 0.052 & 0.054 & 0.058 \\
\hline Other & 0.402 & 0.355 & 0.376 & 0.464 \\
\hline $\begin{array}{l}\text { Single Vehicle run-off-road, Head-on, } \\
\text { Sideswipe }\end{array}$ & 0.052 & & & \\
\hline
\end{tabular}

Table B.52: 2004 to 2006 (Three Years) MR3ST and MR4ST Locally-Derived Values for Nighttime Crashes

\begin{tabular}{c|c|c|c}
\hline \multirow{2}{*}{ Roadway Type } & \multicolumn{2}{|c}{ Locally-Derived Values } \\
\cline { 2 - 4 } & $\begin{array}{c}\text { Proportion of total night-time } \\
\text { crashes by severity level }\end{array}$ & $\begin{array}{c}\text { Proportion of crashes that } \\
\text { occur at night }\end{array}$ \\
\hline & Fatal and & PDO, $\mathrm{p}_{\mathrm{pnr}}$ & $\mathrm{p}_{\mathrm{nr}}$ \\
\hline injury, $\mathrm{p}_{\mathrm{inr}}$ & 0.571 & 0.429 & 0.145 \\
\hline 4ST & 0.600 & 0.400 & 0.164 \\
\hline
\end{tabular}




\section{URBAN SEGMENTS LOCALLY-DERIVED VALUES}

Table B.53: Distribution of Multiple-Vehicle Non-driveway Collisions for Roadway Segments by Manner of Collision Type (Urban)

\begin{tabular}{|c|c|c|c|c|c|c|c|c|c|c|}
\hline \multirow{3}{*}{ Collision type } & \multicolumn{10}{|c|}{ Locally-Derived Values } \\
\hline & \multicolumn{2}{|c|}{$2 \mathbf{U}$} & \multicolumn{2}{|c|}{$3 T$} & \multicolumn{2}{|c|}{$4 \mathbf{U}$} & \multicolumn{2}{|c|}{ 4D } & \multicolumn{2}{|c|}{$5 \mathrm{~T}$} \\
\hline & FI & PDO & FI & PDO & FI & PDO & FI & PDO & FI & PDO \\
\hline Rear-end collision & 0.709 & 0.680 & 0.818 & 0.636 & 0.658 & 0.548 & 0.783 & 0.646 & 0.606 & 0.524 \\
\hline Head-on collision & 0.029 & 0.009 & 0.016 & 0.004 & 0.029 & 0.004 & 0.006 & 0.000 & 0.018 & 0.011 \\
\hline Angle collision & 0.013 & 0.049 & 0.000 & 0.025 & 0.015 & 0.016 & 0.019 & 0.008 & 0.020 & 0.015 \\
\hline Sideswipe, same direction & 0.010 & 0.037 & 0.000 & 0.075 & 0.060 & 0.205 & 0.038 & 0.142 & 0.053 & 0.156 \\
\hline Sideswipe, opposite direction & 0.039 & 0.020 & 0.000 & 0.014 & 0.022 & 0.008 & 0.013 & 0.004 & 0.005 & 0.004 \\
\hline $\begin{array}{l}\text { Other multiple-vehicle } \\
\text { collision }\end{array}$ & 0.201 & 0.206 & 0.166 & 0.246 & 0.216 & 0.219 & 0.140 & 0.200 & 0.298 & 0.289 \\
\hline
\end{tabular}

Table B.54: Distribution of Single-Vehicle Collisions for Roadway Segments by Collision Type (Urban)

\begin{tabular}{|c|c|c|c|c|c|c|c|c|c|c|}
\hline \multirow{3}{*}{ Collision type } & \multicolumn{10}{|c|}{ Locally-Derived Values } \\
\hline & \multicolumn{2}{|c|}{$2 \mathbf{U}$} & \multicolumn{2}{|c|}{$3 \mathrm{~T}$} & \multicolumn{2}{|c|}{$4 \mathbf{U}$} & \multicolumn{2}{|c|}{ 4D } & \multicolumn{2}{|c|}{$5 T$} \\
\hline & FI & PDO & FI & PDO & FI & PDO & FI & PDO & FI & PDO \\
\hline Collision with animal & 0.027 & 0.170 & 0.040 & 0.214 & 0.037 & 0.100 & 0.000 & 0.077 & 0.005 & 0.095 \\
\hline Collision with fixed object & 0.757 & 0.736 & 0.280 & 0.786 & 0.519 & 0.825 & 0.400 & 0.846 & 0.308 & 0.798 \\
\hline Collision with other object & 0.000 & 0.038 & 0.040 & 0.000 & 0.000 & 0.075 & 0.000 & 0.000 & 0.005 & 0.036 \\
\hline $\begin{array}{l}\text { Other single-vehicle } \\
\text { collision }\end{array}$ & 0.216 & 0.057 & 0.640 & 0.000 & 0.444 & 0.000 & 0.600 & 0.077 & 0.681 & 0.071 \\
\hline
\end{tabular}

Table B.55: Crash Severity for Proportions for Multiple-Vehicle Driveway Related Collisions (Urban)

\begin{tabular}{l|c|c|c|c|c}
\hline \multirow{2}{*}{ Driveway type $(\mathbf{j})$} & \multicolumn{5}{c}{ Coefficients for specific roadway types } \\
\cline { 2 - 6 } & $\mathbf{2 U}$ & $\mathbf{3 T}$ & $\mathbf{4 U}$ & $\mathbf{4 D}$ & $\mathbf{5 T}$ \\
\hline Proportion of fatal-and-injury crashes $\left(\mathbf{f}_{\mathbf{d w y}}\right)$ \\
\hline All driveways & 0.556 & 0.467 & 0.462 & 0.778 & 0.500 \\
\hline Proportion of property-damage-only crashes \\
\hline All driveways & 0.444 & 0.533 & 0.538 & 0.222 & 0.500 \\
\hline
\end{tabular}

Table B.56: Pedestrian Crash Adjustment for Roadway Segments (Urban)

\begin{tabular}{|c|c|c|}
\hline \multirow[b]{3}{*}{$\begin{array}{l}\text { Road } \\
\text { type }\end{array}$} & \multicolumn{2}{|c|}{ Pedestrian Crash Adjustment Factor $\left(f_{\text {pedr }}\right)$} \\
\hline & \multicolumn{2}{|c|}{ Locally-Derived Values } \\
\hline & Posted Speed $30 \mathrm{mph}$ or Lower & Posted Speed Greater than $30 \mathrm{mph}$ \\
\hline $2 \mathrm{U}$ & 0.034 & 0.012 \\
\hline $3 \mathrm{~T}$ & 0.020 & 0.014 \\
\hline $4 \mathrm{U}$ & 0.016 & 0.004 \\
\hline 4D & 0.048 & 0.013 \\
\hline $5 \mathrm{~T}$ & 0.010 & 0.021 \\
\hline
\end{tabular}


Table B.57: Bicycle Crash Adjustment Factor for Roadway Segments (Urban)

\begin{tabular}{c|c|c}
\hline \multirow{2}{*}{} & \multicolumn{2}{|c}{ Bicycle Crash Adjustment Factor (fbiker) } \\
\cline { 2 - 3 } $\begin{array}{c}\text { Road } \\
\text { type }\end{array}$ & Posted Speed 30 mph or Lower & Posted Speed Greater than 30 mph \\
\hline $2 \mathrm{U}$ & 0.007 & 0.003 \\
\hline $3 \mathrm{~T}$ & 0.016 & 0.010 \\
\hline $4 \mathrm{U}$ & 0.010 & 0.010 \\
\hline $4 \mathrm{D}$ & 0.024 & 0.009 \\
\hline $5 \mathrm{~T}$ & 0.017 & 0.020 \\
\hline
\end{tabular}

Table B.58: Nighttime Crash Proportions for Unlighted Roadway Segments (Urban)

\begin{tabular}{c|c|c|c}
\hline \multirow{2}{*}{ Road Type } & \multicolumn{2}{|c|}{$\begin{array}{c}\text { Proportion of Total Nighttime } \\
\text { Crashes by Severity Level }\end{array}$} & $\begin{array}{c}\text { Proportion of } \\
\text { Crashes that Occur } \\
\text { at Night }\end{array}$ \\
\cline { 2 - 4 } & $\begin{array}{c}\text { Fatal and Injury } \\
\left(\mathbf{p}_{\text {inr }}\right)\end{array}$ & $\begin{array}{c}\text { PDO } \\
\left(\mathbf{p}_{\text {prr }}\right)\end{array}$ & $\left(\mathbf{p}_{\text {nr }}\right)$ \\
\hline $2 \mathrm{U}$ & 0.606 & 0.394 & 0.215 \\
\hline $3 \mathrm{~T}$ & 0.286 & 0.714 & 0.118 \\
\hline $4 \mathrm{U}$ & 0.385 & 0.615 & 0.234 \\
\hline $4 \mathrm{D}$ & 0.800 & 0.200 & 0.225 \\
\hline $5 \mathrm{~T}$ & 0.474 & 0.526 & 0.228 \\
\hline
\end{tabular}




\section{URBAN INTERSECTIONS LOCALLY-DERIVED VALUES}

Table B.59: Distribution of Multiple-Vehicle Collisions for Intersections by Collision Type (Urban)

\begin{tabular}{l|c|c|c|c|c|c|c|c}
\hline \multirow{2}{*}{ Collision type } & \multicolumn{7}{c}{ Locally-Derived Values } \\
\cline { 2 - 10 } & \multicolumn{2}{|c|}{ 3ST } & \multicolumn{2}{c}{ 3SG } & \multicolumn{2}{c}{ 4ST } & \multicolumn{2}{c}{ 4SG } \\
\cline { 2 - 10 } & FI & PDO & FI & PDO & FI & PDO & FI & PDO \\
\hline Rear-end collision & 0.186 & 0.181 & 0.580 & 0.530 & 0.165 & 0.135 & 0.501 & 0.402 \\
\hline Head-on collision & 0.004 & 0.000 & 0.005 & 0.000 & 0.000 & 0.000 & 0.002 & 0.000 \\
\hline Angle collision & 0.078 & 0.056 & 0.060 & 0.055 & 0.449 & 0.399 & 0.236 & 0.215 \\
\hline Sideswipe & 0.008 & 0.016 & 0.011 & 0.013 & 0.000 & 0.007 & 0.004 & 0.012 \\
\hline $\begin{array}{l}\text { Other multiple-vehicle } \\
\text { collision }\end{array}$ & 0.725 & 0.746 & 0.343 & 0.402 & 0.386 & 0.459 & 0.257 & 0.370 \\
\hline
\end{tabular}

Table B.60: Distribution of Single-Vehicle Crashes for Intersections by Collision Type (Urban)

\begin{tabular}{|c|c|c|c|c|c|c|c|c|}
\hline \multirow{3}{*}{ Collision type } & \multicolumn{8}{|c|}{ Locally-Derived Values } \\
\hline & \multicolumn{2}{|c|}{ 3ST } & \multicolumn{2}{|c|}{ 3SG } & \multicolumn{2}{|c|}{ 4ST } & \multicolumn{2}{|c|}{ 4SG } \\
\hline & FI & PDO & FI & PDO & FI & PDO & FI & PDO \\
\hline $\begin{array}{l}\text { Collision with parked } \\
\text { vehicle }\end{array}$ & 0.000 & 0.000 & 0.000 & 0.000 & 0.000 & 0.000 & 0.000 & 0.000 \\
\hline Collision with animal & 0.000 & 0.000 & 0.000 & 0.000 & 0.000 & 0.000 & 0.000 & 0.000 \\
\hline $\begin{array}{l}\text { Collision with fixed } \\
\text { object }\end{array}$ & 0.077 & 1.000 & 0.115 & 0.875 & 0.138 & 0.750 & 0.097 & 0.722 \\
\hline $\begin{array}{l}\text { Collision with other } \\
\text { object }\end{array}$ & 0.000 & 0.000 & 0.000 & 0.125 & 0.000 & 0.000 & 0.000 & 0.000 \\
\hline $\begin{array}{l}\text { Other single-vehicle } \\
\text { collision }\end{array}$ & 0.923 & 0.000 & 0.769 & 0.000 & 0.862 & 0.000 & 0.888 & 0.056 \\
\hline Noncollision & 0.000 & 0.000 & 0.115 & 0.000 & 0.000 & 0.250 & 0.015 & 0.222 \\
\hline
\end{tabular}

Table B.61: Factors for Equation 12-17 (Urban)

\begin{tabular}{l|cr}
\hline \multirow{2}{*}{ Intersection Type } & \multicolumn{2}{|c}{$\begin{array}{c}\text { Proportion of Single Vehicle Crashes that are } \\
\text { Fatal and Injury }\left(\boldsymbol{f}_{\text {bis }}\right)\end{array}$} \\
\cline { 2 - 3 } $3 \mathrm{ST}$ & \multicolumn{2}{|c}{ Locally-Derived Values } \\
\hline 4ST & & 0.900 \\
\hline
\end{tabular}

Table B.62: Pedestrian Crash Adjustment Factors for Stop-Controlled Intersections (Urban)

\begin{tabular}{l|c}
\multirow{2}{*}{ Intersection Type } & $\begin{array}{c}\text { Proportion of Total Crashes that are Pedestrian Fatal and } \\
\text { Injury Crashes }\left(\mathbf{f}_{\text {pedi }}\right)\end{array}$ \\
\cline { 2 - 2 } 3ST & Locally-Derived Values \\
\hline 4ST & 0.025 \\
\hline
\end{tabular}


Table B.63: Bicycle Crash Adjustment Factors for Intersections (Urban)

\begin{tabular}{l|l}
\hline \multirow{2}{*}{$\begin{array}{l}\text { Intersection } \\
\text { Type }\end{array}$} & $\begin{array}{l}\text { Proportion of Total Crashes that are Bicycle Fatal and Injury } \\
\text { Crashes }\left(f_{\text {bikei }}\right)\end{array}$ \\
\cline { 2 - 2 } $3 \mathrm{ST}$ & Locally-Derived Values \\
\hline $3 \mathrm{SG}$ & 0.022 \\
\hline $4 \mathrm{ST}$ & 0.016 \\
\hline $4 \mathrm{SG}$ & 0.023 \\
\hline
\end{tabular}

Table B.64: Nighttime Crash Proportions for Unlighted Intersections (Urban)

\begin{tabular}{l|c}
\hline \multirow{2}{*}{ Intersection Type } & \begin{tabular}{c} 
Proportion of crashes that occur at night, $\mathbf{p}_{\mathbf{n i}}$ \\
\cline { 2 - 2 }
\end{tabular} \\
\hline 3ST & Locally-Derived Values \\
\hline 4ST & 0.321 \\
\hline 3SG & 0.311 \\
\hline 4SG & 0.160 \\
\hline
\end{tabular}





\section{GOTREC \\ AND EDUCATION CONSORTIUM}

P.O. Box 751

Portland, OR 97207

OTREC is dedicated to stimulating and conducting collaborative multi-disciplinary research on multi-modal surface transportation issues, educating a diverse array of current practitioners and future leaders in the transportation field, and encouraging implementation of relevant research results. 